WSRC-TR-98-00171, Rev. 1

WSRC-TR- $-98-00171-R_{e}$

\title{
Analysis of Steam Heating of a Two-Layer TBP/N-Paraffin/Nitric Acid Mixtures
}

by

J. E. Laurinat

Westinghouse Savannah River Company

Savannah River Site

Aiken, South Carolina 29808

N. M. Hassan

T. S. Rudisill

N. M. Askew

DOE Contract No. DE-AC09-96SR18500

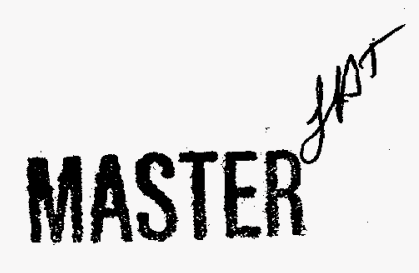

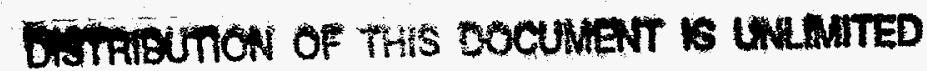

This paper was prepared in connection with work done under the above contract number with the U.S.

Department of Energy. By acceptance of this paper, the publisher and/or recipient acknowledges the U.S.

Government's right to retain a nonexclusive, royalty-free license in and to any copyright covering this paper, along with the right to reproduce and to authorize others to reproduce all or part of the copyrighted paper. 

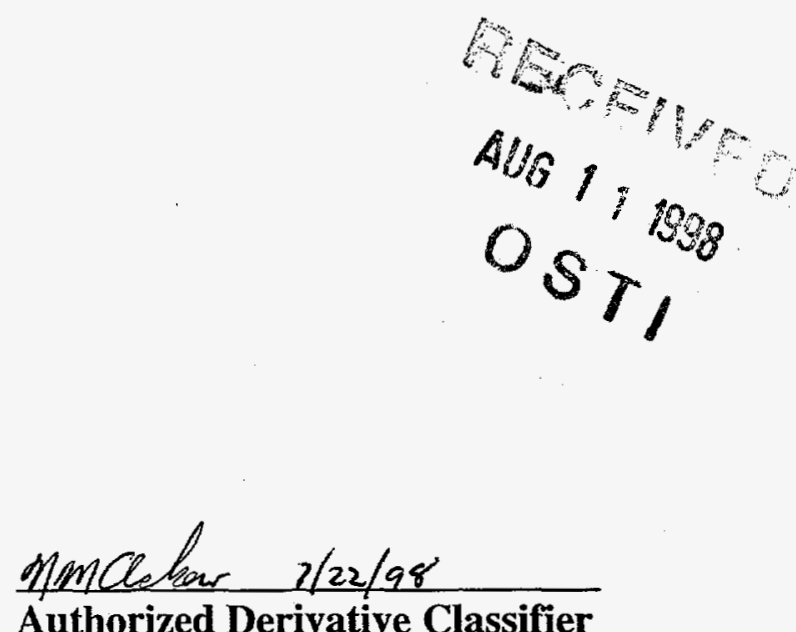

Analysis of Steam Heating of TBP/N-Paraffin/Nitric Acid Mixtures (U)

July 22, 1998

Westinghouse Savannah River Company Aiken, SC 29802

Prepared by the U. S. Department of Energy under Contract DE-AC09-96SR18500 
WSRC-TR-98-00171

Revision 1

\section{DISCLAIMER}

This report was prepared as an account of work sponsored by an agency of the United States Government. Neither the United States Government nor any agency thereof, nor any of their employees, makes any warranty, express or implied, or assumes any legal liability or responsibility for the accuracy, completeness, or usefulness of any information, apparatus, product, or process disclosed, or represents that its use would not infringe privately owned rights. Reference herein to any specific commercial product, process, or service by trade name, trademark, manufacturer, or otherwise does not necessarily constitute or imply its endorsement, recommendation, or favoring by the United States Government or any agency thereof. The views and opinions of authors expressed herein do not necessarily state or reflect those of the United States Government or any agency thereof.

This report has been reproduced directly from the best available copy.

Available to DOE and DOE contractors from the Office of Scientific and Technical Information, P.O. Box 62, Oak Ridge, TN 37831; prices available from (615) 576-8401.

Available to the public from the National Technical Information Service, U.S. Department of Commerce; 5285 Port Royal Road, Springfield, VA 22161. 


\section{DISCLAIMER}

Portions of this document may be illegible in electronic image products. Images are produced from the best available original document. 
Analysis of Steam Heating of TBP/N-Paraffin/Nitric Acid Mixtures (U) By J. E. Laurinat, N. M. Hassan, T. S. Rudisill, and N. M. Askew Issued: July 22, 1998

Approvals

Samer $\varepsilon$ tamint

$7-22-4 \gamma$

J. E. Laurinat, Author, SMT/C\&HTS

Date

Nmothsos

7122198

N. M. Hassan, Author, SMT/C\&HTS

Date

$\frac{\text { Tracy } s}{r} R_{\text {masit }}$

T. S. Rudisill, Author, SMT/C\&HTS

$7 / 22198$

Date

Honcelew

$7 / 22 / 98$

N. M. Askew, Author, SMT/C\&HTS

Date

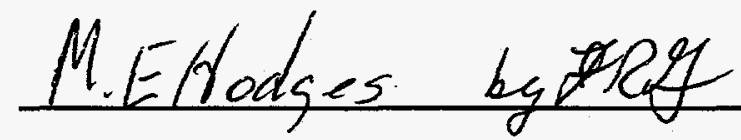

M. E. Hodges, Technical Reviewer, SMT/C\&HTS

Date

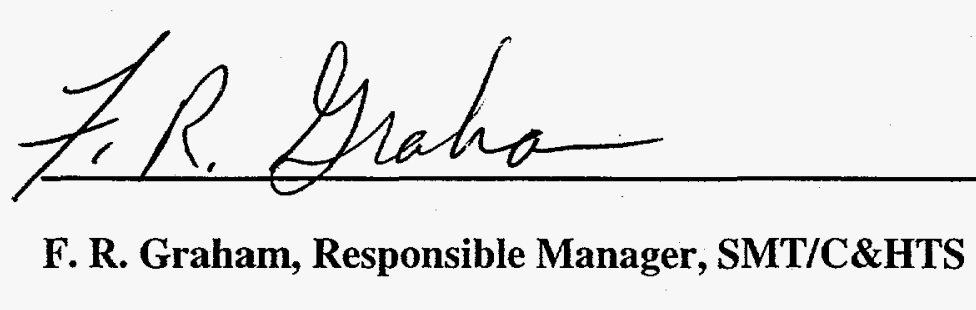

F. R. Graham, Responsible Manager, SMT/C\&HTS

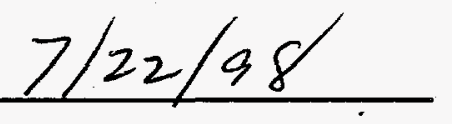




\section{Table of Contents}

Section Page

1.0 Summary 1

2.0 Introduction $2-3$

3.0 Evaluation of Mixing due to Jet Flow $3-4$

4.0 Evaluation of Mixing due to Bubble Dispersion

4.1 Reaction Parameters and Physical Properties for Bubble Dispersion Analysis

4.2 Solution of Heat and Mass Transfer Equations 10

4.3 Results of Bubble Dispersion Calculations $10-12$

5.0 Comparison of Jet and Bubble Mixing Calculations with Evaporator Analysis $12-14$

6.0 Conclusions $14-15$

7.0. Acknowledgments

8.0 References $15-18$

9.0 Nomenclature $18-22$

Figures $23-25$

Appendix A: Measurement of Steam Jet Air Entrainment Rate A1-A2

Appendix B: Heat Transfer Experiments $\mathrm{B} 1-\mathrm{B} 23$

Appendix C: Scale-up Correlation for Jet Impingement on Organic Layer ....... C1-C7 Appendix D: Correlation of Heat Loss Coefficients for Individual Tests.......... D1-D6 Appendix E: Physical Property and Phase Equilibrium Correlations ................ E1-E16 Appendix F: Computer Code Listing for Bubble Mixing Calculations .............F1-F14 Appendix G: Computer Code Listing for Test Benchmarking Calculations ..... G1-G8 


\subsection{Summary}

An analysis of steam heating of two-layer TBP/n-paraffin-nitric acid mixtures has been completed. This analysis covers a situation in which a steam valve is inadvertently left open after the completion of an aqueous solution transfer into a canyon tank containing TBP. If this should occur, the mixture of steam and air from the empty tank could heat the TBP/n-paraffin layer until an exothermic, runaway reaction takes place. The critical factor in preventing a reaction excursion is adequate mixing to replenish water consumed by the reaction, so that significant evaporative cooling can occur within the TBP layer. The object of this analysis is to demonstrate that a runaway reaction is not possible, even without agitation from the tank impeller.

Small-scale experiments were conducted to measure the thermal mixing due to a gas jet impinging on a two-layer mixture, and tracer particles were used to measure TBP layer recirculation velocities for an impinging jet in a 1/6-scale mockup of a tank. The thermal mixing tests demonstrated that the most of the TBP layer is well mixed by jet flow at velocities that would occur in a tank, but that little mixing occurs at the TBP-aqueous interface.

A calculation was performed to evaluate the effectiveness of mixing due to the bubbles generated by the reaction. This calculation used the results of a previous study, in which mass transfer coefficients were measured with sparging of one or both layers of TBPaqueous mixtures. Using conservative assumptions, the calculation showed that bubble mixing alone is sufficient to prevent an excursion. The bubble mixing analysis assumed that there was no mixing due to bubbles generated by oxidation reactions involving water-soluble TBP degradation products within the aqueous layer. Results from calorimetric tests of the TBP-nitric reaction showed that this assumption is also conservative; bubbles were observed in the aqueous layer at interfacial temperatures well below those calculated by the bubble mixing model.

Finally, the present analysis of steam jet heating is compared with a previous analysis of two-layer TBP/n-paraffin-nitric acid mixtures in evaporators and the calorimetric measurements on which it was based. The evaporator analysis showed that such mixtures would not undergo a reaction excursion in an evaporator, even at the relatively high operating temperatures encountered there. The measured rate of heating due to reaction at these temperatures was much greater than the sensible heat that would be provided by the steam jet, leading to the conclusion that evaporative cooling in the organic layer could easily accommodate heating from the jet and thereby prevent a runaway reaction.

It may be concluded that jet mixing studies, an analysis of mixing due to reaction product gases, and previous calorimetric studies of the TBP-nitric acid reaction each demonstrate that heating of a two-layer TBP/n-paraffin mixture will not cause a runaway reaction independent of the depth of the TBP layer. Together, the results from these studies offer conclusive evidence that a safety-class agitation system is not needed to mitigate the consequences of inadvertent steam jet heating of a TBP-nitric acid system in a canyon tank. 


\subsection{Introduction}

This report presents an analysis of steam heating of a two-layer tri- $n$-butyl phosphate (TBP)/n-paraffin-nitric acid mixture. Steam eductors are used to transfer aqueous solutions from tank to tank in both $\mathrm{H}$ - and F-Canyon. If the steam valves were inadvertently left open following a transfer when there was no solution in the transfer lines, steam would enter the vapor space in the tanks through the transfer jets. It must be determined whether the steam could heat the organic TBP/n-paraffin layer until an exothermic, runaway reaction occurs, if a significant quantity of solvent has accumulated in a tank.

The purpose of this study is to determine if the degree of mixing provided by the steam jet or by bubbles generated by the TBP/nitric acid reaction is sufficient to prevent a runaway reaction. Normally, the tanks are continuously agitated by a centrally located impeller. However, this analysis cannot take credit for mixing by this impeller, since it does not qualify as a safety class agitation system.

A previous study examined the safety of TBP/n-paraffin solutions in $\mathrm{F}$ - and $\mathrm{H}$-Canyon evaporators. ${ }^{1}$ This study demonstrated that the TBP/nitric acid oxidation reaction will not undergo an excursion provided that the pressure remains close to atmospheric and there is a sufficient concentration of water in the organic layer, because the heat consumed by the evaporation of water more than compensates for the heat generated by the oxidation of TBP degradation products. The water lost due to reaction is replenished by mixing with the underlying aqueous layer. Bubbles generated by reactions in the aqueous layer enhance the mixing rate, so that relatively thick organic layers are protected. ${ }^{1,2}$

The initial conditions for heating by a steam jet differ from those for a TBP/nitric acid system in an evaporator. The evaporator safety analysis is concerned with conditions immediately after shutdown of the evaporators, when both the organic and aqueous layers are hot. If a steam jet is inadvertently left on after a transfer, both layers start from lower temperatures, and the steam jet supplies heat to the surface of the organic layer. Consequently, the aqueous layer temperature is sufficiently low so that initially no significant reaction occurs in this layer, and bubbles do not enhance the mixing between the two layers. Therefore, there is a greater potential for the concentration of water in the top of the organic layer to drop until the TBP-nitric acid system becomes exothermic. An additional concern is that the steam might heat the TBP above its decomposition temperature and generate flammable gases. The purposes of this study are to determine in the event a steam jet were left on, if it would mix an organic layer in a tank sufficiently to replenish water lost by reaction and if the steam jet could heat the organic layer.above the TBP decomposition temperature.

The temperature and composition of the incoming steam has been calculated from an energy balance using known steam jet dimensions and inlet pressures and a measurement of the flow rate of air entrained by a prototypic steam jet. It was determined that the steam from a steam jet would enter the tank as a superheated gas with a maximum temperature of $139^{\circ} \mathrm{C}$. This temperature exceeds the estimated temperature for the autocatalytic decomposition of TBP in the presence of nitric acid, which is $130^{\circ} \mathrm{C}{ }^{3}$ 
However, the calculated steam jet temperature is a maximum and ignores superheat losses from the pipe and tank walls to the canyon by radiation and natural and forced convection.

This report uses three different approaches to address mixing. In the first approach, mixing due to the impingement of the jet on the organic layer surface is analyzed. The jet mixing was studied using both thermal mixing experiments in which the temperature profile of the organic layer was measured and tracer tests in which the motion of neutrally buoyant particles was viewed. In the second approach, mixing due to bubbles generated by the TBP/nitric acid reaction is modeled. A finite difference computer code was used to compute temperature and composition profiles, based on the results of reaction calorimetry experiments ${ }^{1}$ and bubble sparging mass transfer tests. ${ }^{2}$ Finally, results from the jet and bubble mixing analyses are compared with an analysis of canyon evaporators, which was based on the reaction calorimetry work. ${ }^{1}$

\subsection{Evaluation of Mixing due to Jet Flow}

One way to evaluate the safety of a steam jet impinging on a TBP-nitric mixture is to focus on the mixing caused by the jet flow. Two series of tests were conducted to determine the degree of mixing in the organic layer caused by impingement of a gas jet. In the first series of tests, a hot gas stream was blown down on an initially unheated twolayer organic/aqueous mixture, and the temperature profile of the organic layer was recorded as a function of time. These results showed that the organic layer was thermally well mixed, although there was little heat transfer across the organic/aqueous interface. Because the organic layer was well mixed, the results of these tests were modeled using a lumped mass model, in which the organic layer and the vessel walls in contact with it were assumed to be at a uniform temperature. The model accounts for sensible and latent heat transfer between the gas from the jet and the organic layer and heat losses to the ambient air by thermal radiation and natural convection. Results from these tests and the model calculations appear in Appendix B.

The vessel for these thermal mixing tests consisted of a 4-inch diameter Dewar cylinder, into which nitrogen was discharged through a $1 / 4$-inch tube with an $\mathrm{ID}$ of 0.17 inches. At the start of a typical experiment, the organic layer thickness was 6 inches, and the gas discharge was located about 6 inches above organic layer surface. By contrast, a standard canyon tank has an 8 or 10 foot diameter, and a standard steam jet discharge line is a 3inch pipe. The minimum distance between the steam jet discharge and the organic layer surface is 10 inches when a tank is full, and the TBP layer thickness is about 15 inches, based on an estimated TBP layer inventory of $3000 \mathrm{lbm}$, calculated from a probabilistic risk analysis. ${ }^{4,5}$ These values were used for the initial experimental work as a typical case, but experiments were run at the equivalent of 6 feet in a plant tank.

Because of uncertainties regarding the scaleability of the thermal mixing experiments to tank dimensions, additional studies were performed to estimate scaling factors for bulk mixing of the organic layer by the jet. Scaling factors for mixing are based on data from measurements of recirculation velocities in the organic layer for a jet impinging on a two- 
layer mixture of TBP/n-paraffin and water. These measurements were obtained by adding tracer particles to the organic layer. The tracer tests were performed in a 1/6-scale mockup of a canyon tank. The organic layer thickness, the jet diameter, and the separation distance of the jet discharge from the surface were based on geometric similarity with the canyon tanks. A derivation of the mixing scaling factors for organic layer mixing by the jet and a description of the tracer experiments appear in Appendix C. These experiments show that the jet would recirculate the organic layer in a tank every 15 seconds.

\subsection{Evaluation of Mixing due to Bubble Dispersion}

Another approach to demonstrating the inherent safety of a TBP/nitric acid heated by a steam jet is to neglect the mixing due to jet impingement. In this approach, temperature and concentration transients are calculated for mixing due to bubbles generated by the TBP-nitric acid reaction. This analysis is similar to that previously used to calculate the maximum thickness of the TBP layer supported by an underlying nitric acid layer. ${ }^{1}$ There are two differences between this analysis and the previous calculation. One is that the previous calculation assumed that there was bubble generation in the aqueous layer, whereas this analysis does not take credit for bubble flow across the organic-aqueous interface. The second difference concerns the calculation method. The previous calculation used a lumped mass to represent the organic layer and volumetric coefficients for heat and mass transfer to the organic phase. The present analysis uses a finite difference algorithm to account for concentration and temperature gradients through the organic layer and a dispersion coefficient to model mass and heat transfer. Both the mass transfer coefficient and the dispersion coefficient are derived from mass transfer measurements obtained using a sparged two-layer, TBP-aqueous system. ${ }^{2}$

This section lists the mass and heat transfer equations used in the finite difference model. Terms in these equations are defined in the Nomenclature.

Mass and heat balances are written for each calculation cell in the finite difference method. Separate component mass balances for $\mathrm{H}_{2} \mathrm{O}, \mathrm{HNO}_{3}$, and TBP model mass transfer in the organic layer. The mass balances include terms for formation or destruction by reaction, vaporization due to the heat of reaction, and convection by fluid motion due to bubbles generated by the reaction. To simplify the analysis, all TBP decomposition products other than $\mathrm{H}_{2} \mathrm{O}$ and $\mathrm{HNO}_{3}$ are ignored. The measured reaction rate for the consumption of TBP is divided by three to account for the presence of DBP and MBP, which also decompose via a similar mechanism.

With the assumptions just described, the differential form of the mass balance for TBP is

$$
\frac{\partial \mathrm{x}_{\mathrm{TBP}}}{\partial \mathrm{t}}=\left(\mathrm{D}_{\mathrm{b}}+\mathrm{D}_{\mathrm{a}}\right) \frac{\partial^{2} \mathrm{x}_{\mathrm{TBP}}}{\partial \mathrm{z}^{2}}-\mathrm{r}(\mathrm{T}) \mathrm{x}_{\mathrm{HNO}_{3}}\left[\left(\frac{\mathrm{n}_{\mathrm{TBP}}}{3}\right)+\mathrm{n}_{\mathrm{vap}}\left(\frac{\mathrm{p}_{\mathrm{TBP}}}{\mathrm{p}_{\mathrm{tot}}-\mathrm{p}_{\mathrm{TBP}}-\mathrm{p}_{\mathrm{H}_{2} \mathrm{O}}-\mathrm{p}_{\mathrm{HNO}_{3}}}\right)\right]\left(\frac{\left.\mathrm{M}_{\mathrm{TBP} \rho_{\mathrm{HNO}_{3}}}\right)}{\mathrm{M}_{\mathrm{HNO}_{3}} \rho_{\mathrm{TBP}}}\right)
$$


The mass balance for $\mathrm{H}_{2} \mathrm{O}$ is

$$
\frac{\partial x_{\mathrm{H}_{2} \mathrm{O}}}{\partial t}=\left(\mathrm{D}_{\mathrm{b}}+\mathrm{D}_{\mathrm{a}}\right) \frac{\partial^{2} \mathrm{x}_{\mathrm{H}_{2} \mathrm{O}}}{\partial \mathrm{z}^{2}}-\mathrm{r}(\mathrm{T}) \mathrm{x}_{\mathrm{HNO}_{3}}\left[\mathrm{n}_{\mathrm{H}_{2} \mathrm{O}}+\mathrm{n}_{\text {vap }}\left(\frac{\mathrm{p}_{\mathrm{H}_{2} \mathrm{O}}}{\mathrm{p}_{\mathrm{tot}}-\mathrm{p}_{\mathrm{TBP}}-\mathrm{p}_{\mathrm{H}_{2} \mathrm{O}}-\mathrm{p}_{\mathrm{HNO}_{3}}}\right)\right]\left(\frac{\mathrm{M}_{\mathrm{H}_{2} \mathrm{O}} \rho_{\mathrm{HNO}_{3}}}{\mathrm{M}_{\mathrm{HNO}_{3}} \rho_{\mathrm{H}_{2} \mathrm{O}}}\right)
$$

The mass balance for $\mathrm{HNO}_{3}$ is

$$
\frac{\partial \mathrm{x}_{\mathrm{HNO}_{3}}}{\partial \mathrm{t}}=\left(\mathrm{D}_{\mathrm{b}}+\mathrm{D}_{\mathrm{a}}\right) \frac{\partial^{2} \mathrm{x}_{\mathrm{HNO}_{3}}}{\partial \mathrm{z}^{2}}-\mathrm{r}(\mathrm{T}) \mathrm{x}_{\mathrm{HNO}_{3}}\left[\mathrm{n}_{\mathrm{HNO}_{3}}-\mathrm{n}_{\mathrm{vap}}\left(\frac{\mathrm{p}_{\mathrm{HNO}_{3}}}{\mathrm{p}_{\mathrm{tot}}-\mathrm{p}_{\mathrm{TBP}}-\mathrm{p}_{\mathrm{H}_{2} \mathrm{O}}-\mathrm{p}_{\mathrm{HNO}_{3}}}\right)\right]
$$

The heat transfer equation includes terms for heats of reaction and vaporization, heat transfer by conduction and dispersion due to bubble motion. The differential form of the heat transfer equation for the organic layer is given by

$$
\begin{aligned}
& \frac{\partial \mathrm{T}}{\partial \mathrm{t}}=\left(\frac{\mathrm{k}}{\rho \mathrm{c}_{\mathrm{p}}}+\mathrm{D}_{\mathrm{b}}+\mathrm{D}_{\mathrm{a}}\right) \frac{\partial^{2} \mathrm{~T}}{\partial \mathrm{z}^{2}} \\
& +\mathrm{r}(\mathrm{T}) \mathrm{x}_{\mathrm{HNO}_{3}} n_{\mathrm{vap}}\left(\Delta \mathrm{H}_{\mathrm{R}}-\frac{\mathrm{p}_{\mathrm{H}_{2} \mathrm{O}} \Delta \mathrm{H}_{\mathrm{v}, \mathrm{H}_{2} \mathrm{O}}+\mathrm{p}_{\mathrm{HNO}_{3}} \Delta \mathrm{H}_{\mathrm{v}, \mathrm{HNO}_{3}}}{\mathrm{p}_{\mathrm{tot}}-\mathrm{p}_{\mathrm{TBP}}-\mathrm{p}_{\mathrm{H}_{2} \mathrm{O}}-\mathrm{p}_{\mathrm{HNO}_{3}}}\right)\left(\frac{\rho_{\mathrm{HNO}_{3}}}{\mathrm{M}_{\mathrm{HNO}_{3}}}\right)\left(\frac{1}{\rho c_{\mathrm{p}}}\right)
\end{aligned}
$$

The dispersion coefficients in the mass and heat transfer equations, $D_{b}$ and $D_{a}$, account for mixing caused by bubble flow below and mixing induced by bubble flow above the finite difference calculation cell. These coefficients are modeled using the measured twolayer and single-layer dispersion coefficients reported in Reference 2. It is assumed that mixing due to bubbling from below is analogous to mixing in the TBP layer with sparging of both layers. Similarly, mixing caused by bubbling from above is assumed to be analogous to mixing in the TBP layer with sparging in that layer only (with no bubble flow across the interface). The measured dispersion coefficients for two-layer and singlelayer sparging are given as the product of the superficial gas velocity $v_{\mathrm{sg}}$ and the organic layer height $\mathrm{H}^{2}$

$$
\mathrm{D}_{2 \mathrm{~L}}=\mathrm{H}\left(0.621 \mathrm{v}_{\mathrm{sg}}-0.0084\right)
$$

and

$$
D_{1 L}=H\left(0.0105 v_{s g}-0.0003\right)
$$

The magnitudes of these measured coefficients are consistent with values obtained in other studies. In Reference 2, it was shown that the two-layer sparging coefficient is of the same magnitude as that calculated by Joshi ${ }^{6}$ Measurements of the single-layer dispersion coefficient are in approximate agreement with mass transfer measurements for 
sparging of a two-layer mercury-aqueous mixture performed by Clinton and Perona. ${ }^{7}$ They measured the bulk rate of reduction of an aqueous quinone solution sparged by nitrogen to remove dissolved oxygen. It can be argued that this was equivalent to singlelayer sparging because there was no reaction in the mercury layer and no transport of reactants across the aqueous-mercury interface. They correlated their results with the expression

$\mathrm{Sh}=1.33 \mathrm{Re}^{0.7} \mathrm{Sc}^{1 / 3}$

where the Reynolds number, $\mathrm{Re}$, is defined by

$\mathrm{Re}=\frac{\rho \mathrm{v}_{\mathrm{sg}} \mathrm{H}}{\mu}$

the Schmidt number, Sc, is given by

$\mathrm{Sc}=\frac{\mu}{\rho D_{m}}$

and the Sherwood number, Sh, is defined by

$\mathrm{Sh}=\frac{\mathrm{k}_{\mathrm{L}} \mathrm{d}_{\mathrm{b}}}{\mathrm{D}_{\mathrm{m}}}$

Based on their experimental observations, they assumed that the bubble diameter $d_{b}$ was a constant $0.5 \mathrm{~cm}$.

To allow a comparison of the single-layer sparging results with this correlation, dispersion coefficients from Reference 2 were converted to mass transfer coefficients. An approximate relation between the mass transfer coefficient and the dispersion coefficient was derived in Reference 2. At equilibrium, this relation takes the form

$$
\mathrm{k}_{\mathrm{L}}=\frac{16 \mathrm{D}_{\mathrm{LL}}}{\pi \mathrm{H}}
$$

Two mass transfer measurements were made with sparging of just the TBP layer. The following table compares the measured mass transfer coefficient given by Equation 4-11 with the prediction of the correlation given by Equations 4-7 through 4-10. 
Table 1. Comparison of Measured Mass Transfer Coefficients with Predictions of Clinton and Perona.

\begin{tabular}{|c|c|c|c|c|c|c|}
\hline $\begin{array}{l}D_{1 L} \\
\left(\mathrm{~cm}^{2} / \mathrm{s}\right)\end{array}$ & $\begin{array}{l}\mathrm{H} \\
(\mathrm{cm})\end{array}$ & $\begin{array}{l}\mathrm{k}_{\mathrm{L}}, \text { meas. } \\
(\mathrm{cm} / \mathrm{s})\end{array}$ & $\begin{array}{l}\mathrm{v}_{\mathrm{sg}}{ }^{1} \\
(\mathrm{~cm} / \mathrm{s})\end{array}$ & $\begin{array}{l}\mu^{2} \\
(\mathrm{~g} / \mathrm{cm} / \mathrm{s})\end{array}$ & $\begin{array}{l}\mathrm{D}_{\mathrm{m}}{ }^{3} \\
\left(\mathrm{~cm}^{2} / \mathrm{s}\right)\end{array}$ & $\begin{array}{l}\mathrm{k}_{\mathrm{L}}, \text { pred } \\
(\mathrm{cm} / \mathrm{s})\end{array}$ \\
\hline $\begin{array}{l}0.0014 \\
\text { “ }\end{array}$ & $\begin{array}{l}7.038 \\
\text { “ }\end{array}$ & $\begin{array}{l}0.0010 \\
\text { “ }\end{array}$ & $\begin{array}{l}0.025 \\
0.047\end{array}$ & $\begin{array}{l}0.015 \\
\text { ، }\end{array}$ & $7.2 \times 10^{-6}$ & $\begin{array}{l}0.0013 \\
0.0021\end{array}$ \\
\hline $\begin{array}{l}0.0048 \\
\text { ، }\end{array}$ & $\begin{array}{l}7.038 \\
\text { ، }\end{array}$ & 0.0035 & $\begin{array}{l}0.050 \\
0.094\end{array}$ & $\begin{array}{l}0.015 \\
\&\end{array}$ & $7.2 \times 10^{-6}$ & $\begin{array}{l}0.0022 \\
0.0034\end{array}$ \\
\hline
\end{tabular}

As the results in this table show, the single-layer sparging mass transfer measurements are in approximate agreement with the Clinton and Perona correlation.

Dispersion coefficients for mixing with bubble generation in the TBP layer are modeled by using the correlation given by Reference 2 with equivalent layer heights. The equivalent height for mixing from below is obtained by integrating over the distance from the TBP-aqueous interface. This gives

$$
D_{b}=\int_{z=H}^{z=z}\left(0.621 v_{s g}-0.0084\right) d z
$$

The equivalent height for induced mixing for bubbling from above is obtained by integrating over the distance to the TBP layer surface. This yields

$$
D_{a}=\int_{z=0}^{z=z}\left(0.0105 v_{s g}-0.0003\right) d z
$$

The local bubble flow rate in these integrals is calculated by integrating the volumetric rates of generation of reaction product gases and evaporation of condensable vapors over the distance from the interface. The flow of gases from evaporation of the aqueous layer at the interface is included in the total bubble flow rate. It is assumed that the interfacial bubble flow rate is limited by the rate of the convective heat transfer from the TBP layer that supplies the latent heat of vaporization. Thus, the equation for the local superficial gas velocity is

\footnotetext{
${ }^{1}$ Two superficial gas velocities were analyzed, one assuming that the bubbles did not absorb any vapors from the TBP solution, and another assuming that the bubbles became saturated with vapors. In the correlation of dispersion coefficients, it was conservatively assumed that the bubbles became saturated with vapor.

${ }^{2}$ The viscosity is that for water-saturated TBP, ${ }^{8}$ extrapolated to the test temperature. 9

${ }^{3}$ The diffusivity is that for self-diffusion of TBP, ${ }^{10}$ extrapolated to the test temperature.
} 


$$
\mathrm{v}_{\mathrm{sg}}=\mathrm{v}_{\mathrm{sg}, \text { surf }}+\int_{\mathrm{z}=\mathrm{H}}^{\mathrm{z}=\mathrm{z}} \mathrm{r}(\mathrm{T}) \mathrm{x}_{\mathrm{HNO}_{3}} \mathrm{n}_{\mathrm{vap}}\left(1+\frac{1}{\mathrm{p}_{\mathrm{tot}}-\mathrm{p}_{\mathrm{TBP}}-\mathrm{p}_{\mathrm{H}_{2} \mathrm{O}}-\mathrm{p}_{\mathrm{HNO}_{3}}}\right)\left(\frac{\rho_{\mathrm{HNO}_{3}} \mathrm{R}_{\mathrm{g}} \mathrm{T}}{\mathrm{M}_{\mathrm{HNO}_{3}}}\right) \mathrm{dz}
$$

where $v_{s g, \text { surf }}$, the superficial velocity at the interface, is given by

$$
\mathrm{v}_{\mathrm{sg}, \text { surf }}=\left[\mathrm{k}+\rho \mathrm{c}_{\mathrm{p}}\left(\mathrm{D}_{\mathrm{a}}+\mathrm{D}_{\mathrm{b}}\right)\right]_{\mathrm{z}=\mathrm{H}}\left(\frac{\partial \mathrm{T}}{\partial \mathrm{z}}\right)_{z=\mathrm{H}}\left(\frac{\mathrm{R}_{\mathrm{g}} \mathrm{T}}{\mathrm{p}_{\mathrm{H}_{2} \mathrm{O}} \Delta \mathrm{H}_{\mathrm{v}, \mathrm{H}_{2} \mathrm{O}}+\mathrm{p}_{\mathrm{HNO}_{3}} \Delta \mathrm{H}_{\mathrm{v}, \mathrm{HNO}_{3}}}\right)_{\mathrm{z}=\mathrm{H}}
$$

It may be noted that according to Equations 4-12 and 4-13 the value of the two-layer dispersion coefficient for mixing from below drops to zero at the interface, as it must, while the value of the single-layer dispersion coefficient for mixing from above reaches a maximum at this location.

The finite difference analysis is made conservative by the use of appropriate boundary conditions at the TBP layer surface and the TBP-aqueous interface. An adiabatic condition is applied at the surface. At the interface, all heat transfer is ignored, including latent losses to the underlying aqueous phase. In addition, convective heat losses to the underlying aqueous layer and the tank walls by conduction and heat losses to the steam by evaporation at the surface are ignored. Mass transfer at the surface is also ignored. This is probably conservative because the steam, which has a partial pressure of about 0.9 atmospheres, will act to strip nitric acid from solution at the surface and thereby lower both its concentration in the TBP layer and the rate of reaction. Mass transfer at the interface is governed by the amount of bubble dispersion, with the concentrations set at saturation values that give the maximum ratio of $\mathrm{HNO}_{3}$ to $\mathrm{H}_{2} \mathrm{O}$ entering the TBP phase. According to room temperature equilibrium data, ${ }^{12}$ this occurs at a composition of 0.8008 volume fraction TBP, 0.1762 volume fraction $\mathrm{HNO}_{3}$, and 0.0230 volume fraction $\mathrm{H}_{2} \mathrm{O}$ (see Appendix E). This particular composition will yield the highest possible $\mathrm{HNO}_{3}$ concentrations, and hence the highest rates of reaction, for a given $\mathrm{H}_{2} \mathrm{O}$ concentration.

The boundary conditions at the TBP layer surface (at $z=0$ ) take the form:

$$
\begin{aligned}
& \frac{\partial \mathrm{T}}{\partial \mathrm{z}}=0 \\
& \frac{\partial \mathrm{x}_{\mathrm{HNO}_{3}}}{\partial \mathrm{z}}=0 \\
& \frac{\partial \mathrm{x}_{\mathrm{H}_{2} \mathrm{O}}}{\partial \mathrm{z}}=0
\end{aligned}
$$


and

$\frac{\partial \mathrm{x}_{\mathrm{TBP}}}{\partial \mathrm{z}}=0$

The boundary conditions at the TBP-aqueous interface (at $z=H$ ) are given by

$$
\begin{aligned}
& \frac{\partial \mathrm{T}}{\partial \mathrm{Z}}=0 \\
& \mathrm{X}_{\mathrm{H}_{2} \mathrm{O}}=\mathrm{X}_{\mathrm{H}_{2} \mathrm{O} \text {,sat }} \\
& \mathrm{X}_{\mathrm{HNO}_{3}}=\mathrm{x}_{\mathrm{HNO}_{3} \text {,sat }}
\end{aligned}
$$

and

$\mathrm{X}_{\mathrm{TBP}}=\mathrm{X}_{\mathrm{TBP}, \text { sat }}$

At the start of the calculation, it is assumed that both the temperature and the composition are uniform throughout the TBP layer. It is assumed that the composition is at the same saturation level specified for the interface. Arbitrary starting temperatures will be selected for the analysis. The assumption of uniform starting temperature and composition can be justified on several grounds. First, the TBP layer is mixed by the aqueous phase that transfers into the tank. Second, the tracer tests described in Section 3 and the jet mixing heat transfer tests documented in Appendix B demonstrate that the impinging jet flow mixes the bulk of the TBP layer well, at least in the amount of time required for self-heating by reaction. Finally, since, as stated previously, the steam will strip nitric acid from the TBP layer surface to some extent, any deviation from a uniform concentration profile will lead to lower rates and heats of reaction.

\subsection{Reaction Parameters and Physical Properties for Bubble Dispersion Analysis}

The mass balances and the heat transfer equation for the organic layer require the input of component rate constants and the heat of reaction for TBP decomposition. As stated previously, these parameters were measured in recent calorimetry experiments.' The following table lists values for the rate constants at $110^{\circ} \mathrm{C}$ and for the heat of reaction in terms of $\mathrm{kcal} / \mathrm{gmole}$ noncondensible vapor generated 
Table 2. Rate Constants and Heat of Reaction for the Nitric Acid-TBP Decomposition Reaction at $110^{\circ} \mathrm{C}$

Parameter

$\mathrm{n}_{\mathrm{HNO}_{3}}$

$\mathrm{n}_{\mathrm{H}_{2} \mathrm{O}}$

$\mathrm{n}_{\text {TBP }}$

$\mathrm{n}_{\text {vap }}$

$\Delta \mathrm{H}_{\mathrm{R}}$
Value

$-18.7 \times 10^{-4} / \mathrm{min}$

$6.1 \times 10^{-4} / \mathrm{min}$

$-13.3 \times 10^{-4} / \mathrm{min}$

$7.0 \times 10^{-4} / \mathrm{min}$

$61.965 \mathrm{kcal} / \mathrm{gmole}$

noncondensable vapor

To account for the acceleration of the reaction rate with increasing temperatures, an Arrhenius-type multiplier $\mathrm{r}(\mathrm{T})$ is used. This multiplier is ${ }^{1}$

$$
\mathrm{r}(\mathrm{T})=2.43 \exp \left(\frac{\mathrm{T}-110}{10}\right)
$$

The initial $\mathrm{H}_{2} \mathrm{O}$ and $\mathrm{HNO}_{3}$ concentrations were set at their saturation values. Saturation concentrations for $\mathrm{HNO}_{3}$ and $\mathrm{H}_{2} \mathrm{O}$ dissolved in TBP are based on correlations of solubility measurements at $25^{\circ} \mathrm{C}^{12}$ These correlations are listed in Appendix E.

Physical properties for the TBP and aqueous phases were evaluated using standard literature correlations. These are listed in Appendix E.

\subsection{Solution of Heat and Mass Transfer Equations}

The TBP layer heat and mass balances were integrated using a finite difference computer code. The code listing is attached as Appendix F.

\subsection{Results of Bubble Dispersion Calculations}

To determine if bubble mixing is sufficient by itself to prevent a runaway reaction, the bubble dispersion model was used to calculate temperature transients for the heating of a TBP layer with initially uniform temperature and composition. As explained in Section 4.0, the initial composition was set to give the maximum ratio of $\mathrm{HNO}_{3}$ to $\mathrm{H}_{2} \mathrm{O}$ and therefore the maximum initial reaction rate and heat. An initial TBP layer thickness of 50 $\mathrm{cm}$ was arbitrarily chosen as the baseline case of $5000 \mathrm{lbm}$ of TBP in a tank. Cases were also run at 80 and $100 \mathrm{~cm}$. To examine the effect of the starting temperature and hence the steam conditions, on the transient, the starting temperature was varied from $90^{\circ} \mathrm{C}$ to $110^{\circ} \mathrm{C}$. 
Figure 1 depicts the surface temperature transients for the baseline case calculations. The surface temperature was chosen because, under the imposed surface conditions, the resistance to mass transfer is greatest and consequently the temperature is highest at the surface. All three initial temperatures increased to the same maximum temperature of about $128^{\circ} \mathrm{C}$ and then remained approximately constant. The time required to reach the maximum temperature ranged from about 45 minutes for the layer initially at $110^{\circ} \mathrm{C}$ to approximately 3 hours for the layer initially at $90^{\circ} \mathrm{C}$.

The surface temperature reaches a maximum because the heat generated by the reaction is balanced by heat losses due to the evaporation of volatile components, i.e., $\mathrm{H}_{2} \mathrm{O}$ and $\mathrm{HNO}_{3}$. At the surface, the TBP phase is not saturated with $\mathrm{H}_{2} \mathrm{O}$ and $\mathrm{HNO}_{3}$ due to mass transfer limitations, so the vapor pressures of these components are lower than they would be for saturated TBP. Thus, the surface boiling temperature is higher than it would be for saturated TBP and does in fact exceed the azeotropic boiling point of nitric acid, which is approximately $121^{\circ} \mathrm{C}$.

The most significant conclusion to be drawn from these results is that the bubbleenhanced mass transfer rate is sufficient to maintain the surface concentration of $\mathrm{H}_{2} \mathrm{O}$ sufficiently high so that its rate of evaporation balances the heat generated by the TBPnitric reaction. These heats are balanced at a temperature just below that for the onset of the autocatalytic decomposition of TBP, $130^{\circ} \mathrm{C}^{3}$

It was found that the calculation of the temperature transients subsequent to reaching the maximum surface temperature were subject to numerical errors related to finite difference discretization. These errors were magnified as the temperature at the surface approached saturation and the pressure differences in the denominators of the heat and mass transfer equations became small. Nevertheless, a reasonable accurate calculation of the maximum temperature where the heats of reaction and evaporation balanced each other, which is all that was required of this analysis, was achieved.

It may be noted that for all three starting temperatures the maximum temperature is nearly identical. This probably occurs because the dispersion coefficient is assumed to be proportional to the layer thickness and the bubble flow rate. At equilibrium, the concentration gradient is inversely proportional to the layer thickness. It follows that the rate of mass transfer, which is the product of the dispersion coefficient and the concentration gradient, is proportional to the rate of bubble generation by reaction. Thus, as the TBP layer evaporates, both the mass transfer rate and the rate of reaction decrease in the same proportion and can therefore remain in equilibrium.

Figure 2 compares surface temperature transients for three different initial organic layer thicknesses. Transients were calculated for the baseline case of $50 \mathrm{~cm}, 80 \mathrm{~cm}$, and 100 $\mathrm{cm}$. A 100-cm TBP layer represents the bounding case. This is the thickest TBP layer that could be present in a tank, following evaporation of the more volatile n-paraffin compounds from a full tank of $30 \%$ TBP in n-paraffin. The transients for all three thicknesses are nearly identical. As explained in the previous paragraph, this occurs 
because the dispersion coefficient is assumed to increase with the layer thickness, while the concentration gradient decreases as the layer becomes thicker. Thus, the rate of mass transfer, which is the product of these two terms, remains the same for layers of different thicknesses.

Figure 3 shows the concentration profile for the baseline calculation starting at $90^{\circ} \mathrm{C}$, after about 3 hours, when the surface temperature levels off. The temperatures range from $128^{\circ} \mathrm{C}$ at the surface to $116^{\circ} \mathrm{C}$ at the interface.

The bubble dispersion calculations involve extrapolation of the test conditions on which the dispersion coefficient correlation is based. ${ }^{2}$ The sparging mass transfer experiments were limited to a maximum superficial gas velocity of $0.094 \mathrm{~cm} / \mathrm{sec}$ and most of the tests were conducted in a vessel with a TBP layer height of $7 \mathrm{~cm}$. The calculations for the $50-\mathrm{cm}$ layer initially at $90^{\circ} \mathrm{C}$ give a maximum superficial velocity of about $1.0 \mathrm{~cm} / \mathrm{sec}$ at a layer height of $44 \mathrm{~cm}$, when the maximum temperature was reached. Thus, the extrapolation factors are about six times for the height and ten times for the superficial velocity at the TBP layer surfaces. Smaller extrapolation factors apply between the two surfaces because lower values of the dispersion coefficients are used there. Fortunately, a linear extrapolation of the dispersion coefficient appears to be conservative, at least with respect to the superficial velocity. ${ }^{2}$

From these calculations, it may be concluded that bubble mixing is just sufficient to replenish the water consumed by the TBP-nitric acid reaction and thereby prevent a thermal excursion. The margin for avoiding an excursion is not great, as evidenced by the relatively high maximum temperature $\left(128^{\circ} \mathrm{C}\right)$ for bubble mixing.

\subsection{Comparison of Jet and Bubble Mixing Calculations with Evaporator Safety Analysis}

As stated in the Introduction, results of recent calorimetry experiments were used to establish the safety basis for operation of acidic evaporators in F-Canyon. An isothermal calorimeter was used to measure the heating characteristics for both single (organic) and two phase (organic and aqueous) systems of TBP and $\mathrm{HNO}_{3}$ at temperatures between 110 and $124^{\circ} \mathrm{C}$. Forced evaporation of the volatile components (water, nitric acid, butanol, etc.) by the product gases from oxidation resulted in a cooling mechanism which more than balanced the heat from the oxidation reactions in two-phase TBP/HNO 3 systems. Water, the primary coolant in the organic phase, was maintained by interfacial mixing by gas produced from oxidation of water-soluble organic compounds in the aqueous phase. Using the reaction rate expressions and rate constants measured for single and two phase $\mathrm{TBP} / \mathrm{HNO}_{3}$ systems, an approximating mathematical model showed that one foot of reacting $14.3 \mathrm{M}$ nitric acid solution in an evaporator at $121^{\circ} \mathrm{C}$ will transport sufficient water to the organic phase to replace evaporative losses, cooling organic layers up to $12.2 \pm 6.0 \mathrm{ft}$ thick. ${ }^{1}$

The analysis used to establish the safety basis for evaporator operation can be qualitatively extended to the inadvertent heating of a $\mathrm{TBP} / \mathrm{HNO}_{3}$ system by a steam 
transfer jet. The initial conditions for heating by a steam jet differ from those for a runaway TBP/nitric acid system in an evaporator. The evaporator analysis is concerned with conditions immediately after shutdown of the evaporators, when both the organic and aqueous layers are assumed to be slightly below the aqueous phase boiling point (approximately $122^{\circ} \mathrm{C}$ ). If a steam jet is inadvertently left on after a transfer, both layers start from lower temperatures $\left(<60^{\circ} \mathrm{C}\right)$.

The amount of sensible heat added to the organic layer by the steam jet is small compared to the heat generated by the oxidation of TBP degradation products at the evaporator temperature (see Table 1).

Table 3. Comparison of Rates of Heating by Reaction in a TBP Layer with Rates of Heat Transfer from the Steam Jet

$\begin{array}{lrlr}\begin{array}{l}\text { TBP Layer } \\ \text { Temperature } \\ \left({ }^{\circ} \mathrm{C}\right)\end{array} & \begin{array}{l}\text { Reaction } \\ \text { Heat } \\ (\mathrm{cal} / \mathrm{sec})\end{array} & \begin{array}{l}\text { Steam } \\ \text { Heat } \\ (\mathrm{cal} / \mathrm{sec})\end{array} & \begin{array}{l}\text { Total } \\ \text { Heat } \\ (\mathrm{cal} / \mathrm{sec})\end{array} \\ 110 & 6907 & 1866 & 8773 \\ 115 & 10767 & 1544 & 12311 \\ 120 & 16784 & 1222 & 18006 \\ 125 & 26163 & 901 & 27064\end{array}$

The amount of heat generated by the $\mathrm{TBP} / \mathrm{HNO}_{3}$ reaction, $\mathrm{Q}_{\mathrm{rxn}}$, is calculated using Equation 5-1.

$Q_{\mathrm{rxn}}=\mathrm{n}_{\text {vap }} \mathrm{r}(\mathrm{T}) \frac{\mathrm{X}_{\mathrm{HNO}_{3}} \rho_{\mathrm{HNO}_{3}}}{\mathrm{M}_{\mathrm{HNO}_{3}}} \Delta \mathrm{H}_{\mathrm{R}} \mathrm{AH}$

In a tank, a jet of superheated steam and air enters through a 3.07-inch-diameter pipe at a velocity of $56 \mathrm{~m} / \mathrm{s}$ at a temperature of $139^{\circ} \mathrm{C}$ (see Appendix A). Scaled experiments show that the jet splashes the organic layer, cooling the jet to the organic layer temperature. The heat provided by the jet, $\mathrm{Q}_{s t}$, is therefore:

$\mathrm{Q}_{\mathrm{st}}=\rho_{\mathrm{g}} \mathrm{V}_{\mathrm{n}} \mathrm{A}_{\mathrm{n}} \mathrm{c}_{\mathrm{p}, \mathrm{g}} \Delta \mathrm{T}$

where $\Delta T$ is the difference between the temperature of the steam and the temperature of the organic layer.

Since the evaporator analysis showed that the heat of reaction must be balanced by heat losses due to the forced evaporation of water and other volatiles by noncondensable reaction products, these losses will more than compensate for the heat added to the organic phase by the steam. 
Since the aqueous phase in the steam jet accident scenario is initially cool, heat must be transferred from the organic phase to raise the temperature to a point where the oxidation rate of water-soluble organic compounds is sufficient to generate bubbles of noncondensable gases. Once the aqueous phase begins to bubble, water evaporated from the organic phase is replenished due to the interfacial mixing. Heating of the aqueous phase is facilitated by the mixing provided by the momentum of the impinging steam and bubbles generated in the organic phase due to the oxidation of TBP degradation products. The bubble dispersion model for a reacting $\mathrm{TBP} / \mathrm{HNO}_{3}$ system shows that the temperature drop across the organic layer is less than $15^{\circ} \mathrm{C}$; therefore, the temperature at the aqueous/organic interface does not lag far behind the surface temperature. In the isothermal calorimeter experiments, bubbling began at about $94^{\circ} \mathrm{C}$ in the organic phase and at $102^{\circ} \mathrm{C}$ in the aqueous phase. Therefore, heat transferred from the organic phase will be sufficient to raise the aqueous layer temperature at the interface to a point where oxidation of organic material will initiate bubbling. Bubbling in the aqueous phase will then provide the mixing necessary to replenish water lost by evaporation from the organic phase. Forced evaporation will provide the cooling mechanism for the steam jet accident scenario in the same manner as demonstrated by the isothermal calorimeter experiments for a runaway $\mathrm{TBP} / \mathrm{HNO}_{3}$ system in an evaporator.

\subsection{Conclusions}

This report demonstrates that a runaway reaction will not occur if a steam transfer jet is inadvertently left on after the completion of a tank transfer. An analysis of the steam flow through the jet nozzle and a measurement of the amount of air that would be entrained from an empty tank showed that the jet would discharge a mixture of $90 \%$ superheated steam and $10 \%$ air at $139^{\circ} \mathrm{C}$, if heat losses in the transfer line are neglected.

Mixing by bubbles generated by product gases from the TBP-nitric acid reaction would mix the TBP layer sufficiently well to prevent a thermal excursion due to this steam discharge. Bubble mixing was evaluated using a correlation developed from mass transfer measurements for sparged two-layer TBP-aqueous mixtures. A finite difference calculation was performed to calculate temperature profiles for a TBP layer that was selfheated by the TBP-nitric acid reaction. This calculation was conservative in that it ignored heat transfer across the TBP-aqueous interface as well as heat losses by evaporation at the TBP layer surface. The results showed that the bubble mixing was sufficient to prevent a thermal excursion. The calculation gave an equilibrium surface temperature of $128^{\circ} \mathrm{C}$ and an equilibrium interfacial temperature of about $116^{\circ} \mathrm{C}$.

Two series of tests were conducted to measure the mixing due to jet flow. In the first series, organic layer temperature profiles were measured for a hot jet impinging on a twolayer organic-aqueous mixture. These tests showed that the organic layer was thermally well mixed but that there was little heat transfer to the underlying aqueous layer. Because it proved difficult to scale these test results from 4 inch diameter up to 10 foot diameter, a second series of mixing tests was conducted in a 1/6-scale mockup of a tank. In these tests, small plastic beads were suspended in the organic layer to measure recirculation 
velocities for impinging jet flow. From these measured velocities, scaling factors were used that showed that organic layer recirculated every 15 seconds.

The bubble mixing analysis relied on the results of a calorimetric study of TBP-nitric acid systems. In addition to furnishing heats and rates of reaction for these analyses, this calorimetric study provided additional evidence that a reaction excursion will not occur. This evidence comes from an analysis of canyon evaporators that was part of this study. The evaporator analysis demonstrated that even at canyon operating temperatures of about $121^{\circ} \mathrm{C}$, the rate of forced evaporation of volatiles (chiefly water) was sufficient to balance the heat of reaction and thereby prevent an excursion. The jet mixing analysis shows that the sensible heat transferred from the steam flow to the organic layer is small compared to the heat of reaction at this temperature. It follows that the evaporation of volatile components from the organic layer can compensate for any heat transferred from the steam.

Finally, the calorimetry experiments demonstrate the inherent conservatism of the bubble mixing analysis. During the calorimetry experiments, bubbling began in the aqueous layer at a temperature of $102^{\circ} \mathrm{C}$. This temperature is lower than the interfacial temperature calculated by the bubble mixing model, which was about $116^{\circ} \mathrm{C}$, when the surface was at $128^{\circ} \mathrm{C}$. It may be inferred that oxidation reactions of TBP and its reaction products will occur and generate bubbles in the aqueous phase for a self-heating two-layer mixture. The bubble mixing model does not account for generation of bubbles within the aqueous layer. Consequently, this model underestimates the rates of heat and mass transfer at the interface and overestimates the temperature increases in the TBP layer due to the TBP-nitric acid reaction. These conservatisms would result in a lower equilibrium temperature than calculated in this report.

\subsection{Acknowledgments}

E. F. Dyer set up the computer data logging and display hardware and programmed the software for the thermal mixing tests. He also calibrated the thermocouples. J. G. Dobos and W. C. Sexton fabricated the test vessel and furnished the resistance heater. The SRTC machine shop built the Lexan vessel enclosure and catch pan and coiled the gas flow tube that was inserted in the furnace. The SRTC Thermal Fluids Lab provided and calibrated the anemometer and furnished much of the tubing and fittings that were used to assemble the test apparatus.

\subsection{References}

1. J. R. Smith and W. S. Cavin, "Isothermal Heat Measurements of TBP-Nitric Acid Solutions (U)," WSRC-TR-94-0540, December 16, 1994.

2. J. E. Laurinat, "Mass Transfer Model for Two-Layer Oxidation Reactions (U)," WSRC-TR-94-0437, November 4, 1994. 
3. W. W. Schulz, J. D. Navratil, and A. E. Talbot, Science and Technology of Tributyl Phosphate: Volume 1, Synthesis, Properties, Reactions and Analysis, CRC Press, Inc., Boca Raton, Florida (1984), 152-153.

4. "F Canyon Basis for Interim Operations (UCNI)," WSRC-RP-93-1215, Rev. 5, April 13, 1998.

5. L. W. Christiansen and C. R. Lux, "Fault Tree Analysis of Red Oil Reactions in the F-Canyon Evaporators (U)," WSRC Calc-Note S-CLC-F-00140, Rev. B, March 14, 1995.

6. J. B. Joshi, "Axial Mixing in Multiphase Contactors - A Unified Correlation," Trans. I. Chem. E., 58, 1980, pp. 155-165.

7. S. D. Clinton and J. J. Perona, "Mass Transfer in a Bubble-Agitated Liquid-Liquid System,” Ind. Eng. Chem. Fundam., 221, 269-271 (1982).

8. W. W. Schulz, J. D. Navratil, and A. E. Talbot, Science and Technology of Tributyl Phosphate: Volume 1, Synthesis, Properties, Reactions and Analysis, CRC Press, Inc., Boca Raton, Florida (1984), 31.

9. R. H. Perry and D. W. Green, Perry's Chemical Engineers' Handbook, 6th ed., McGraw-Hill, New York (1984), 3-282.

10. W. W. Schulz, J. D. Navratil, and A. E. Talbot, Science and Technology of Tributyl Phosphate: Volume 1, Synthesis, Properties, Reactions and Analysis, CRC Press, Inc., Boca Raton, Florida (1984), 56.

11. R. H. Perry and D. W. Green, Perry's Chemical Engineers' Handbook, 6th ed., McGraw-Hill, New York (1984), 3-286.

12. W. Davis, Jr., J. Mrochek, and C. J. Hardy, "The System: Tri-N-Butyl Phosphate (TBP) - Nitric Acid - Water - I: Activities of TBP in Equilibrium with Aqueous Nitric Acid and Partial Molar Volumes of the Three Phase Components in the TBP Phase," J. Inorg. Nucl. Chem., 28, 2201-2014 (1966).

13. Detail Drawing $137945,221 \mathrm{~F}$ and H Jet Components (U)

14. Laboratory Notebook WSRC-NB-92-42, 139-153.

15. G. J. Van Wylen and R. E. Sontag, Fundamentals of Classical Thermodynamics, John Wiley and Sons, New York (1973), 622.

16. W. W. Schulz, J. D. Navratil, and A. E. Talbot, Science and Technology of Tributyl Phosphate, Volume 1: Synthesis, Properties, Reactions, and Analysis, CRC Press, Inc., Boca Raton, Florida (1984), Chapter 3, 25-67. 
17. Detail Drawing 129823, Building 221 F \& H, Standard 8'0" Dia. X 11'0" Cell Tank

18. R. H. Perry and D. W. Green, Perry's Chemical Engineers' Handbook, 6th ed., McGraw-Hill, New York (1984), 10-51.

19. L. C. Burmeister, Convective Heat Transfer, Wiley-Interscience, New York (1983), 538-562.

20. R. B. Banks and D.V.Chandrasekhara, "Experimental Investigation of the Penetration of a High-Velocity Gas Jet through a Liquid Surface," J. Fluid Mech., 1963, 15, 13-34.

21. E. A. Fox and V. E. Gex, "Single-phase Blending of Liquids," AIChE J., 1956, 2(4), 539-544.

22. R. H. Perry and D. W. Green, Perry's Chemical Engineers' Handbook, 6th ed., McGraw-Hill, New York (1984), 3-81 to 3-82.

23. V. M. Pilyugin, V. P. Krasavin, E. E. Grinberg, and A. A. Efremov, "Physicochemical Properties of Specially Purified Tributyl Phosphate," Russ. J. Phys. Chem., 60(6), 926-927 (1986).

24. R. C. Reid, J. M. Prausnitz, and T. K. Sherwood, The Properties of Gases and Liquids, McGraw-Hill, New York (1977), 629-665.

25. R. H. Perry and D. W. Green, Perry's Chemical Engineers' Handbook, 6th ed., McGraw-Hill, New York (1984), 3-145.

26. H. A. C McKay and T. V. Healy, "Tri-n-Butyl Orthophosphate (TBP) as an Extracting Solvent," Appendix III in F. R. Bruce, J. M. Fletcher, and H. H. Hyman, Progress in Nuclear Energy, Series III: Process Chemistry, Vol. 2, Pergamon Press, New York (1958).

27. R. H. Perry and D. W. Green, Perry's Chemical Engineers' Handbook, 6th ed., McGraw-Hill, New York (1984), 3-70.

28. A. L. Horvath, Physical Properties of Inorganic Compounds: SI Units, Crane, Russak and Co., Inc., New York (1975), 220.

29. J. F. Zemaitis, Jr., D. M. Clark, M. Rafal, and N. C. Scrivner, Handbook of Aqueous Electrolyte Thermodynamics: Theory and Application, A. I. Ch. E. Design Institute for Physical Property Data (DIPPR), A. I. Ch. E., New York (1986), 725-726.

30. R. H. Perry and D. W. Green, Perry's Chemical Engineers' Handbook, 6th ed., McGraw-Hill, New York (1984), 3-238 to 3-239. 
31. S. R. S. Sastri, M. V. Ramana Rao, K. A. Reddy, and L. K. Doraiswamy, “A Generalized Method for Estimating The Latent Heat of Vaporisation of Organic Compounds," British Chem. Eng., 14(7), 959-963 (1969).

\subsection{Nomenclature}

\section{Variable Definition}

A

$A_{n}$

$A_{\text {ves }}$

$\mathrm{c}_{\mathrm{p}}$

$\mathrm{c}_{\mathrm{p}, \mathrm{a}}$

$\mathrm{c}_{\mathrm{p}, \text { amb }}$

$\mathrm{C}_{\mathrm{p}, \mathrm{C}_{12} \mathrm{H}_{26}}$

$\mathrm{C}_{\mathrm{p}, \mathrm{C}_{12} \mathrm{H}_{26}}$

$\mathrm{C}_{\mathrm{p}, \mathrm{C}_{12} \mathrm{H}_{26}}$

$\mathrm{C}_{\mathrm{p}, \mathrm{g}}$

$\mathrm{c}_{\mathrm{p}, \mathrm{TBP}}$

$\mathrm{c}_{p, \mathrm{ves}}$

d

$d_{b}$

$\mathrm{d}_{0}$

D

$\mathrm{D}_{\mathrm{a}}$

$\mathrm{D}_{\mathrm{b}}$

$\mathrm{D}_{\mathrm{c}}$

$\mathrm{D}_{\mathrm{m}}$

$D_{n}$

$\mathrm{D}_{1 \mathrm{~L}}$

$\mathrm{D}_{2 \mathrm{~L}}$

$\mathrm{Fr}_{\mathrm{o}}$

g

$\mathrm{H}$ surface area of organic layer, $\mathrm{m}^{2}$

cross-sectional area of steam jet discharge pipe, $\mathrm{m}^{2}$

heat transfer area of vessel walls in thermal contact with the organic layer, $\mathrm{m}^{2}$

organic layer mixture heat capacity, $\mathrm{J} / \mathrm{kg} / \mathrm{K}$

heat capacity of the mixture of $\mathrm{H}_{2} \mathrm{O}$ and $\mathrm{HNO}_{3}$ in solution, $\mathrm{J} / \mathrm{kg} / \mathrm{K}$

heat capacity of ambient air, $\mathrm{J} / \mathrm{kg} / \mathrm{K}$

heat capacity of dodecane, $\mathrm{J} / \mathrm{kg} / \mathrm{K}$

heat capacity of tridecane, $\mathrm{J} / \mathrm{kg} / \mathrm{K}$

heat capacity of tetradecane, $\mathrm{J} / \mathrm{kg} / \mathrm{K}$

heat capacity of the steam flow, $\mathrm{J} / \mathrm{kg} / \mathrm{K}$

heat capacity of TBP, $\mathrm{J} / \mathrm{kg} / \mathrm{K}$

heat capacity of vessel walls in thermal contact with the organic layer, $\mathrm{J} / \mathrm{kg} / \mathrm{K}$

gas jet diameter at organic layer surface, $\mathrm{m}$

bubble diameter assumed for sparging mass transfer correlation, $\mathrm{m}$

gas jet diameter at inlet tube discharge, $\mathrm{m}$

tank diameter, $\mathrm{m}$

dispersion coefficient for liquid phase motion induced by bubble

flow from above, $\mathrm{m}^{2} / \mathrm{sec}$

dispersion coefficient for mixing by bubble flow from below, $\mathrm{m}^{2} / \mathrm{sec}$

characteristic length in the organic layer, $m$

organic layer, liquid molecular diffusivity, $\mathrm{m}^{2} / \mathrm{sec}$

jet discharge nozzle diameter, $m$

dispersion coefficient for sparging of just the top layer of a two-layer mixture, $\mathrm{m}^{2} / \mathrm{sec}$

dispersion coefficient for sparging of both layers of a two-layer

mixture, $\mathrm{m}^{2} / \mathrm{sec}$

Froude number for jet-driven circulation in the organic layer

gravitational acceleration, $\mathrm{m} / \mathrm{sec}^{2}$

organic layer thickness, $\mathrm{m}$ 


\section{Variable}

$h_{f, t}$

$h_{g, t}$

$\mathrm{h}_{\mathrm{g}, 0}$

$\Delta \mathrm{H}_{\mathrm{R}}$

$\mathrm{h}_{\mathrm{t}}$

$\overline{\mathrm{h}}_{\mathrm{t}}$

$\Delta \mathrm{H}_{\mathrm{v}, \mathrm{C}_{12} \mathrm{H}_{26}}$

$\Delta \mathrm{H}_{\mathrm{v}, \mathrm{C}_{13} \mathrm{H}_{28}}$

$\Delta \mathrm{H}_{\mathrm{v}, \mathrm{C}_{14} \mathrm{H}_{30}}$

$\Delta \mathrm{H}_{\mathrm{v}, \mathrm{HNO}}$

$\Delta \mathrm{H}_{\mathrm{v}, \mathrm{H}_{2} \mathrm{O}}$

$\Delta \mathrm{H}_{\mathrm{v}, \mathrm{TBP}}$

$\mathrm{k}_{\mathrm{amb}}$

$\mathrm{k}_{\mathrm{L}}$

L

M

$\mathrm{M}_{\mathrm{C}_{12} \mathrm{H}_{26}}$

$\mathrm{M}_{\mathrm{C}_{13} \mathrm{H}_{28}}$

$\mathrm{M}_{\mathrm{C}_{14} \mathrm{H}_{30}}$

$\mathbf{M}_{\mathrm{g}}$

$\mathrm{M}_{\mathrm{HNO}_{3}}$

$\mathrm{M}_{\mathrm{H}_{2} \mathrm{O}}$

$\mathrm{m}_{\mathrm{o}}$

$\dot{\mathrm{M}}_{\mathrm{s}}$

$\mathrm{M}_{\mathrm{TBP}}$

$\dot{\mathrm{n}}_{\mathrm{g}}$

$\mathrm{n}_{\mathrm{H}_{2} \mathrm{O}}$

$\mathrm{n}_{\mathrm{HNO}_{3}}$

$\mathrm{n}_{\text {TBP }}$

$\mathbf{n}_{\text {vap }}$

$\mathrm{Nu}$

\section{Definition}

saturated liquid phase enthalpy at the throat for steam jet flow, $\mathrm{J} / \mathrm{kg}$ saturated vapor phase enthalpy at the throat for steam jet flow, $\mathrm{J} / \mathrm{kg}$ saturated vapor phase enthalpy at stagnation for steam jet flow, $\mathrm{J} / \mathrm{kg}$ heat of reaction per mole of noncondensible vapor generated, $\mathrm{J} / \mathrm{kgmole}$ heat transfer coefficient for natural convection heat transfer from vessel or tank to surrounding air, $\mathrm{J} / \mathrm{m}^{2} / \mathrm{sec} / \mathrm{K}$ heat transfer coefficient for heat losses from test vessel to surrounding air, divided by the thermal mass of the test vessel and multiplied by the heat transfer area, $1 / \mathrm{min}$ molar heat of vaporization for dodecane, $\mathrm{J} / \mathrm{kgmole}$ molar heat of vaporization for tridecane, $\mathrm{J} / \mathrm{kgmole}$ molar heat of vaporization for tetradecane, $\mathrm{J} / \mathrm{kgmole}$ molar heat of vaporization for $\mathrm{HNO}_{3}, \mathrm{~J} / \mathrm{kgmole}$ molar heat of vaporization for $\mathrm{H}_{2} \mathrm{O}, \mathrm{J} / \mathrm{kgmole}$ molar heat of vaporization for TBP, $\mathrm{J} / \mathrm{kgmole}$ thermal conductivity of ambient air, $\mathrm{J} / \mathrm{m} / \mathrm{sec} / \mathrm{K}$ liquid phase mass transfer coefficient for sparging, $\mathrm{m} / \mathrm{sec}$ characteristic length scale for natural convection heat transfer from vessel or tank to surrounding air, $m$ jet momentum, $\mathrm{kg} \mathrm{m} / \mathrm{sec}^{2}$ molecular weight of dodecane, $\mathrm{kg} / \mathrm{kgmole}$ molecular weight of tridecane, $\mathrm{kg} / \mathrm{kgmole}$ molecular weight of tetradecane, $\mathrm{kg} / \mathrm{kgmole}$ molecular weight of gas, $\mathrm{kg} / \mathrm{kgmole}$ molecular weight of $\mathrm{HNO}_{3}, \mathrm{~kg} / \mathrm{kgmole}$ moleculär weight of $\mathrm{H}_{2} \mathrm{O}, \mathrm{kg} / \mathrm{kgmole}$ total mass of the organic layer, $\mathrm{kg}$ rate of momentum transfer from the jet to the organic layer, $\mathrm{m}^{2} / \mathrm{sec}^{2}$ molecular weight of TBP, $\mathrm{kg} / \mathrm{kgmole}$ molar flow rate of gas into vessel or tank, kgmole/sec reaction rate constant for $\mathrm{H}_{2} \mathrm{O}, 1 / \mathrm{sec}$ reaction rate constant for $\mathrm{HNO}_{3}, 1 / \mathrm{sec}$ reaction rate constant for $\mathrm{TBP}, 1 / \mathrm{sec}$ reaction rate constant for noncondensible vapors, $1 / \mathrm{sec}$ Nusselt number for turbulent natural convection heat transfer between the vessel or tank and the ambient air 


\section{Variable}

$\mathrm{P}_{\mathrm{C}_{12} \mathrm{H}_{26}}$

$\mathrm{p}_{\mathrm{C}_{13} \mathrm{H}_{28}}$

$\mathrm{p}_{\mathrm{C}_{14} \mathrm{H}_{30}}$

$\mathrm{p}_{\mathrm{HNO}_{3}}$

$\mathrm{p}_{\mathrm{HNO}_{3}}^{*}$

$\mathrm{p}_{\mathrm{H}_{2} \mathrm{O}}$

$\mathrm{p}_{\mathrm{H}_{2} \mathrm{O}}^{*}$

$\mathrm{p}_{\mathrm{TBP}}$

$\mathrm{p}_{\text {tot }}$

$\mathrm{Q}_{\mathrm{rxn}}$

$\mathrm{Q}_{\text {st }}$

$\mathrm{r}(\mathrm{T})$

$\mathrm{R}_{\mathrm{g}}$

$\mathrm{Ra}$

$\operatorname{Re}$

t

$s_{f, t}$

$\mathrm{s}_{\mathrm{g}, \mathrm{t}}$

$\mathrm{S}_{\mathrm{g}, 0}$

Sc

$\mathrm{Sh}$

$\mathrm{t}$

$\mathrm{T}$

$\mathrm{T}_{\mathrm{amb}}$

$\mathrm{T}_{\text {in }}$

$\mathrm{T}_{\text {org }}$

$\Delta \mathrm{T}$

$\mathrm{v}_{\mathrm{c}}$

$v_{n}$

$V_{\text {org }}$

$\mathrm{v}_{\text {sg }}$

\section{Definition}

vapor pressure of dodecane, atm

vapor pressure of tridecane, atm

vapor pressure of tetradecane, atm

vapor pressure of $\mathrm{HNO}_{3}$, atm

effective vapor pressure of $\mathrm{HNO}_{3}$ in organic solution, defined by

Equation 3, atm

vapor pressure of $\mathrm{H}_{2} \mathrm{O}$, atm

effective vapor pressure of $\mathrm{H}_{2} \mathrm{O}$ in organic solution, defined by

Equation 2, atm

vapor pressure of TBP, atm

total pressure, atm

heat generated by TBP-nitric acid, kcal

heat transferred from steam jet flow to organic layer, $\mathrm{kcal}$

Arrhenius-type factor for reaction rate constants ideal gas law constant, $\mathrm{m}^{3}$ atm $/ \mathrm{kgmole} / \mathrm{K}$

Rayleigh number for turbulent natural convection heat transfer between the vessel or tank and the ambient air

Reynolds number

time, sec

saturated liquid phase entropy at the throat for steam jet flow, $\mathrm{J} / \mathrm{kg} / \mathrm{K}$

saturated vapor phase entropy at the throat for steam jet flow, $J / \mathrm{kg} / \mathrm{K}$

saturated vapor phase entropy at stagnation for steam jet flow, $\mathrm{J} / \mathrm{kg} / \mathrm{K}$

Schmidt number

Sherwood number

time, sec

temperature, $\mathrm{K}$

also, tank diameter, in scaling analysis for jet-driven circulation of the organic layer, $\mathrm{m}$

ambient temperature, $\mathrm{K}$

gas inlet temperature, $\mathrm{K}$

organic layer temperature, $\mathrm{K}$

difference between gas inlet temperature and organic layer, $\mathrm{K}$ temperature, $\mathrm{K}$

characteristic velocity for circulation in the organic layer, $\mathrm{m} / \mathrm{sec}$

discharge velocity of the steam jet, $\mathrm{m} / \mathrm{sec}$

organic layer volume, $\mathrm{m}^{3}$

superficial velocity for bubble flow, $\mathrm{m} / \mathrm{sec}$ 


\section{Variable}

$v_{t}$

$\mathrm{V}_{\text {ves }}$

$\mathrm{w}_{\mathrm{a}}$

$\mathrm{X}_{\mathrm{C}_{12} \mathrm{H}_{26}}$

$\mathrm{X}_{\mathrm{C}_{13} \mathrm{H}_{28}}$

$\mathrm{X}_{\mathrm{C}_{14} \mathrm{H}_{30}}$

$\mathrm{X}_{\mathrm{HNO}_{3}}$

$\mathrm{X}_{\mathrm{HNO}_{3}, \mathrm{aq}}^{*}$

$\mathrm{X}_{\mathrm{HNO}_{3} \text {, org }}^{*}$

$\mathrm{X}_{\mathrm{HNO}_{3} \text {,sat }}$

$\mathrm{X}_{\mathrm{H}_{2} \mathrm{O}}$

$\mathrm{X}_{\mathrm{H}_{2} \mathrm{O} \text {,org }}^{*}$

$\mathrm{X}_{\mathrm{H}_{2} \mathrm{O} \text {,sat }}$

$\mathrm{X}_{\mathrm{t}}$

$\mathrm{x}_{\text {TBP }}$

$\mathrm{X}_{\mathrm{TBP}, \text { sat }}$

$\mathrm{y}_{\mathrm{HNO}_{3} \text {,aq }}^{*}$

z

$v$

$v_{g}$

$v_{\mathrm{amb}}$

$\theta_{\mathrm{c}}$

$\mu$

$\rho$

$\rho_{\text {amb }}$

$\rho_{\mathrm{C}_{12} \mathrm{H}_{26}}$

$\rho_{\mathrm{C}_{13} \mathrm{H}_{28}}$

$\rho_{\mathrm{C}_{14} \mathrm{H}_{30}}$

$\rho_{\mathrm{g}}$

$\rho_{\mathrm{HNO}_{3}}$

$\rho_{\mathrm{H}_{2} \mathrm{O}}$

$\rho_{\text {surf }}$

\section{Definition}

velocity at the throat for steam jet flow, $\mathrm{m} / \mathrm{sec}$

volume of vessel walls in thermal contact with the organic layer

or the vapor space above this layer, $\mathrm{m}^{3}$

weight fraction of nitric acid in the TBP phase that is $\mathrm{HNO}_{3}$

volume fraction of dodecane in the organic layer

volume fraction of tridecane in the organic layer

volume fraction of tetradecane in the organic layer

volume fraction of $\mathrm{HNO}_{3}$ in the organic layer

volume fraction $\mathrm{HNO}_{3}$ in the aqueous layer at saturation

volume fraction $\mathrm{HNO}_{3}$ in the organic layer at saturation

volume fraction of $\mathrm{HNO}_{3}$ in the TBP phase at saturation

volume fraction of $\mathrm{H}_{2} \mathrm{O}$ in the organic layer

volume fraction $\mathrm{H}_{2} \mathrm{O}$ in the organic layer at saturation

volume fraction of $\mathrm{H}_{2} \mathrm{O}$ in the TBP phase at saturation

quality at the throat for steam jet flow

volume fraction of TBP in the TBP phase

volume fraction of TBP in the TBP phase at saturation

mole fraction $\mathrm{HNO}_{3}$ in the aqueous phase in equilibrium with the

organic phase

distance from the surface of the organic layer, $m$

kinematic viscosity of the liquid in the organic layer, $\mathrm{m}^{2} / \mathrm{sec}$

kinematic viscosity of gas in the vapor space above the organic layer, $\mathrm{m}^{2} / \mathrm{sec}$

kinematic viscosity of ambient air, $\mathrm{m}^{2} / \mathrm{sec}$

circulation time for jet mixing of the organic layer, sec

organic layer, liquid viscosity, $\mathrm{kg} / \mathrm{m} / \mathrm{sec}$

organic layer mixture density, liquid density, $\mathrm{kg} / \mathrm{m}^{3}$

density of ambient air, $\mathrm{kg} / \mathrm{m}^{3}$

partial density of dodecane in the organic layer, $\mathrm{kg} / \mathrm{m}^{3}$

partial density of tridecane in the organic layer, $\mathrm{kg} / \mathrm{m}^{3}$

partial density of tetradecane in the organic layer, $\mathrm{kg} / \mathrm{m}^{3}$

density of gas in the vapor space above the organic layer, $\mathrm{kg} / \mathrm{m}^{3}$

partial density of $\mathrm{HNO}_{3}$ in the organic layer, $\mathrm{kg} / \mathrm{m}^{3}$

partial density of $\mathrm{H}_{2} \mathrm{O}$ in the organic layer, $\mathrm{kg} / \mathrm{m}^{3}$

density of air at vessel or tank surface, $\mathrm{kg} / \mathrm{m}^{3}$ 
Revision 1

Variable

$\rho_{\text {TBP }}$

$\rho_{\text {ves }}$

\section{Definition}

partial density of TBP in the organic layer, $\mathrm{kg} / \mathrm{m}^{3}$

density of vessel walls in thermal contact with the organic layer, $\mathrm{kg} / \mathrm{m}^{3}$ 
Revision 1

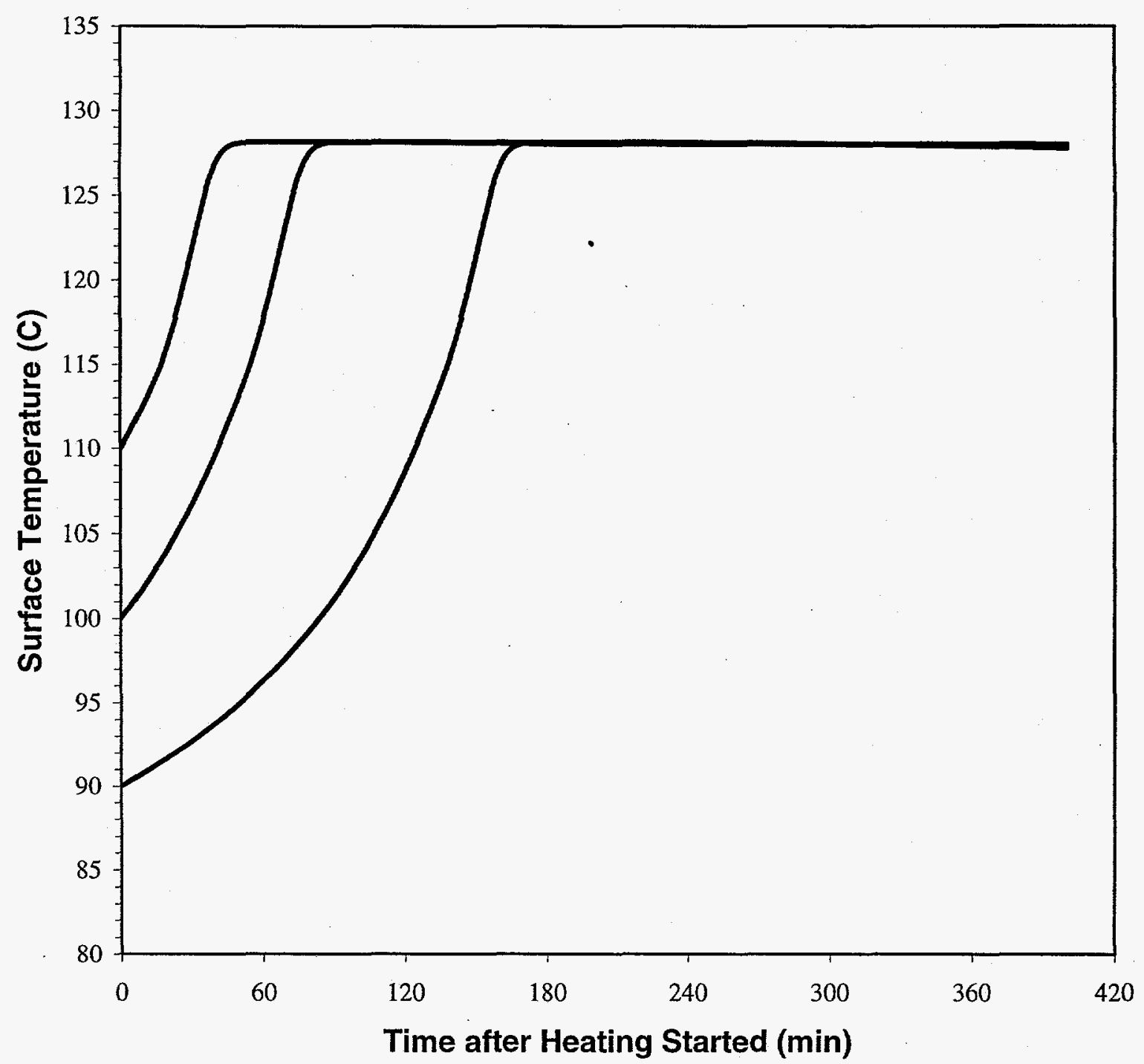

Figure 1. Surface Temperature Transients for TBP Layer Initially 50-cm Thick 
WSRC-TR-98-00171

Revision 1

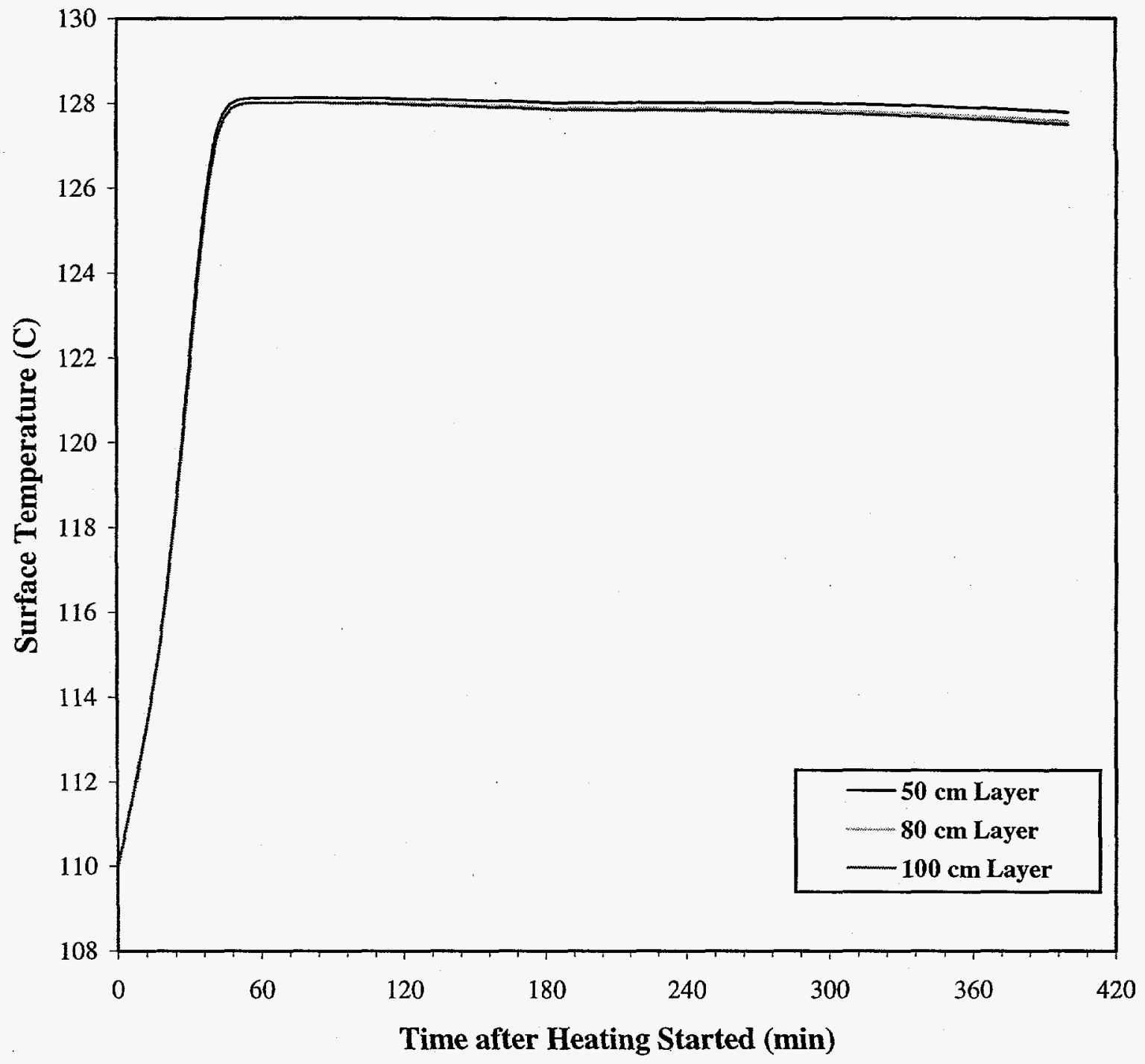

Figure 2. Effect of Initial TBP Layer Thickness on Surface Temperature Transients 


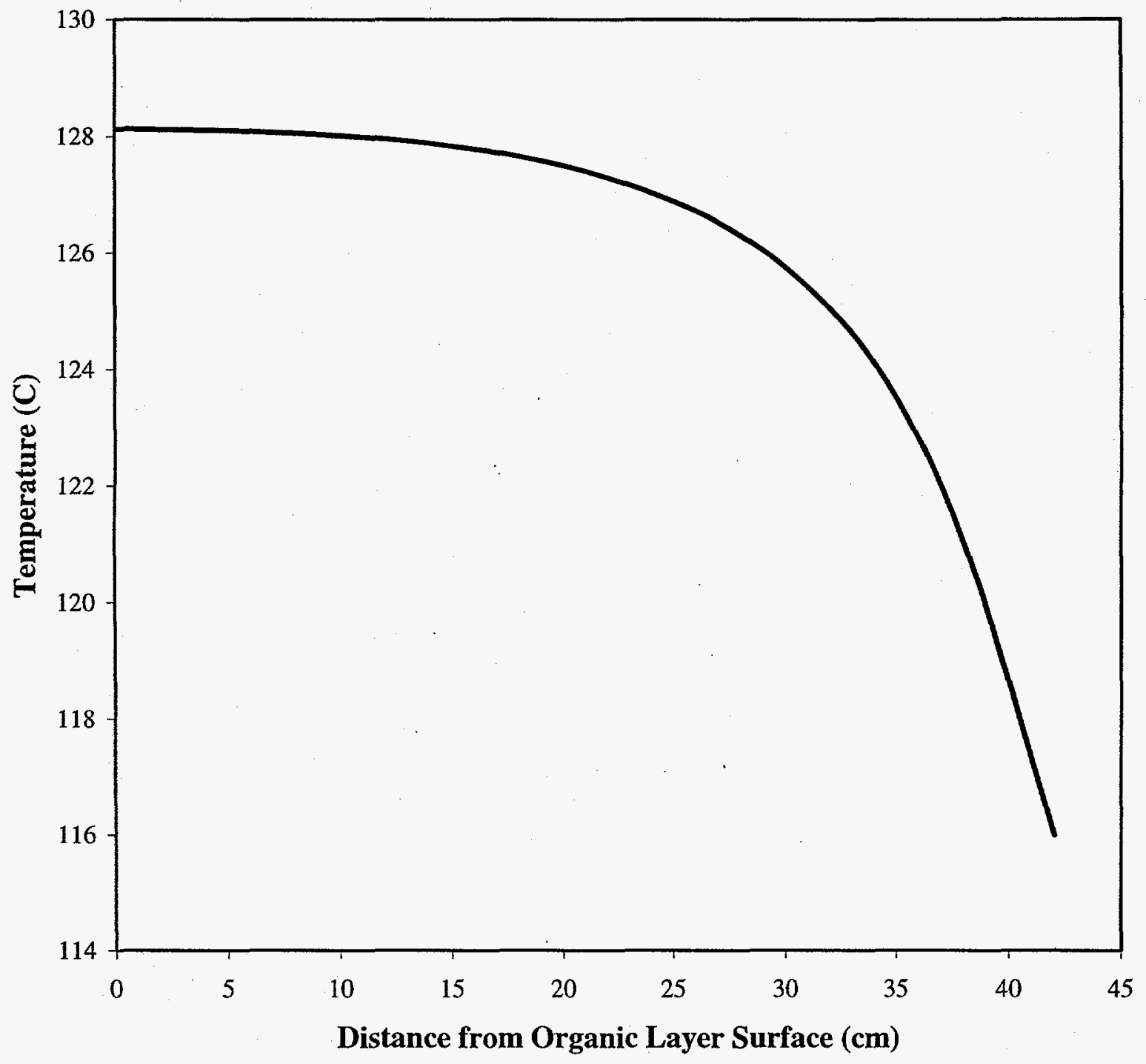

Figure 3. Equilibrium Temperature Profile for $50-\mathrm{cm}$ Thick TBP Layer Initially at $90^{\circ} \mathrm{C}$, after Heating for 400 Minutes. 


\section{Appendix A: Measurement of Steam Jet Air Entrainment Rate}

Prior to the start of the heat transfer experiments, the flow rate of air entrained by a tank transfer steam jet was measured using a mockup of a steam jet in the 717-F shop building. This measurement was needed to calculate the temperature of the steam-air mixture that would be transferred if a steam jet were inadvertently left on after the completion of a solution transfer.

The mockup was prototypical of a transfer line between two canyon tanks. The inlet to the steam jet was connected to a 15 -foot length of 2 -inch Schedule 40 pipe, and the outlet was connected to a 3 -inch Schedule 40 pipe. A type $75-\mathrm{CB}$ jet was used because it was the only type available for testing. This is the largest jet that is used for solution transfers; it is capable of delivering solution at $75 \mathrm{gpm}$. The jet has a jet throat diameter of $0.437 \pm 0.001$ inches and a diffuser throat diameter of $0.828 \pm 0.001$ inches. ${ }^{13}$ Steam was supplied from the same source that is used for the actual jets in the canyons.

The measurement was performed using a Davis Instrumentation Model LCA 6000 rotating vane anemometer. This instrument consisted of a rotating vane in a 4-inch diameter housing. It was calibrated to give the air velocity in $\mathrm{ft} / \mathrm{min}$ over a range of 0 $6000 \mathrm{ft} / \mathrm{min}$ with an uncertainty of $\pm 2 \%$. A welded PVC expansion coupling was fabricated so that this instrument could be used to measure the inlet air flow rate. The test was conducted by placing the anemometer flush against the bottom flange of the adapter. A total of five readings were taken and averaged to calculate the velocity. The results gave an average velocity of $470.2 \mathrm{ft} / \mathrm{min}$ with a standard deviation of $\pm 8.0 \mathrm{ft} / \mathrm{min}^{14}$

The flow rate was calculated by multiplying the velocity by the cross-sectional flow area of the anemometer and the density of air at standard conditions. This multiplication gives a mass flow rate of $3.1 \mathrm{lbm} / \mathrm{min}$.

The mass flow rate of steam through the jet was calculated by applying an adiabatic, isentropic choked flow condition. An adiabatic heat balance gives the throat velocity in terms of the stagnation enthalpy and the mixture enthalpy at the throat:

$v_{t}=\left[2\left(h_{g, 0}-x_{t} h_{g, t}-h_{f, t}+x h_{f, t}\right)\right]^{1 / 2}$

and an isentropic flow condition yields the steam quality at the throat:

$x_{t}=\frac{s_{g, 0}-s_{f, t}}{s_{g, t}-s_{f, t}}$

Enthalpies and entropies for these equations are obtained from saturated steam tables, based on the stagnation pressure upstream from the throat and the pressure for choked flow at the throat. The throat pressure is estimated to be 0.577 times the stagnation pressure. ${ }^{15}$ 
The mass flow rate of steam is calculated by multiplying the velocity given by Equation 1 by the steam density at the throat and the cross-sectional throat area.

The steam pressure just upstream from the jet was 135 psig before the start of the test and 110 psig during the test. The conditions during the test give a steam mass flow rate of $15.9 \mathrm{lbm} / \mathrm{min}$. Thus the ratio of the mass of air entrained to the mass of steam was 0.194 . For this entrainment ratio and a steam inlet pressure of $120 \mathrm{psig}$, an adiabatic heat balance gives a maximum steam temperature of $139^{\circ} \mathrm{C}$ at the inlet to the solvent storage tank. 


\section{Appendix B: Heat Transfer Experiments}

\section{B.1.0. Description of Heat Transfer Experiments}

To simulate steam heating in a canyon tank, bench scale experiments were performed. Figure B-1 depicts the experimental apparatus. As this figure shows, the apparatus consisted of a 4-inch diameter cylindrical vessel containing aqueous and TBP/n-paraffin layers. During the tests hot nitrogen gas was introduced into the vapor space above the liquid layers via a 1/4-inch tube that protruded through the top wall of the vessel. The discharge was directed downward so that it impinged directly onto the organic layer. The gas flow rate was scaled to reflect conditions for discharge from a steam jet into a solvent tank. A 1-inch diameter vessel vent was used to minimize pressure inside the vessel. An overflow beaker was placed underneath the vent discharge to collect the condensate and entrained liquid from the vent. To protect personnel and prevent spillage in case the vessel should break, the vessel was placed in a Lexan enclosure and a stainless steel catch pan.

The gas was heated to the estimated steam jet discharge temperature $\left(139^{\circ} \mathrm{C}\right)$ using a resistance heater. To minimize heat losses out the sides, the vessel was constructed as a Dewar, i.e., the sides had a double wall enclosing a vacuum space and were wrapped with a reflective surface of aluminum foil. To permit viewing of the organic layer, a thin strip running down the side was left uninsulated. The vessel cap was loosely covered with insulation. Neither the bottom of the vessel nor the vent line was insulated.

A significant loss of condensate out the vent was observed during a preliminary test. More than half of the original one liter organic layer was collected in the overflow beaker during about an hour and a half of gas flow. A comparison with results of subsequent tests and operation of the apparatus with unheated gas flow confirmed that most of this loss was caused by entrainment rather than evaporation. To remove this entrainment, a demister was installed in the vertical section of the vent line above the test vessel. The demister was constructed by placing four layers of Type 16/96 plastic mesh material, obtained from Kimre, Inc., in a section of 2-inch pipe. The effective flow diameter for this demister was 1.5 inches. Unheated tests demonstrated that this demister was effective in removing entrained droplets.

Temperature profiles in both the organic and aqueous layers were measured using sheathed Type $\mathrm{T}$ thermocouples, which have a range of $0-200^{\circ} \mathrm{C}$. Air flow rates were measured using a Kurz Model TR-519 anemometer, which had a range of 0-10 scfm. Both the thermocouples and the anemometer were connected to a data logging computer. This computer used LabVIEW, Version 2, software to display temperatures and flow rates at 1 second intervals and record these quantities at 1 minute intervals. In addition to these measurements, samples were withdrawn from the organic layer and the condensate collected in the overflow beaker for measurement of water content using the Karl Fisher method and for measurement of TBP content using gas chromatography/mass spectrometry (GC/MS). 
Six tests were conducted. In the first two tests, hot gas was blown over a two-layer mixture of 30 volume \% TBP in n-paraffin over water. The tests used samples of TBP and an n-paraffin solution, Exxon Norpar 13, obtained from F-Area. According to the manufacturer, Norpar 13 is a mixture of trace amounts of undecane $\left(\mathrm{C}_{11} \mathrm{H}_{24}\right), 15-20 \%$ dodecane $\left(\mathrm{C}_{12} \mathrm{H}_{26}\right), 50-55 \%$ tridecane $\left(\mathrm{C}_{13} \mathrm{H}_{28}\right)$, and 30-35\% tetradecane $\left(\mathrm{C}_{14} \mathrm{H}_{30}\right)$. A nominal composition of $20 \%$ dodecane, $50 \%$ tridecane, and $30 \%$ tetradecane was used in the analysis of results.

Four additional tests were conducted to determine the effects of the vapor pressures of the organic and aqueous phases and the inlet gas temperature on the maximum temperature of the organic layer. These tests differed from the first two tests in that the organic layer consisted of pure TBP saturated with aqueous solution. In the third test, the TBP was saturated with water, and in the fourth, fifth, and sixth tests, the TBP was saturated with a 22.5 weight $\%$ aqueous $\mathrm{NaCl}$ solution. The surface of the organic layer started 6 inches below the gas discharge in both the third and fourth tests. In the fifth and sixth tests, the solution remaining at the end of the previous test was reheated. The inlet gas temperature was set at $139^{\circ} \mathrm{C}$ for the fourth and fifth tests and was raised to $159^{\circ} \mathrm{C}$ for the sixth test. All other aspects of these tests were the same as for the previous tests.

These experiments were prototypic of conditions when steam would vent into one of the tanks due to the high heat losses from the mixing vessel. The greatest differences lie in the compositions of the gas (approximately $90 \%$ steam for the tank and dry nitrogen for the test vessel) and the aqueous and organic layers (30\% TBP in n-paraffin/nitric acid assumed for the tank, $30 \% \mathrm{TBP}$ in $\mathrm{n} / \mathrm{paraffin}$ or pure TBP/water in the tests). Table B-1 compares tank and test vessel dimensions and flow rates.

\section{Table B-1. Comparison of Tank and Experimental Conditions}

\begin{tabular}{|c|c|c|}
\hline & Tank & Experimental Vessel \\
\hline Diameter & 8 feet & 4 inches \\
\hline Height & 11 feet & 4 feet \\
\hline Gas inlet pipe diameter & 3.07 inches & 0.17 inches \\
\hline Entering gas velocity & $56 \mathrm{~m} / \mathrm{sec}$ & $77 \mathrm{~m} / \mathrm{sec}$ \\
\hline $\begin{array}{l}\text { Entering gas temperature } \\
\text { Separation between }\end{array}$ & $139^{\circ} \mathrm{C}$ maximum & $137-159^{\circ} \mathrm{C}$ \\
\hline gas inlet and organic layer & 10 inches minimum $^{1}$ & 2.75-6 inches \\
\hline Organic layer thickness & $0-15$ inches $^{2}$ & 6 inches \\
\hline Gas composition & $90 \%$ steam, $10 \%$ air & nitrogen \\
\hline Organic composition & $30 \%$ TBP in n-paraffin & $30-100 \%$ TBP in $n$-paraffin \\
\hline Aqueous composition & ca. $11 \mathrm{M} \mathrm{HNO}_{3}$ & water, $22 \mathrm{wt} \% \mathrm{NaCl}$ \\
\hline
\end{tabular}


Prior to the start of the experiments, one liter of the TBP/n-paraffin phase was saturated with water or aqueous salt solution by mixing vigorously using a magnetic stirrer. The two-layer mixture prepared by this method was added to the top of the test vessel, where the organic phase formed a 6 -inch thick layer. The organic layer surface was located 2.75 inches below the gas inlet tube discharge in the first test and approximately 6 inches below the discharge in the second and subsequent tests. Thermocouples were placed in a glass tube thermowell so that they were located at the top surface of the organic layer, two and four inches below the surface, at the organic-aqueous interface, and six inches below the interface in the aqueous layer. To promote better thermal contact with the solution, the thermowell was filled with silicone heat transfer fluid. Additional thermocouples were placed in the gas inlet tube, in the bypass line that discharged gas from the furnace into the hood, in the vapor space above the organic layer, in the vent tube, and outside the Lexan enclosure to measure the ambient temperature.

To start the tests, nitrogen flow to the bypass was started at a rate of $2.4 \mathrm{scfm}$; and the heater was turned on. When the air was preheated close to the desired inlet temperature of $139^{\circ} \mathrm{C}$ (this required about one hour), flow was redirected to the test vessel.

Temperatures were then monitored and recorded until the organic layer approached an equilibrium temperature which was determined by rates of evaporation and heat transfer from the column. Finally, the heater was turned off, and the rate of cooling of the organic layer was recorded. In the first test, the gas flow to the test vessel was maintained during this cooling interval. In subsequent tests, the flow was diverted to the bypass line so that the intrinsic rate of heat transfer from the test vessel to the surrounding could be measured.

During the tests it was observed that the gas flow churned and thoroughly mixed the organic layer. There was some entrainment of gas bubbles into the organic layer, and considerable splashing and entrainment of droplets into the vapor space above this layer and the vent line. The organic-aqueous interface remained relatively calm, with only small amplitude oscillations in its level. The amplitude of these oscillations increased as the thickness of the organic layer dropped due to evaporation. Condensate began to collect in the overflow beaker when the organic layer temperature reached about $80^{\circ} \mathrm{C}$; the absence of condensate at lower temperatures confirmed the effectiveness of the demister. The thickness of the organic layer decreased with time, and the organic solution that stayed in the test vessel turned orange. Table B-2 lists the volumes of the organic and aqueous layers before and after each test and the amount of condensate that was collected during each test. As the results in this table show, not all liquid evaporated from the organic layer was collected as condensate; some vapor was discharged to the hood vent. 
Table B-2. Material Balance Results for Tests

$\begin{array}{cccc}\text { Test No. } & \begin{array}{l}\text { Starting Volume } \\ \text { in Vessel (ml) }\end{array} & \begin{array}{l}\text { Ending Volume } \\ \text { in Vessel }(\mathrm{ml})\end{array} & \begin{array}{l}\text { Volume Condensate } \\ \text { Collected }(\mathrm{ml})\end{array} \\ 1 & 1060 & 640 & 215 \\ 2 & 1060 & 260 & 457 \\ 3 & 1020 & 860 & 48 \\ 4,5,6^{3} & 1020 & 610 & 155\end{array}$

The condensate that collected in the overflow beaker consisted entirely of one phase. After the completion of the tests, the condensate was mixed with water to determine if it was organic or aqueous. This mixing test proved that it was an organic phase. Results from the Karl Fisher moisture tests of the condensate and the organic layer that remained in the vessel confirmed this observation. According to the results of these tests, the water content of the organic layer in the vessel ranged up to slightly over 2 weight percent, while the water content of the condensate was at or below the lower detection limit of 0.5 weight percent. Table B-3 summarizes the results of the Karl Fisher analyses, as well as a measurement of the TBP content of the condensate and the organic layer in the vessel for Test 6. This latter measurement indicates that the most of the condensate was TBP, with a small but significant amount of other organic constituents. No tests were run to determine the composition of these constituents, but it is assumed that they probably were products of the aqueous decomposition of TBP, i. e., dibutyl phosphate (DBP), monobutyl phosphate (MBP), phosphoric acid, or butanol.

Table B-3. Results of Chemical Analyses of the Condensate and Organic Layer from Steam Heating Tests

Test No.

1
2
3
4
5
6

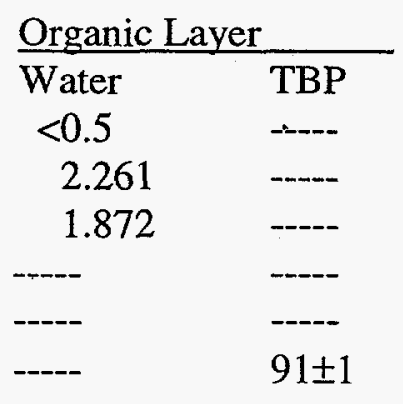

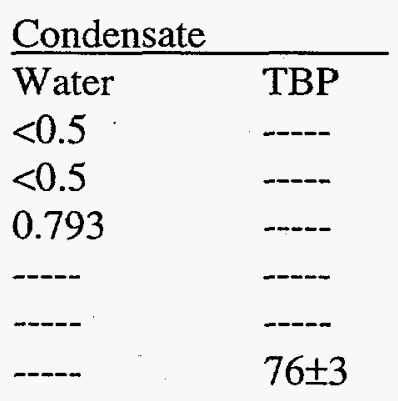

Figures B-2 through B-7 depict the temperature transients for the tests. Only the latter portion of the transient, after an equilibrium temperature had been approached, is shown for the second and sixth tests, because no temperatures were recorded for the earlier portions of these tests. The remaining figures show the entire temperature history, from

\footnotetext{
${ }^{3}$. Tests 4,5 , and 6 used the same starting solution; the inventories of the test vessel and the condensate collection beaker inventories were not changed between tests. Results are from the beginning of Test 4 to the end of Test 6 .
} 
the time hot gas flow was redirected to the test vessel through the initial portion of the cooling period after the heat was turned off. In each of the first five tests, the organic layer temperatures increased nearly linearly until they approached values ranging from about $90^{\circ} \mathrm{C}$ to $103^{\circ} \mathrm{C}$. The temperatures then either leveled off, peaked, or increased much more slowly. Temperature gradients in the organic layer were much smaller than in the aqueous layer, demonstrating that this layer was indeed well-mixed. The temperature of the vapor above the organic layer generally exceeded that of the organic layer by about $10^{\circ} \mathrm{C}$ early in the transient and by up to $5^{\circ} \mathrm{C}$ as equilibrium temperatures approached, indicating that there was some resistance to heat transfer between the vapor and the organic layer. (During the latter portion of the transients, the temperatures recorded by the thermocouple near the organic layer surface are a measure of the vapor temperature rather than the organic phase temperature because of the drop in the organic level.) Temperatures decreased relatively rapidly after heat and/or flow to the test vessel was turned off. This cooling was due to convective and radiative heat losses to the surroundings from the test vessel cap, which was not insulated as a Dewar.

The results for the sixth test differ from those of the previous tests. In this test, the vapor space temperature, which was measured by the thermocouples for the vapor space and the organic layer due to the drop from the initial liquid level; rose as high as $117^{\circ} \mathrm{C}$, while the organic layer temperature, which was measured by the thermocouple originally at the organic/aqueous interface, did not exceed about $99^{\circ} \mathrm{C}$. Once the organic layer had been heated to near this temperature, small bubbles were generated throughout this layer. The presence of these bubbles and the fact that the organic layer temperature did not exceed the boiling point of water probably indicates that incipient boiling of water dissolved in the organic layer limits the organic layer temperature to the saturation temperature of the underlying aqueous layer.

\section{B.2.0. Model of Mass and Heat Transfer in the Organic Layer}

The experiments in this study do not provide a direct measurement of temperatures that would be observed for steam heating of a TBP-nitric acid mixture because they did not use either nitric acid or steam. Instead, these experiments were used to measure heat transfer parameters for use in a computer code that calculates temperature and composition transients for steam heating. Since the tests demonstrated that the TBP layer was well-mixed in that it was heated to a nearly uniform temperature by the hot gas, the computer code models the TBP layer as a lumped system with a single temperature and composition. The computer model includes heats of reaction and vaporization as well as heat losses to the surroundings. The tests showed that the aqueous layer was heated only slowly, so the model neglects heat transfer to the aqueous layer. The code calculations are benchmarked versus the test results and are then used to predict temperature and concentration transients in a solvent storage tank.

This section lists the mass and heat transfer equations used in the computer model. These equations are similar to those listed in Section 4 . The equations in Section 4 have been changed by deleting the reaction terms, adding terms for the n-paraffin constituents, and 
adding terms to account for heat transfer to the steam flow and to the surrounding air. Terms in these equations are defined in the Nomenclature.

Separate component mass balances are used for the $\mathrm{H}_{2} \mathrm{O}, \mathrm{HNO}_{3}, \mathrm{TBP}$, and $\mathbf{n}$-paraffin constituents in the organic layer. All mass balances include losses due to evaporation into the steam jet flow. It is assumed that the steam jet flow mixes sufficiently well with the organic layer to become saturated with TBP and the n-paraffin components.

Experimental results and observations suggest that mixing is not sufficient for the vapor phase to become saturated with $\mathrm{H}_{2} \mathrm{O}$ and $\mathrm{HNO}_{3}$ vapors, however. If the hot nitrogen gas had become saturated with water vapor, some aqueous condensate should have collected in the overflow beaker. As stated previously, none was observed. In addition, if the gas flow had been saturated with water vapor, there should have been a plateau in the organic layer temperature transient, since steam should have been stripped from this layer at a relatively low temperature. With the possible exception of the third test, no such plateau was recorded. It is conjectured that instead of being stripped by the hot gas, the $\mathrm{H}_{2} \mathrm{O}$ and $\mathrm{HNO}_{3}$ in the organic layer are chemically bound with the $\mathrm{TBP}^{16}$ so that their vapor pressures are limited by the TBP vapor pressure. The computer model treats this hypothesis by assigning the $\mathrm{H}_{2} \mathrm{O}$ and $\mathrm{HNO}_{3}$ components effective vapor pressures which are proportional to the TBP vapor pressure, with the proportionality constant being the ratio of volume fraction of these components to that of TBP in solution. In the following mass balances these effective vapor pressures are denoted by an asterisk.

With the assumptions just described, the mass balance for $\mathrm{H}_{2} \mathrm{O}$ takes the form

$$
\frac{\mathrm{dx}_{\mathrm{H}_{2} \mathrm{O}}}{\mathrm{dt}}=-\left(\frac{\mathrm{x}_{\mathrm{H}_{2} \mathrm{O}}}{\mathrm{x}_{\mathrm{TBP}}}\right)\left(\frac{\dot{\mathrm{n}}_{\mathrm{g}} \mathrm{M}_{\mathrm{TBP}}}{\rho_{\mathrm{TBP}} \mathrm{V}_{\mathrm{org}}}\right)\left(\frac{\mathrm{p}_{\mathrm{TBP}}}{\mathrm{p}_{\mathrm{tot}}-\mathrm{p}_{\mathrm{TBP}}-\mathrm{p}_{\mathrm{H}_{2} \mathrm{O}}^{*}-\mathrm{p}_{\mathrm{HNO}_{3}}^{*}-\mathrm{p}_{\mathrm{C}_{12} \mathrm{H}_{26}}-\mathrm{p}_{\mathrm{C}_{13} \mathrm{H}_{28}}-\mathrm{p}_{\mathrm{C}_{14} \mathrm{H}_{30}}}\right)
$$

where

$$
\mathrm{p}_{\mathrm{H}_{2} \mathrm{O}}^{*}=\left(\frac{\mathrm{x}_{\mathrm{H}_{2} \mathrm{O}} \rho_{\mathrm{H}_{2} \mathrm{O}} \mathrm{M}_{\mathrm{TBP}}}{\mathrm{x}_{\mathrm{TBP}} \rho_{\mathrm{TBP}} \mathrm{M}_{\mathrm{H}_{2} \mathrm{O}}}\right) \mathrm{p}_{\mathrm{TBP}}
$$

and

$$
p_{\mathrm{HNO}_{3}}^{*}=\left(\frac{\mathrm{x}_{\mathrm{HNO}_{3}} \rho_{\mathrm{HNO}_{3}} \mathrm{M}_{\mathrm{TBP}}}{\mathrm{x}_{\mathrm{TBP}} \rho_{\mathrm{TBP}} \mathrm{M}_{\mathrm{HNO}_{3}}}\right) p_{\mathrm{TBP}}
$$


The mass balance for $\mathrm{HNO}_{3}$ is

$$
\frac{\mathrm{dx}_{\mathrm{HNO}_{3}}}{\mathrm{dt}}=-\left(\frac{\mathrm{x}_{\mathrm{HNO}_{3}}}{\mathrm{x}_{\mathrm{TBP}}}\right)\left(\frac{\dot{\mathrm{n}}_{\mathrm{g}} \mathrm{M}_{\mathrm{TBP}}}{\rho_{\mathrm{TBP}} \mathrm{V}_{\mathrm{org}}}\right)\left(\frac{\mathrm{p}_{\mathrm{TBP}}}{\mathrm{p}_{\text {tot }}-\mathrm{p}_{\mathrm{TBP}}-\mathrm{p}_{\mathrm{H}_{2} \mathrm{O}}^{*}-\mathrm{p}_{\mathrm{HNO}_{3}}^{*}-\mathrm{p}_{\mathrm{C}_{12} \mathrm{H}_{26}}-\mathrm{p}_{\mathrm{C}_{13} \mathrm{H}_{28}}-\mathrm{p}_{\mathrm{C}_{14} \mathrm{H}_{30}}}\right)
$$

The mass balance for TBP is

$$
\begin{aligned}
& \frac{\mathrm{dx}_{\mathrm{TBP}}}{\mathrm{dt}}=-\mathrm{r}(\mathrm{T}) \mathrm{x}_{\mathrm{HNO}_{3}}\left(\frac{\mathrm{n}_{\mathrm{TBP}}}{3}\right)\left(\frac{\mathrm{M}_{\mathrm{TBP} \rho_{\mathrm{HNO}_{3}}}}{\mathrm{M}_{\mathrm{HNO}_{3}} \rho_{\mathrm{TBP}}}\right) \\
& -\left(\frac{\dot{\mathrm{n}}_{\mathrm{g}} \mathrm{M}_{\mathrm{TBP}}}{\rho_{\mathrm{TBP}} \mathrm{V}_{\mathrm{org}}}\right)\left(\frac{\mathrm{p}_{\mathrm{TBP}}}{\mathrm{p}_{\text {tot }}-\mathrm{p}_{\mathrm{TBP}}-\mathrm{p}_{\mathrm{H}_{2} \mathrm{O}}^{*}-\mathrm{p}_{\mathrm{HNO}_{3}}^{*}-\mathrm{p}_{\mathrm{C}_{12} \mathrm{H}_{26}}-\mathrm{p}_{\mathrm{C}_{13} \mathrm{H}_{28}}-\mathrm{p}_{\mathrm{C}_{14} \mathrm{H}_{30}}}\right)
\end{aligned}
$$

The mass balances for dodecane, tridecane, and tetradecane, respectively, take the form

$$
\begin{aligned}
& \frac{\mathrm{dx}_{\mathrm{C}_{12} \mathrm{H}_{26}}}{\mathrm{dt}}=-\left(\frac{\dot{\mathrm{n}}_{\mathrm{g}} \mathrm{M}_{\mathrm{C}_{12} \mathrm{H}_{26}}}{\rho_{\mathrm{C}_{12} \mathrm{H}_{26}} \mathrm{~V}_{\text {org }}}\right)\left(\frac{\mathrm{p}_{\mathrm{C}_{12} \mathrm{H}_{26}}}{\mathrm{p}_{\text {tot }}-\mathrm{p}_{\mathrm{TBP}}-\mathrm{p}_{\mathrm{H}_{2} \mathrm{O}}^{*}-\mathrm{p}_{\mathrm{HNO}_{3}}^{*}-\mathrm{p}_{\mathrm{C}_{\mathrm{r} 2} \mathrm{H}_{26}}-\mathrm{p}_{\mathrm{C}_{13} \mathrm{H}_{28}}-\mathrm{p}_{\mathrm{C}_{14} \mathrm{H}_{30}}}\right) \\
& \frac{\mathrm{dx}_{\mathrm{C}_{13} \mathrm{H}_{28}}}{\mathrm{dt}}=-\left(\frac{\dot{\mathrm{n}}_{\mathrm{g}} \mathrm{M}_{\mathrm{C}_{13} \mathrm{H}_{28}}}{\rho_{\mathrm{C}_{13} \mathrm{H}_{28}} \mathrm{~V}_{\text {org }}}\right)\left(\frac{\mathrm{p}_{\mathrm{C}_{13} \mathrm{H}_{28}}}{\mathrm{p}_{\text {tot }}-\mathrm{p}_{\mathrm{TBP}}-\mathrm{p}_{\mathrm{H}_{2} \mathrm{O}}^{*}-\mathrm{p}_{\mathrm{HNO}_{3}}^{*}-\mathrm{p}_{\mathrm{C}_{12} \mathrm{H}_{26}}-\mathrm{p}_{\mathrm{C}_{13} \mathrm{H}_{28}}-\mathrm{p}_{\mathrm{C}_{14} \mathrm{H}_{30}}}\right)
\end{aligned}
$$

and

$$
\frac{\mathrm{dx}_{\mathrm{C}_{14} \mathrm{H}_{30}}}{\mathrm{dt}}=-\left(\frac{\dot{\mathrm{n}}_{\mathrm{g}} \mathrm{M}_{\mathrm{C}_{14} \mathrm{H}_{30}}}{\rho_{\mathrm{C}_{14} \mathrm{H}_{30}} \mathrm{~V}_{\mathrm{org}}}\right)\left(\frac{\mathrm{p}_{\mathrm{C}_{14} \mathrm{H}_{30}}}{\mathrm{p}_{\mathrm{tot}}-\mathrm{p}_{\mathrm{TBP}}-\mathrm{p}_{\mathrm{H}_{2} \mathrm{O}}^{*}-\mathrm{p}_{\mathrm{HNO}_{3}}^{*}-\mathrm{p}_{\mathrm{C}_{12} \mathrm{H}_{26}}-\mathrm{p}_{\mathrm{C}_{13} \mathrm{H}_{28}}-\mathrm{p}_{\mathrm{C}_{14} \mathrm{H}_{30}}}\right)
$$

The heat transfer equation includes terms for heats of reaction and vaporization, heat transfer between the hot gas and the organic layer and heat losses to the surroundings due to natural and forced convection and thermal radiation. Heat transfer between the aqueous and organic layers is assumed to be small enough to be neglected; this is a conservative assumption in that it leads to higher calculated temperatures. The heat balance includes the effect of the thermal mass of the vessel. For the tests this was estimated by adding the product of the weights and specific heats of the vessel lid, the flange connecting the top with the bottom of the vessel, and the portion of the inner wall of the Dewar in contact with the organic layer. The thermal mass of a canyon tank was calculated as the product of the volume, density, and specific heat of the tank wall, which was treated as a $3 / 8$-inch steel plate. ${ }^{17}$ 
With these assumptions, the heat transfer equation for the organic layer is given by

$$
\begin{aligned}
& \frac{\partial \mathrm{T}}{\partial \mathrm{t}}=\left[-\dot{\mathrm{n}}_{\mathrm{g}}\left(\frac{\Delta \mathrm{H}_{\mathrm{v}, \mathrm{TBP}} \mathrm{p}_{\mathrm{TBP}}+\Delta \mathrm{H}_{\mathrm{v}, \mathrm{H}_{2} \mathrm{O}} \mathrm{p}_{\mathrm{H}_{2} \mathrm{O}}^{*}+\Delta \mathrm{H}_{\mathrm{v}, \mathrm{HNO}_{3}} \mathrm{p}_{\mathrm{HNO}_{3}}^{*}}{\mathrm{p}_{\text {tot }}-\mathrm{p}_{\mathrm{TBP}}-\mathrm{p}_{\mathrm{H}_{2} \mathrm{O}}^{*}-\mathrm{p}_{\mathrm{HNO}_{3}}^{*}-\mathrm{p}_{\mathrm{C}_{12} \mathrm{H}_{26}}-\mathrm{p}_{\mathrm{C}_{13} \mathrm{H}_{28}}-\mathrm{p}_{\mathrm{C}_{14} \mathrm{H}_{30}}}\right)\right. \\
& -\dot{\mathrm{n}}_{\mathrm{g}}\left(\frac{\Delta \mathrm{H}_{\mathrm{v}, \mathrm{C}_{12} \mathrm{H}_{26}} \mathrm{p}_{\mathrm{C}_{12} \mathrm{H}_{26}}+\Delta \mathrm{H}_{\mathrm{v}, \mathrm{C}_{13} \mathrm{H}_{28}} \mathrm{p}_{\mathrm{C}_{13} \mathrm{H}_{28}}+\Delta \mathrm{H}_{\mathrm{v}, \mathrm{C}_{14} \mathrm{H}_{30}} \mathrm{p}_{\mathrm{C}_{14} \mathrm{H}_{30}}}{\mathrm{p}_{\text {tot }}-\mathrm{p}_{\mathrm{TBP}}-\mathrm{p}_{\mathrm{H}_{2} \mathrm{O}}^{*}-\mathrm{p}_{\mathrm{HNO}}^{*}-\mathrm{p}_{\mathrm{C}_{12} \mathrm{H}_{26}}-\mathrm{p}_{\mathrm{C}_{13} \mathrm{H}_{28}}-\mathrm{p}_{\mathrm{C}_{14} \mathrm{H}_{30}}}\right) \\
& \left.+\dot{n}_{g} M_{g} c_{p, g}\left(T_{i n}-T_{\text {org }}\right)+h_{t} A_{\text {ves }}\left(T_{\text {amb }}-T_{\text {org }}\right)\right] /\left(\rho c_{p} V_{\text {org }}+\rho_{\text {ves }} c_{p, v e s} V_{\text {ves }}\right)
\end{aligned}
$$

The heat transfer coefficient for heat transfer to the surroundings, $h_{t}$, was estimated from heat losses measured after flow of hot gas to the test vessel was shut off. These losses were calculated by integrating the transient heat transfer equation to get

$h_{t}=-\left(\frac{\rho c_{p} V_{o r g}+\rho_{\text {ves }} c_{p, \text { ves }} V_{\text {ves }}}{A_{\text {ves }}}\right) \frac{d \ln \left(T_{\text {org }}-T_{\text {amb }}\right)}{d t}$

Curve fit values for this coefficient were obtained from least-squares regression fits to test data, shown in Appendix D. It was assumed that the rate of heat transfer per unit area from a canyon tank should be similar to that measured during the tests. Accordingly, heat transfer rates obtained from the tests were corrected for changes in the heat transfer area and the thermal mass and used to model heating in a canyon tank. Both best estimate values based on average heat transfer coefficients for the tests and conservative values based on a $90 \%$ lower confidence bound were used in the model. These values are summarized in Table D-1 in Appendix D.

The assumption that the heat transfer coefficient and hence the heat transfer per unit area should be the same for the test vessel and the canyon tanks can be justified by examining heat transfer correlations. The primary mechanisms for heat transfer between either the test apparatus or a tank and the surroundings are natural convection and thermal radiation. Thermal radiation heat transfer depends only on the temperature difference between the hot surface and the surroundings and the thermal emissivity of either the test column or a tank. The thermal emissivity for the test column was only about 0.04 (for aluminum foil, which was wrapped around the sides and the top of the column ${ }^{18}$ ). Thus, radiative heat losses from the test vessel were small compared to convective heat losses and can be ignored. To be conservative, radiative heat losses from a tank were also ignored in the model. This implies that the scale-up of test conditions to actual tank conditions is based solely on natural convection.

Turbulent natural convection is governed by a relationship of the form ${ }^{19}$

$\mathrm{Nu} \propto \mathrm{Ra}^{1 / 3}$ 
where $\mathrm{Nu}$ is the Nusselt number, defined by

$\mathrm{Nu}=\frac{\mathrm{hL}}{\mathrm{k}_{\mathrm{amb}}}$

and $\mathrm{Ra}$ is the Rayleigh number, defined by

$\mathrm{Ra}=\frac{\left(\rho_{\text {amb }}-\rho_{\text {surf }}\right) \mathrm{c}_{\text {p,amb }} \mathrm{gL}^{3}}{\mathrm{v}_{\text {amb }} \mathrm{k}_{\text {amb }}}$

Note that the length scale $L$ appears to the net first power on both sides of the heat transfer correlation. This implies that the heat transfer coefficient, and the heat transfer rate per unit surface area, is independent of the size of the container, and that, furthermore, heat transfer coefficients measured during the experiment can be applied directly to a model of a tank. In the input to the tank model, allowance was made to account for the difference in total surface area per unit volume.

Physical properties for the TBP and aqueous phases were evaluated using standard literature correlations. These are listed in Appendix E.

\section{B.3.0. Use of Model to Benchmark Test Results}

The TBP layer heat and mass balances were integrated with respect to time using a computer code. The code listing is attached as Appendix G.

The computer code was benchmarked against the results of the nitrogen/water tests described in this report. The comparison was made between the model calculations and the average of the temperature measured at the organic surface and the two organic layer temperatures measured $1 / 3$ and $2 / 3$ of the distance to the organic/aqueous interface. Figures B-8 through B-13 compare the average measured temperatures with those predicted by the model. As these figures show, the model predicts both the initial rates of temperature rise and the maximum temperatures of the organic layer reasonably accurately. The model also successfully correlates the rates of heat loss after the heater was turned off, but this is to be expected, since the model heat transfer coefficient was based on these heat loss measurements. The model slightly underestimates the organic layer temperatures for Tests 1 and 2 and overestimates these temperatures for Tests 3 through 6 .

The discrepancies between the measured and predicted temperatures for the latter four tests probably occurs because the organic layer temperature is limited by the boiling point of the underlying aqueous layer. The organic layer temperatures reported in these figures are approximately equal to these saturation temperatures, which ranged from $100^{\circ} \mathrm{C}$ for aqueous layers that contained water to $105^{\circ} \mathrm{C}$ for aqueous layers containing $\mathrm{NaCl}$ solution. A comparison of Figures B-6 and B-7 with Figures B-12 and B-13 shows that for Tests 5 and 6 the temperatures predicted by the heat transfer calculations more closely 
approximate measured temperatures in the vapor phase. (As explained previously, for Test 6, the organic layer dropped due to evaporation, so the organic surface and upper and lower organic layer thermocouples actually were in the vapor phase.) The most plausible explanation for these observations is that the vapor phase became saturated with vapor at an equilibrium temperature determined by heats of vaporization, even though the bulk organic phase remained at the boiling point of the aqueous layer. 


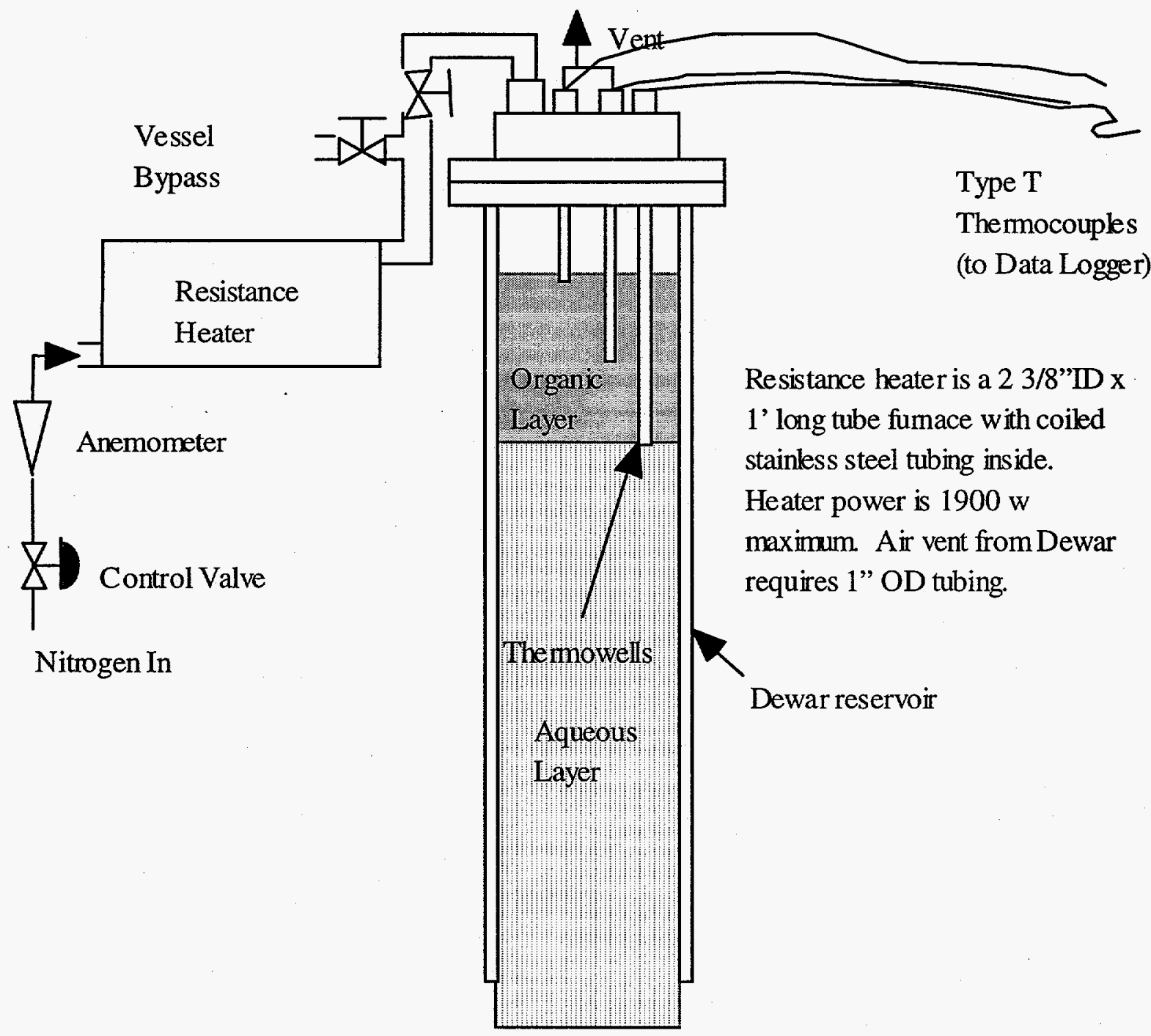

Figure B-1. TB P Steam Heating Apparatus 


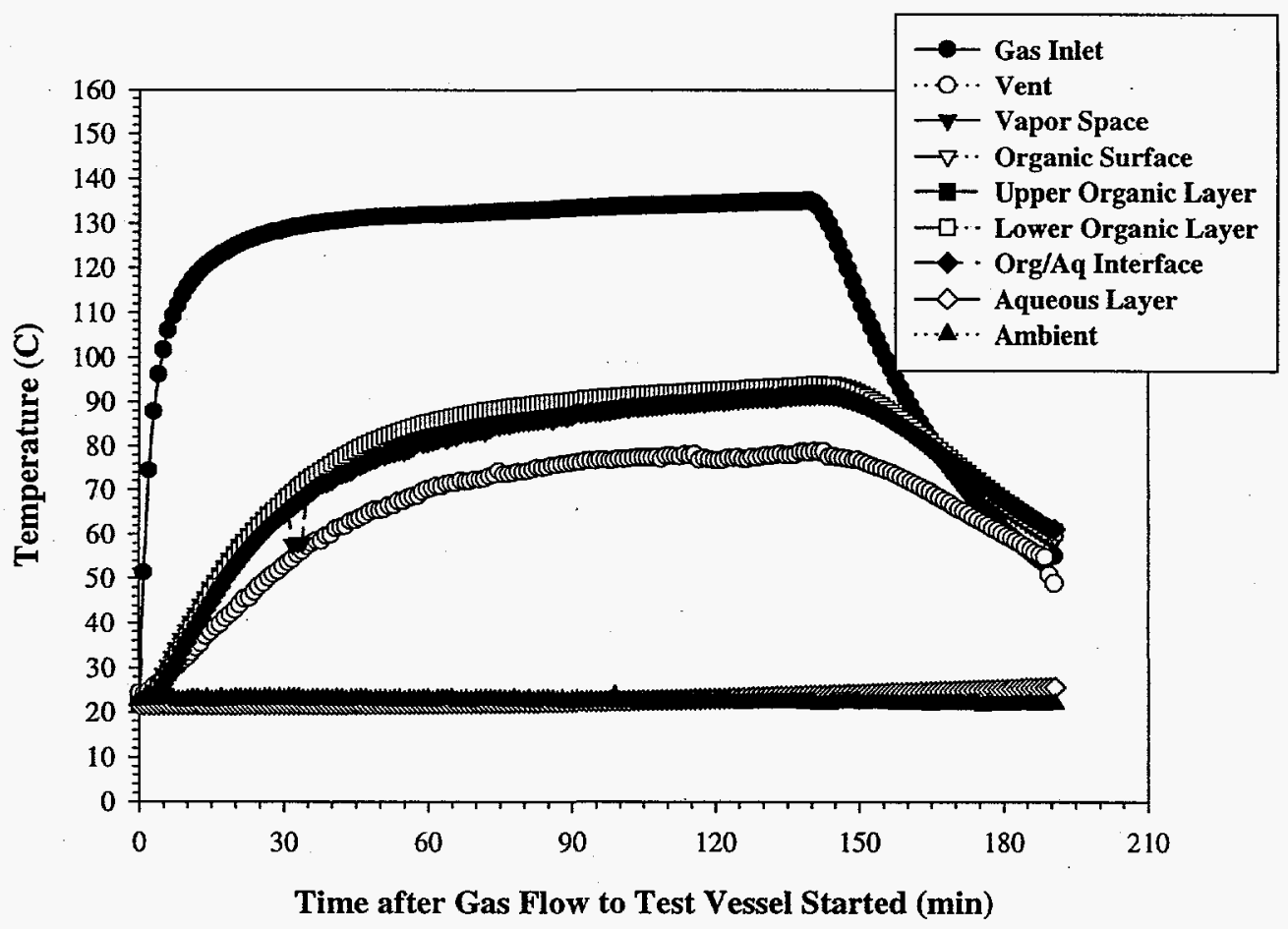

Figure B-2. Measured Temperature Transients for Test 1. 


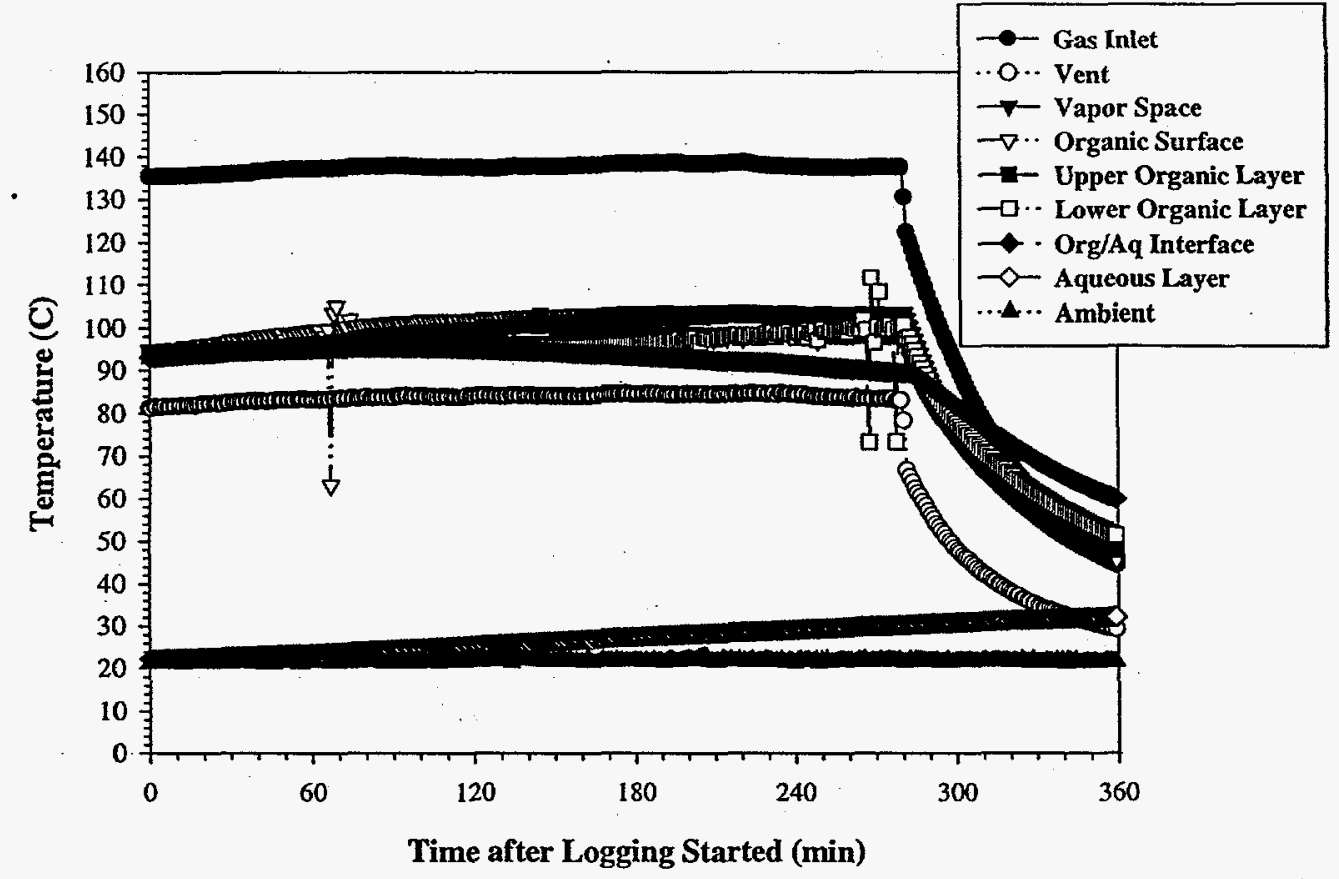

Figure B-3. Measured Temperature Transients for Test 2. 


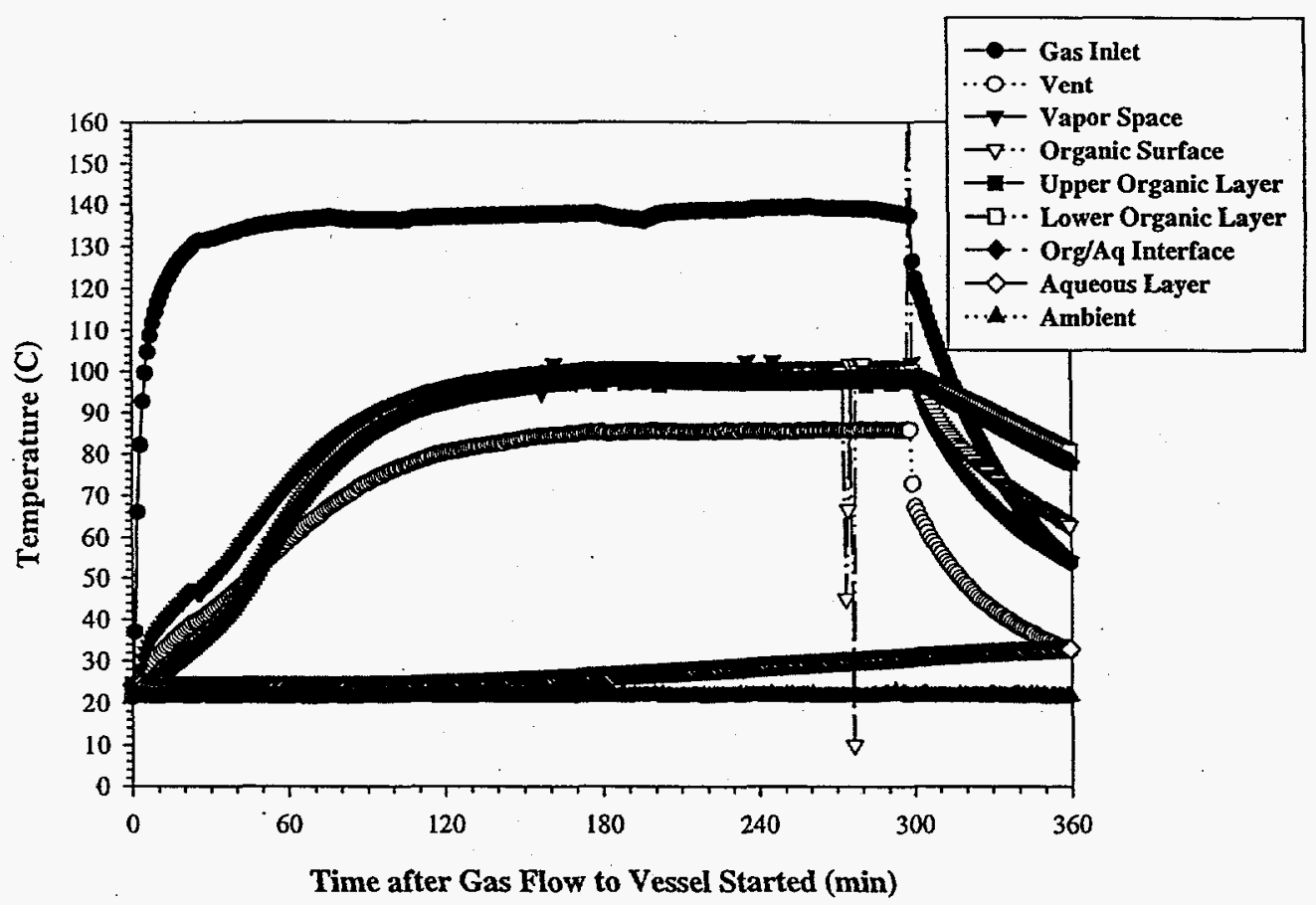

Figure B-4. Measured Temperature Transients for Test 3. 


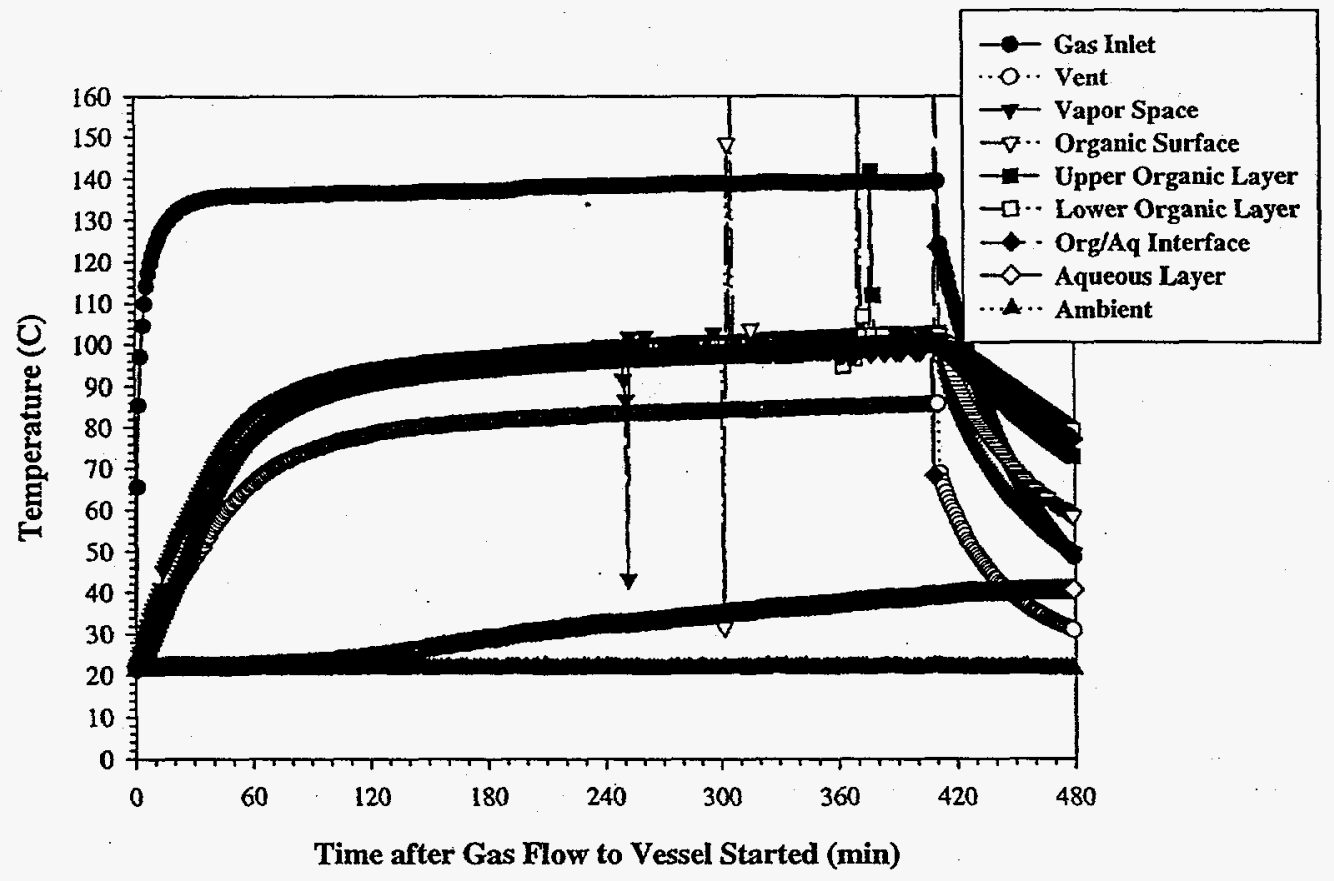

Figure B-5. Measured Temperature Transients for Test 4. 


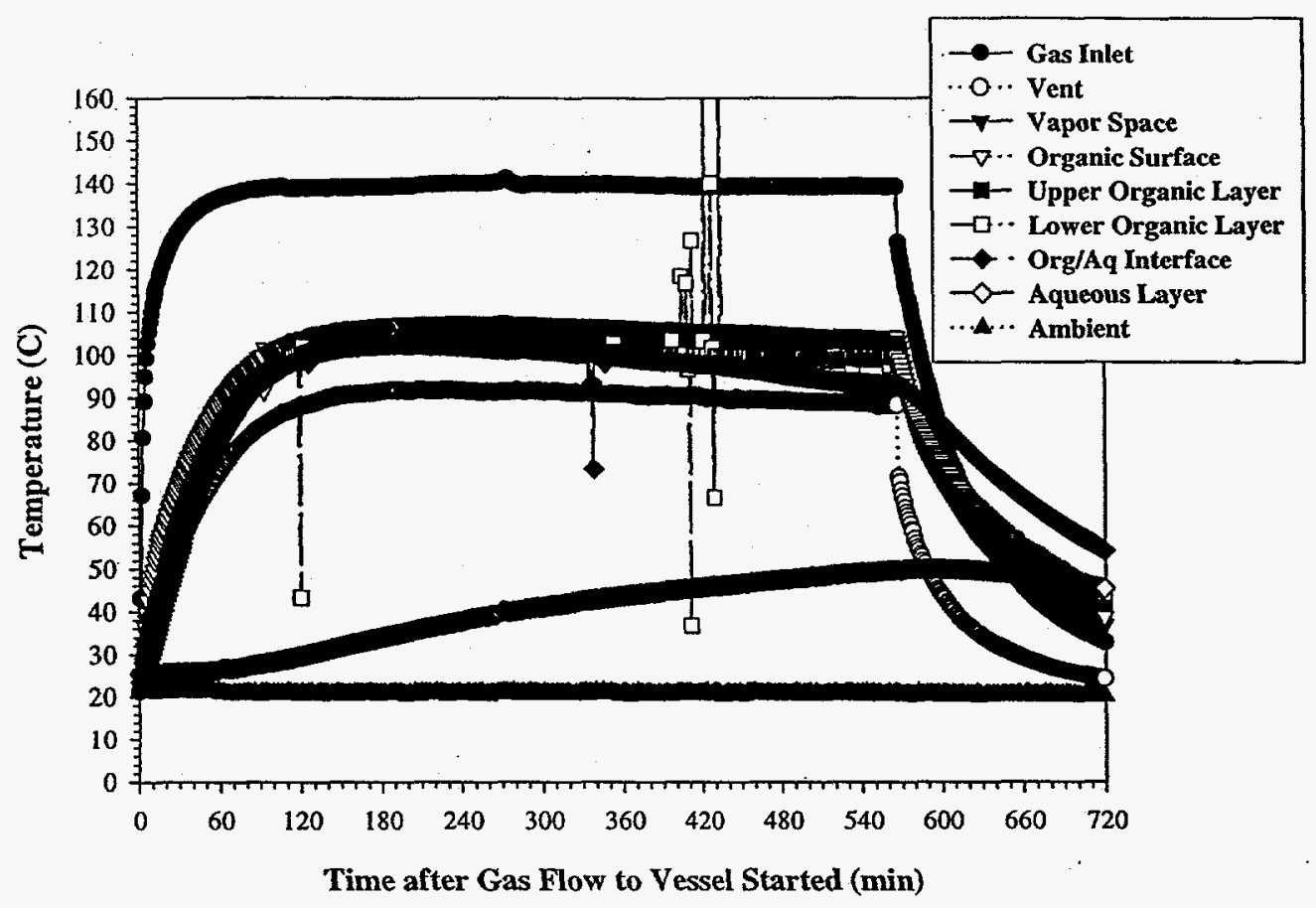

Figure B-6. Measured Temperature Transients for Test 5. 


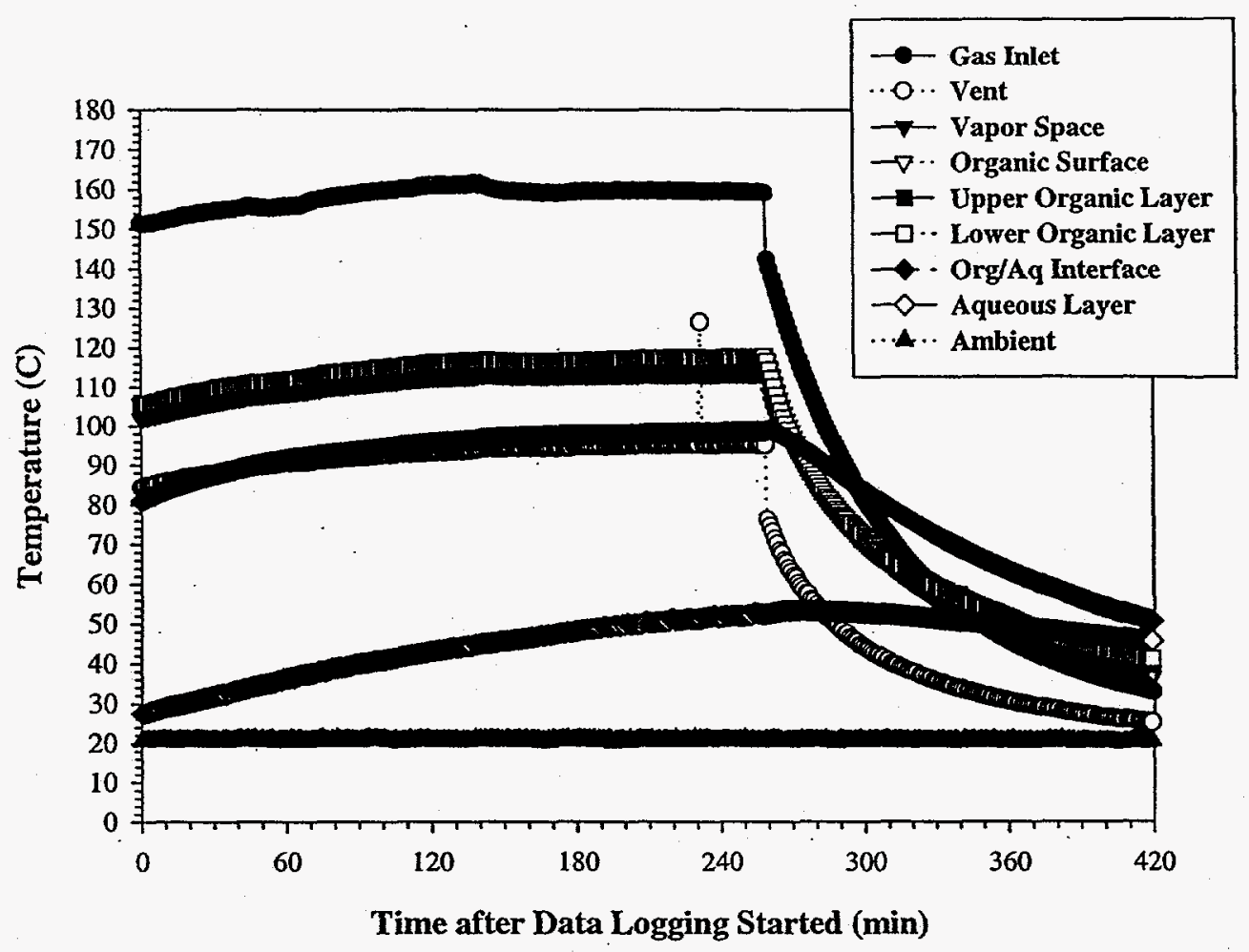

Figure B-7. Measured Temperature Transients for Test 6. 


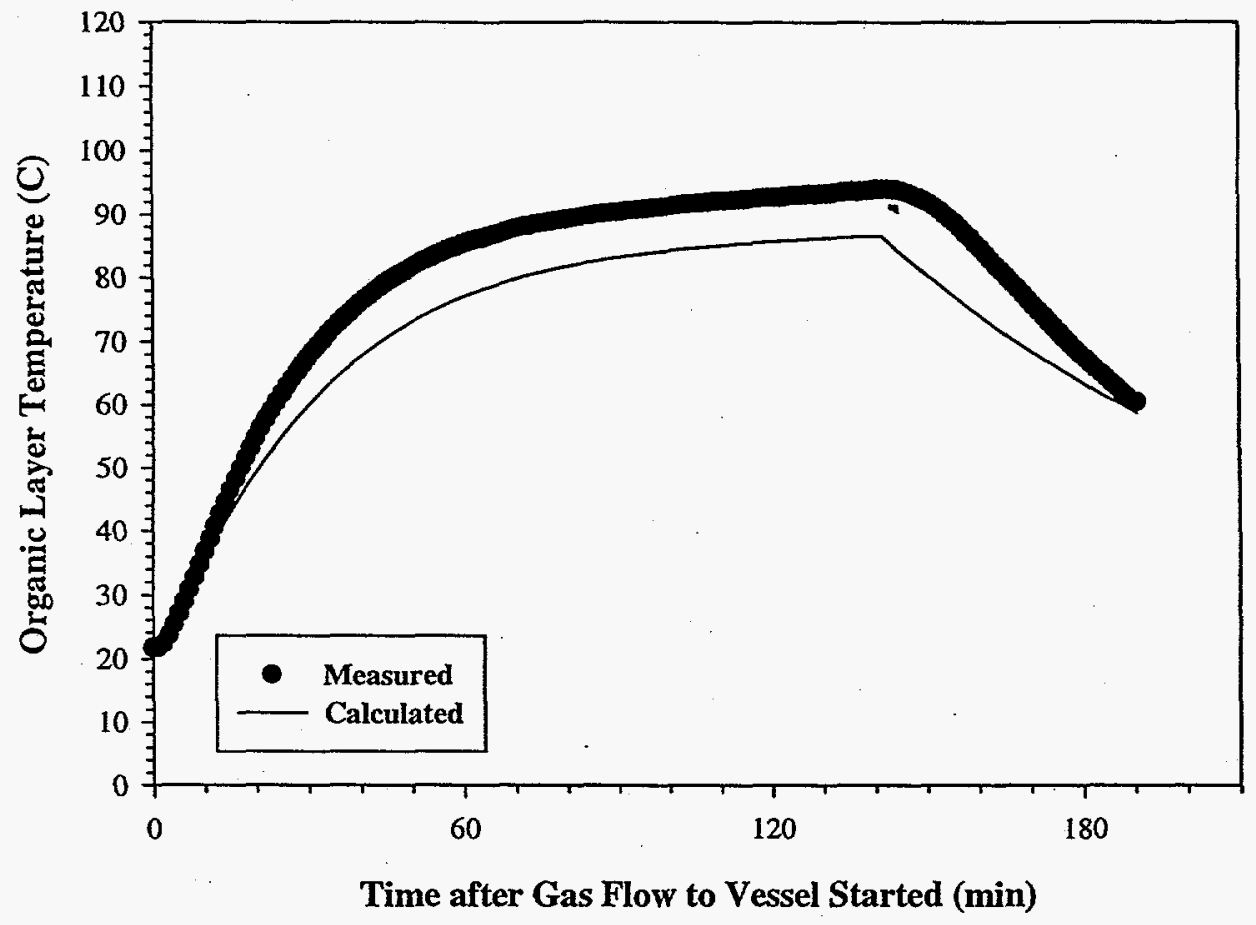

Figure B-8. Comparison of Measured and Predicted Organic Layer Temperature Transients for Test 1 . 


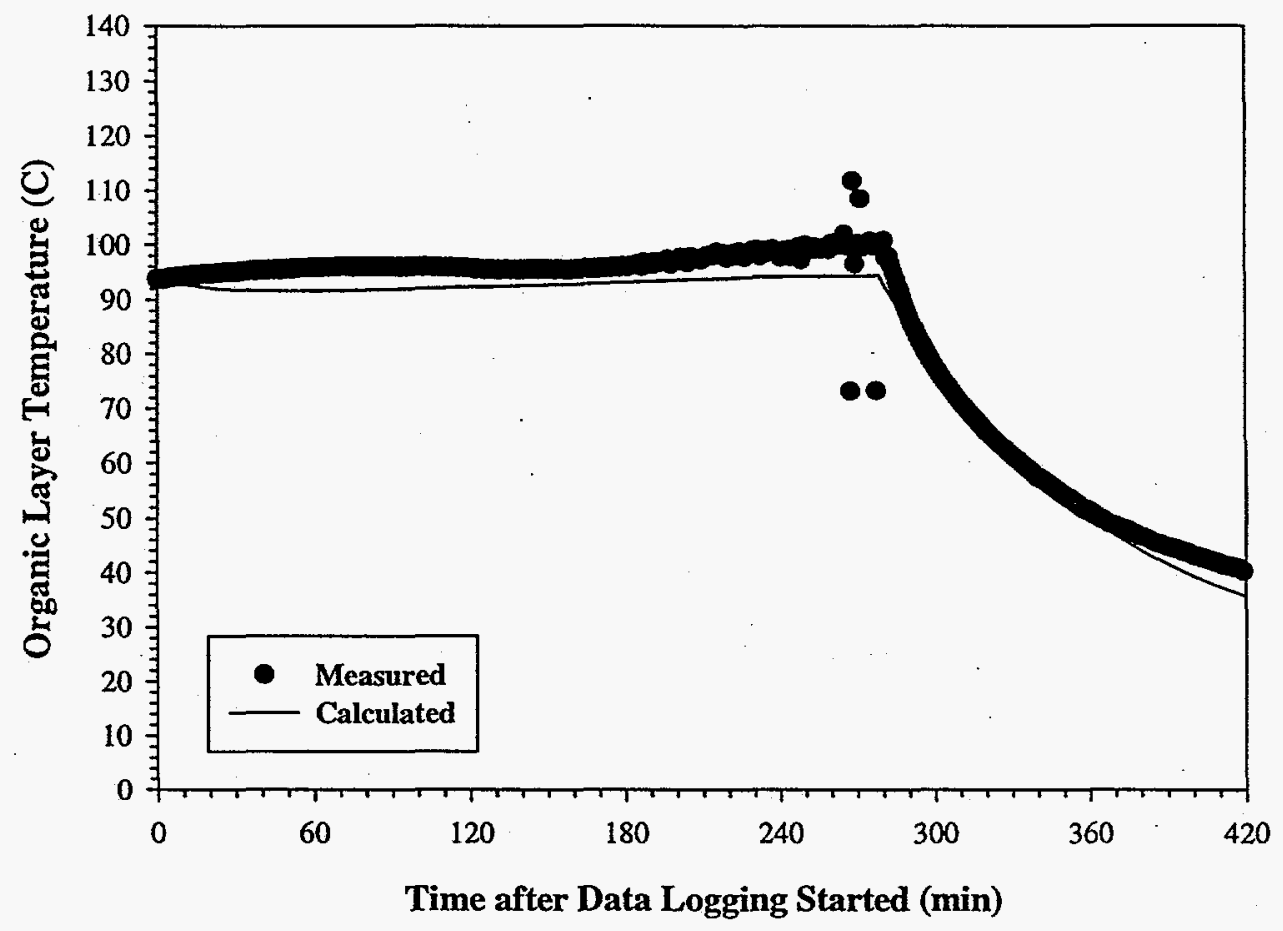

.Figure B-9. Comparison of Measured and Predicted Organic Layer Temperature Transients for Test 2. 


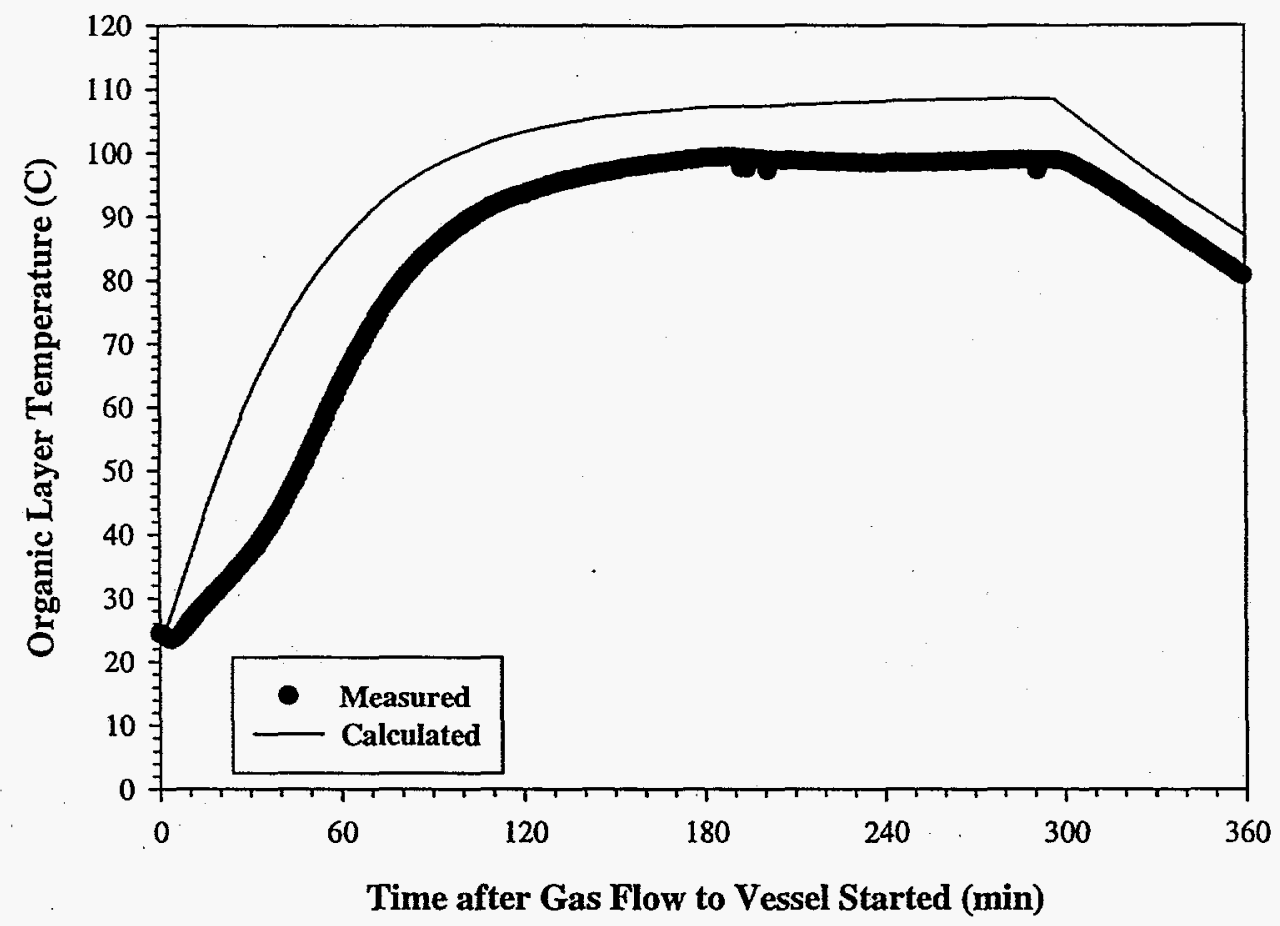

Figure B-10. Comparison of Measured and Predicted Organic Layer Temperature Transients for Test 3 . 


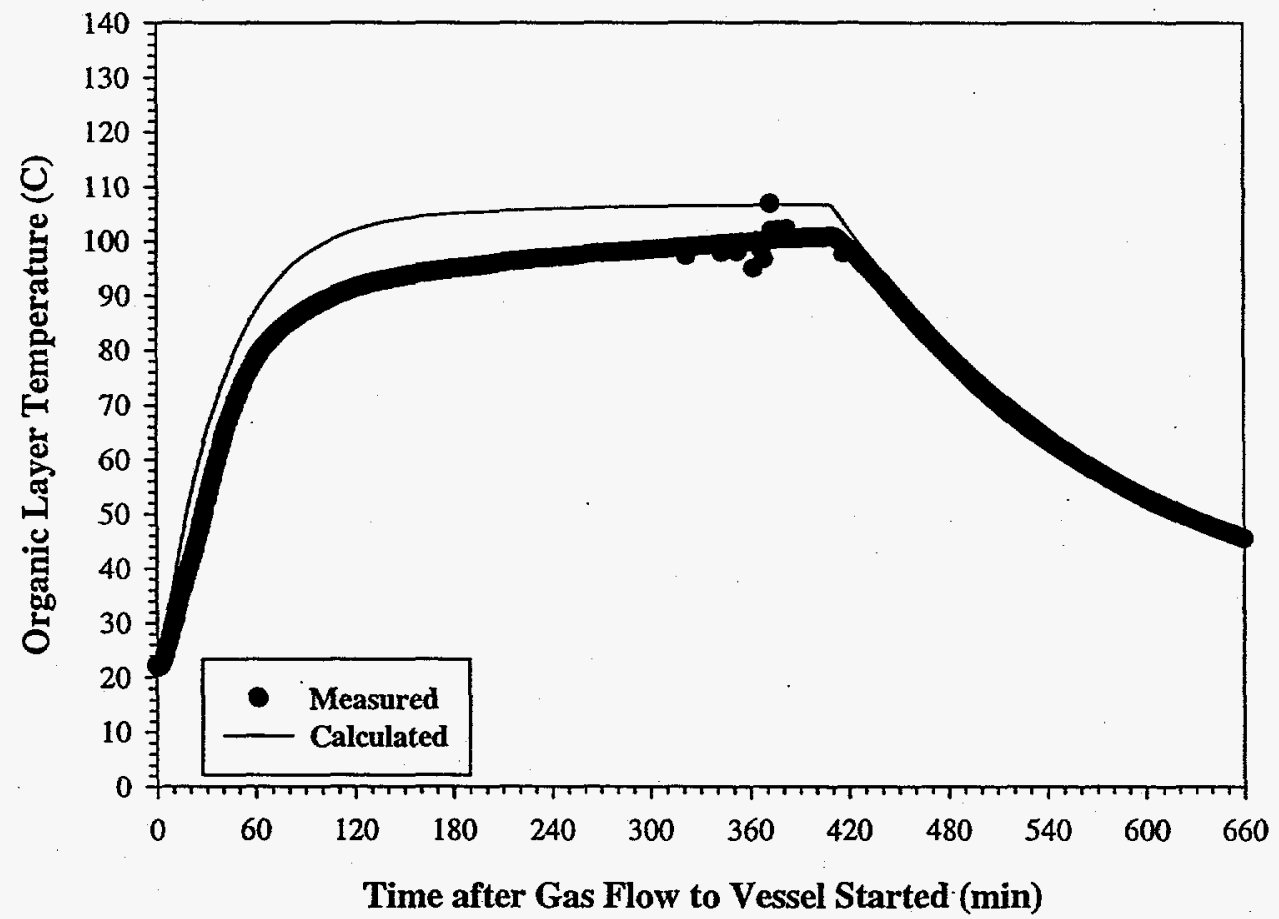

Figure B-11. Comparison of Measured and Predicted Organic Layer Temperature Transients for Test 4. 
WSRC-TR-98-00171

Revision 1

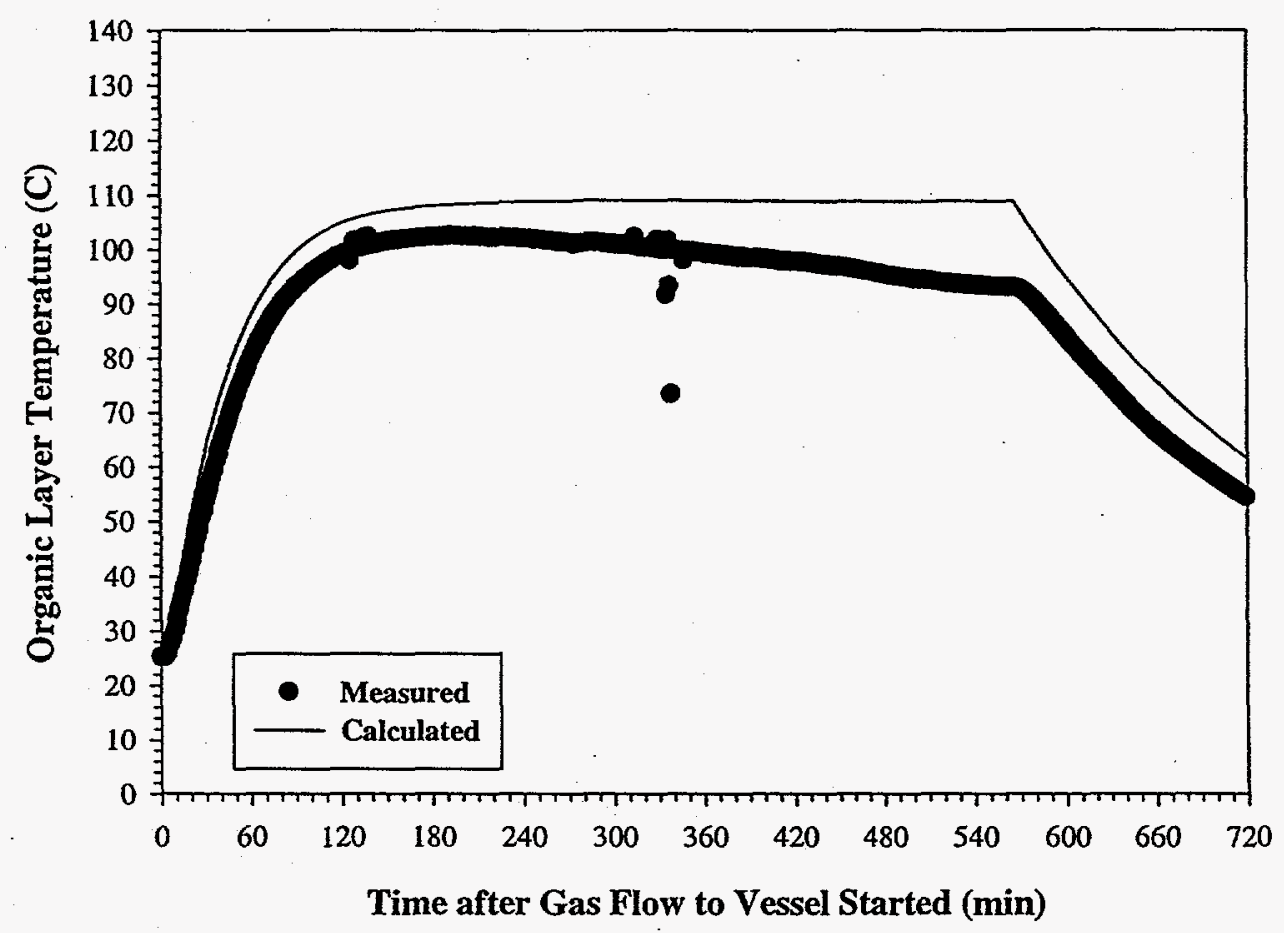

Figure B-12. Comparison of Measured and Predicted Organic Layer Temperature Transients for Test 5 . 


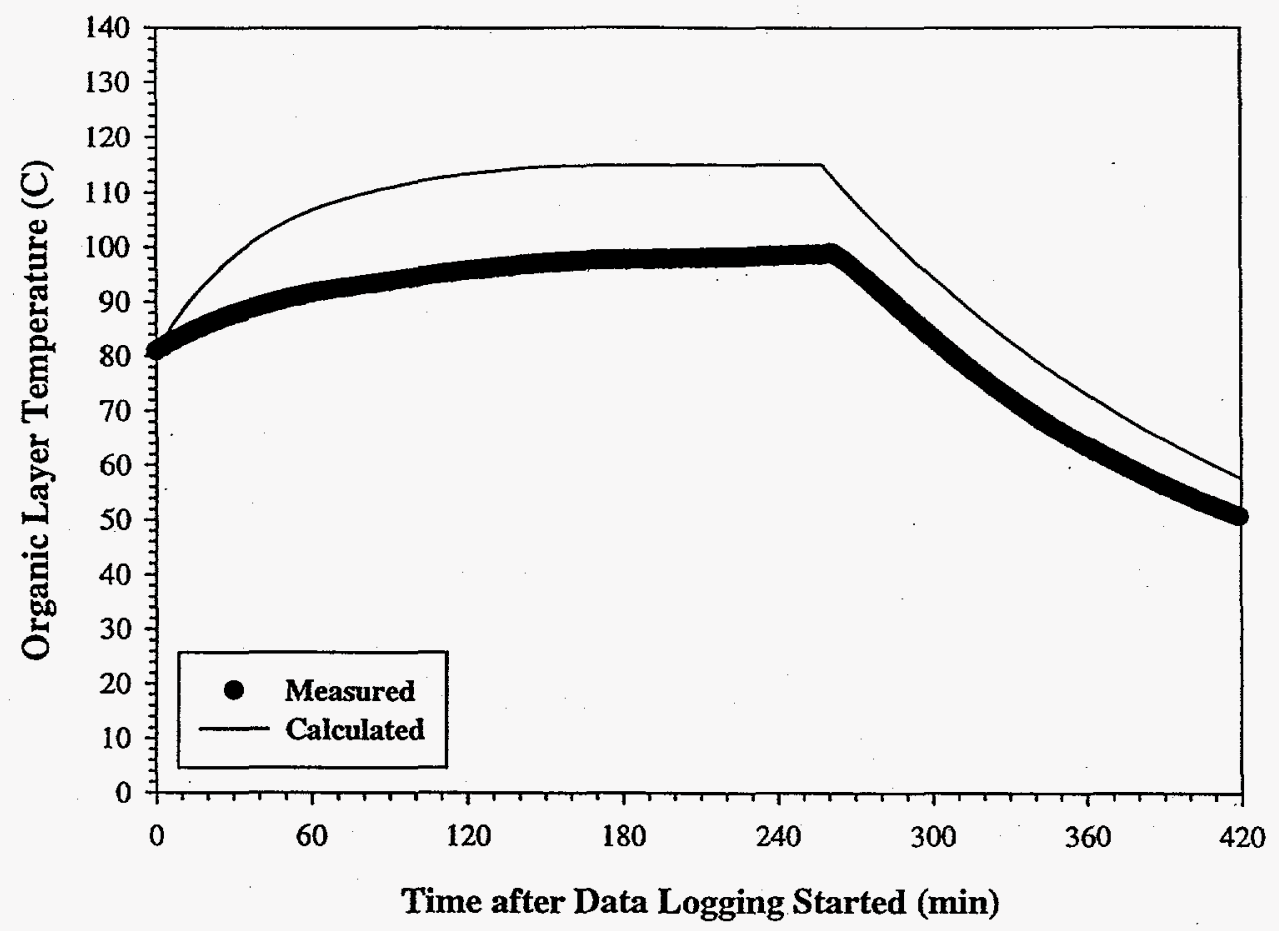

Figure B-13. Comparison of Measured and Predicted Organic Layer Temperature Transients for Test 6 . 


\section{Appendix C: Scale-up Correlation for Jet Impingement on Organic Layer}

This appendix contains a description of tracer mixing experiments performed in a 1/6scale mockup of a canyon tank. These experiments were performed to obtain a scaling factor for mixing of the organic layer in a two-layer TBP-nitric acid system due to jet impingement. In Section 3, this scaling factor is used to estimate a mass transfer coefficient for transfer of water across the aqueous-organic interface.

Professor A. H. Peter Skelland of the Georgia Institute of Technology, who has worked with SRTC in previous tank mixing studies, was consulted for his recommendations on how to scale up the results of these small scale mixing tests to tank dimensions. After reviewing the scaling requirements and viewing a videotape of some preliminary tracer mixing tests, he suggested a scaling correlation for use in estimating the organic layer circulation rates. The tracer experiments were performed to obtain data at different jet flow rates for use in this correlation. An explanation of his correlation and a description of the tests follow.

Professor Skelland based his scaling correlation on the momentum theory of mixing. ${ }^{20}$ Momentum theory stipulates that equal characteristic fluid velocities at corresponding points in two different size vessels guarantees similar mixing results based on scale up criteria. Thus for geometrically similar systems, one can postulate that the circulation time, $\theta_{c}$, is a function of what might be called the average specific momentum transfer rate, defined as the average rate of momentum transfer from the gas jet into each unit mass of organic layer or

$$
\frac{\frac{\mathrm{dM}}{\mathrm{dt}}}{\mathrm{m}_{\mathrm{o}}}=\dot{\mathrm{M}}_{\mathrm{s}}
$$

where $\mathrm{M}$ is the momentum of the jet stream, $t$ is the time momentum transferred into the liquid, $m_{o}$ is the mass of organic layer, $\dot{M}_{s}$ is the rate of momentum transfer. The circulation time, $\theta_{c}$, may be written as a function of the following variables

$\theta_{c}=f\left(\dot{M}_{s}, g, v_{c}, D_{c}, D_{m}, v\right)$

where $\dot{M}_{s}$ is the average rate of momentum transfer, $g$ is the gravitational acceleration constant, $v_{c}$ is a characteristic, but unknown, velocity in the organic layer, and $D_{c}$ is a characteristic length in the organic layer (i.e., $\mathrm{T}$ or $\mathrm{H}$ ). The kinematics viscosity of the organic layer, $v$, should influence $v_{c}$. Since ultimate contacting of the reactants presumably occurs by molecular diffusion, the reactant diffusivity in the organic layer, $\mathrm{D}_{\mathrm{m}}$, is also included as a variable.

Inspection of Equation C-2 suggests the following appropriate dimensionless groups of the significant variables 
$\theta_{c}=f\left[\left(\frac{\dot{\mathrm{M}_{s}}}{\mathrm{~g}}\right),\left(\frac{v}{\mathrm{D}_{\mathrm{m}}}\right),\left(\frac{\mathrm{v}_{\mathrm{c}}}{\mathrm{D}_{\mathrm{c}}}\right)\right]$

Thus, a dimensionless circulation time may be written as

$\frac{\theta_{c} v_{c}}{D_{c}}=$ function $\left(\frac{D_{n}^{2} v_{n}^{2} \rho_{g}}{T^{2} H \rho g}\right.$, other possible geometric ratios $)$

It should be noted that $\left(\theta_{c} v_{n} / D_{n}\right)$ will have the same value in two sizes of geometrically similar equipment if the values of the other dimensionless group, $\frac{D_{n}^{2} v_{n}^{2} \rho_{g}}{T^{2} H \rho g}$, is also the same. Since enough geometric similarity exists in the present situation, the other possible geometric ratios will drop out from Equation C-4. The group on the right-hand side of this equation may therefore be rearranged as

$\left(\frac{D_{n}}{T}\right)^{2}\left(\frac{\rho_{g}}{\rho}\right)\left(\frac{v_{n}^{2}}{H g}\right)$

Note that the last group in Equation C-5 represents the Froude number. The reason it is included here is that the free surface of the organic layer and the recirculation flow patterns within the organic layer are affected by gravity. Thus

$$
\left(\frac{\mathrm{v}_{\mathrm{n}}^{2}}{\mathrm{Hg}}\right) \propto\left(\frac{\mathrm{v}_{\mathrm{c}}^{2}}{\mathrm{Hg}}\right)=\mathrm{Fr}_{\mathrm{o}}
$$

A plot of the dimensionless circulation time, $\frac{\theta_{c} v_{n}}{D_{n}}$, as a function of the dimensionless group $\left(\frac{D_{n}}{T}\right)^{2}\left(\frac{\rho_{g}}{\rho}\right)\left(\frac{v_{n}^{2}}{H g}\right)$ should provide adequate an scale-up correlation for jet . impingement of the organic layer. This correlation, however, may be rearranged to obtain a dimensionless circulation time similar to that used by Fox and Gex,${ }^{21}$ but with their (internal) liquid jet Reynolds number replaced by the following equation

$\frac{D_{c} v_{c} \rho}{\mu}=\frac{D_{c} v_{c}}{v}$

Since $\mathrm{v}_{\mathrm{c}}$ is an unknown characteristic velocity, it may be expressed as

$\mathrm{v}_{\mathrm{c}}=(\text { constant })^{*} \mathrm{v}_{\mathrm{n}}$ 
Similarly,

$D_{c}=\left(\right.$ constant $\left.t^{\prime}\right) * D_{n}$

Ignoring the constant/constant' ratio, $\frac{D_{c} \cdot v_{c}}{v}$ will be replaced with $\frac{D_{n} v_{n}}{v}$.

A plot of the redefined dimensionless circulation time, $\frac{\left(\frac{\theta_{c} v_{c}}{D_{n}}\right)}{\left(\frac{D_{n}}{T}\right)^{2}\left(\frac{\rho_{g}}{\rho}\right)\left(\frac{v_{n}^{2}}{H g}\right)}$, versus the jet Reynolds number, $\frac{D_{n} v_{n}}{v}$, on a $\log$-log scale should provide an appropriate scale-up correlation for jet impingement on the organic layer.

To obtain data for use in Skelland's correlation, tests were conducted in which a gas jet was directed onto an organic layer on top of an aqueous solution. These tests were performed using a 1/6-scale lab unit that exhibits full geometric similarity with a canyon tank. The lab unit was a cylindrical, flat-bottomed; Plexiglas tank, having an inside diameter of 18 inches and an overall height of 36 inches. Six radial baffles and three concentric cooling coils made of 0.5 -inch diameter stainless steel tubing were mounted on the inside of the baffles in the tank. A schematic diagram of the lab unit is shown in Figure C-1.

Experiments were carried out in which a 0.57 -inches diameter nozzle was used to direct a gas jet normally onto the surface of the organic layer. The measured depth of the organic layer in the tank was 15 inches, and the distance between the nozzle and the organic layer was fixed at 15 inches. The jet was located about 1.12 inches from the tank wall, which corresponds to approximately 6 inches in a canyon tank.

Low-density polyethylene beads, $3 \mathrm{~mm}$ in diameter, were dispersed in the organic layer, which was illuminated by a narrow source of light. The density of the organic layer was adjusted to $0.9225 \mathrm{~g} / \mathrm{cm}^{3}$ to make the beads neutrally buoyant. In the tests, the jet velocity was increased in steps from approximately $2.5 \mathrm{~m} / \mathrm{s}$ to $56 \mathrm{~m} / \mathrm{s}$. The circulation time was the interval required for a bead to travel across the surface of organic layer, drop down into the bottom of the layer, and resurface. An average of five measurements was taken for each jet velocity.

The circulation pattern observed was such that the beads move radially outward from the jet on the surface and turn downward as they approach the tank wall. As the beads approach the bottom of the organic layer, they travel horizontally at a lower speed and then return up toward the surface. A stagnant area was visible in the lower half of organic layer directly under the jet when the jet velocity was lower than $20 \mathrm{~m} / \mathrm{s}$. As the velocity 
was increased, however, this area joined the bulk circulation as indicated by movement of beads in and out of this region. The circulation pattern observed with various jet velocities suggests a laminar flow exists throughout the bottom of the organic layer. At a jet velocity of $56 \mathrm{~m} / \mathrm{s}$, the top and middle portions of the organic layer were clearly in turbulent motion, and the circulation loop of the beads was much shorter than at lower jet velocities.

Results from these mixing tests are listed in Table C-1. A logarithmic plot of the dimensionless group, $\frac{\left(\frac{\theta_{c} v_{c}}{D_{n}}\right)}{\left(\frac{D_{n}}{T}\right)^{2}\left(\frac{\rho_{g}}{\rho}\right)\left(\frac{v_{n}^{2}}{H g}\right)}$, representing the circulation time in the organic layer versus the jet Reynolds number, $\frac{D_{n} v_{n}}{v}$, in Figure C-2 shows that most of the calculated points lie on a straight line with a slope equal to about -1.0 . This suggests that, in the range of jet velocities tested, a laminar flow prevailed at the bottom of the organic layer.

Table C-1. Results of Circulation Velocity Measurements

\begin{tabular}{|c|c|c|c|c|c|}
\hline $\begin{array}{l}\text { Volumetric } \\
\text { Jet Flow } \\
(\mathrm{scfm})\end{array}$ & $\begin{array}{l}\text { Jet Discharge } \\
\text { Velocity } \\
(\mathrm{m} / \mathrm{s})\end{array}$ & $\begin{array}{l}\text { Circulation } \\
\text { Time } \\
\text { (s) }\end{array}$ & $\begin{array}{l}\text { Froude } \\
\text { Number } \\
\left(\mathrm{v}_{\mathrm{n}}^{2} / \mathrm{Hg}\right)\end{array}$ & $\begin{array}{l}\text { Reynolds } \\
\text { Number } \\
\left(D_{n} V_{n} / v\right)\end{array}$ & $\begin{array}{l}\text { Dimensionless } \\
\text { Circulation Time } \\
\left(\rho_{g} / \rho\right)\left(v_{n}{ }^{2} / H g\right)\left(D_{n} / T\right)^{2}\end{array}$ \\
\hline 2.61 & 7.5 & 63.5 & 14 & 30085 & $2.55 \times 10^{9}$ \\
\hline 5.44 & 15.6 & 37.5 & 61 & 62765 & $7.22 \times 10^{8}$ \\
\hline 7.89 & 22.6 & 30.1 & 128 & 90947 & $4.00 \times 10^{8}$ \\
\hline 10.94 & 31.3 & 19.5 & 247 & 126085 & $1.87 \times 10^{8}$ \\
\hline 13.77 & 39.5 & 13.4 & 391 & 158705 & $1.02 \times 10^{8}$ \\
\hline 16.21 & 46.5 & 13.2 & 542 & 186887 & $8.54 \times 10^{7}$ \\
\hline 19.28 & 55.3 & 20.2 & 766 & 222265 & $1.10 \times 10^{8}$ \\
\hline
\end{tabular}

Due to the larger size (3-inch) discharge pipes in the canyon tanks, the jet Reynolds number for a tank greatly exceeds the range covered by the tests, so the test data must be extrapolated to estimate a mixing time for a steam jet in a canyon tank. If it is conservatively assumed that the organic layer depth in the tank is 6 feet, a straight-line logarithmic extrapolation to tank conditions using the regression fit shown in Figure C-1 would give a mixing time of 0.6 seconds. This approach assumes that the flow remains laminar at higher Reynolds numbers. As has already been mentioned, however, considerable turbulent mixing was observed at the highest flow rates in the tests. Fox and Gex found that for both jet and impeller mixing the mixing time decreased with the Reynolds number to only the $-1 / 6^{\text {th }}$ power. ${ }^{21}$ From these observations, it must be assumed that the mixing time does not decrease nearly as rapidly as shown in Figure C-1 at higher 
Reynolds numbers. Accordingly, to be conservative, it was assumed that the dimensionless mixing time for the tank is the same as that for the highest flow rate tests, approximately $1 \times 10^{8}$. This yields a tank mixing (or circulation) time of 15 seconds. 


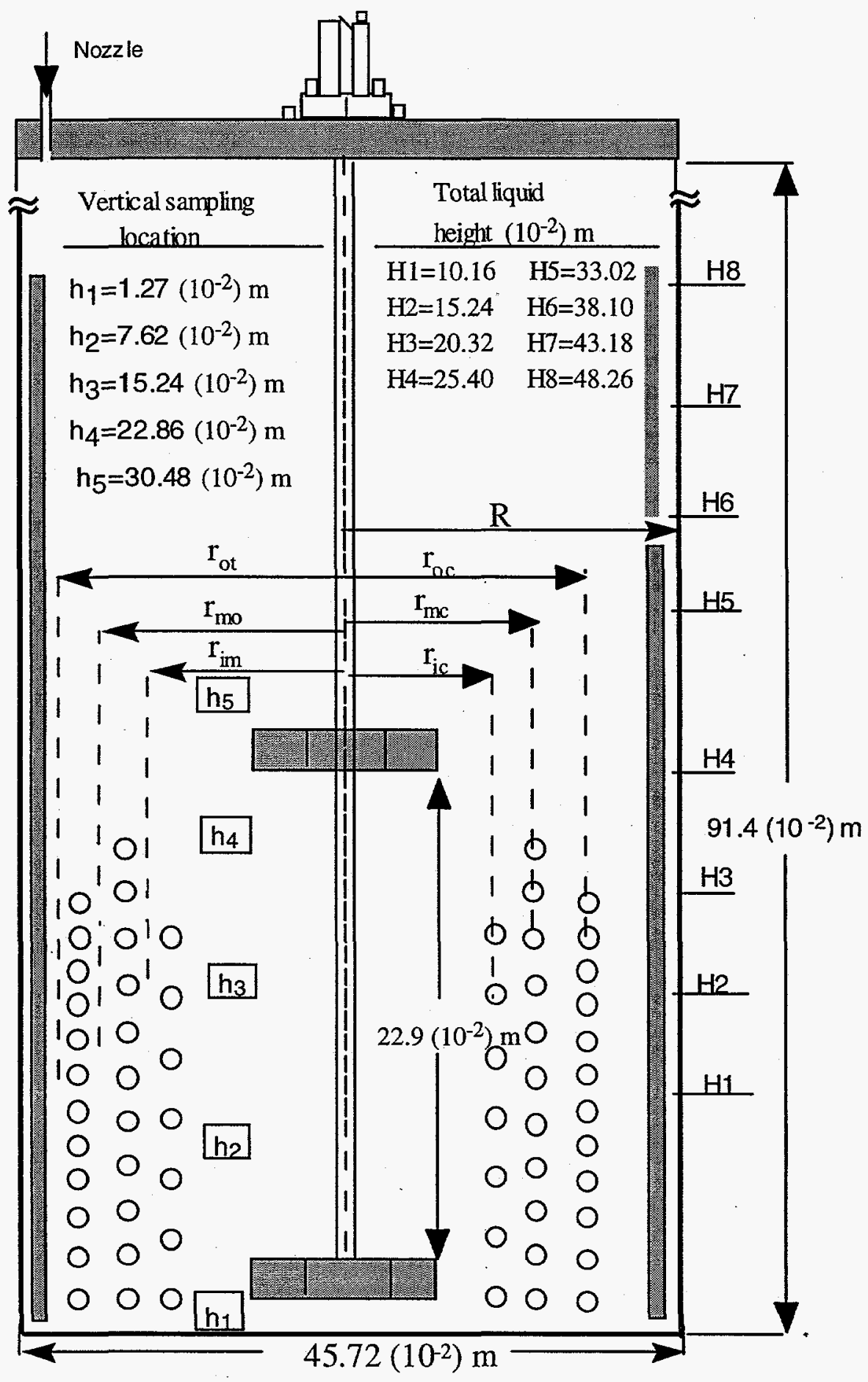

Figure C-1. Schematic of Canyon Tank Mockup 


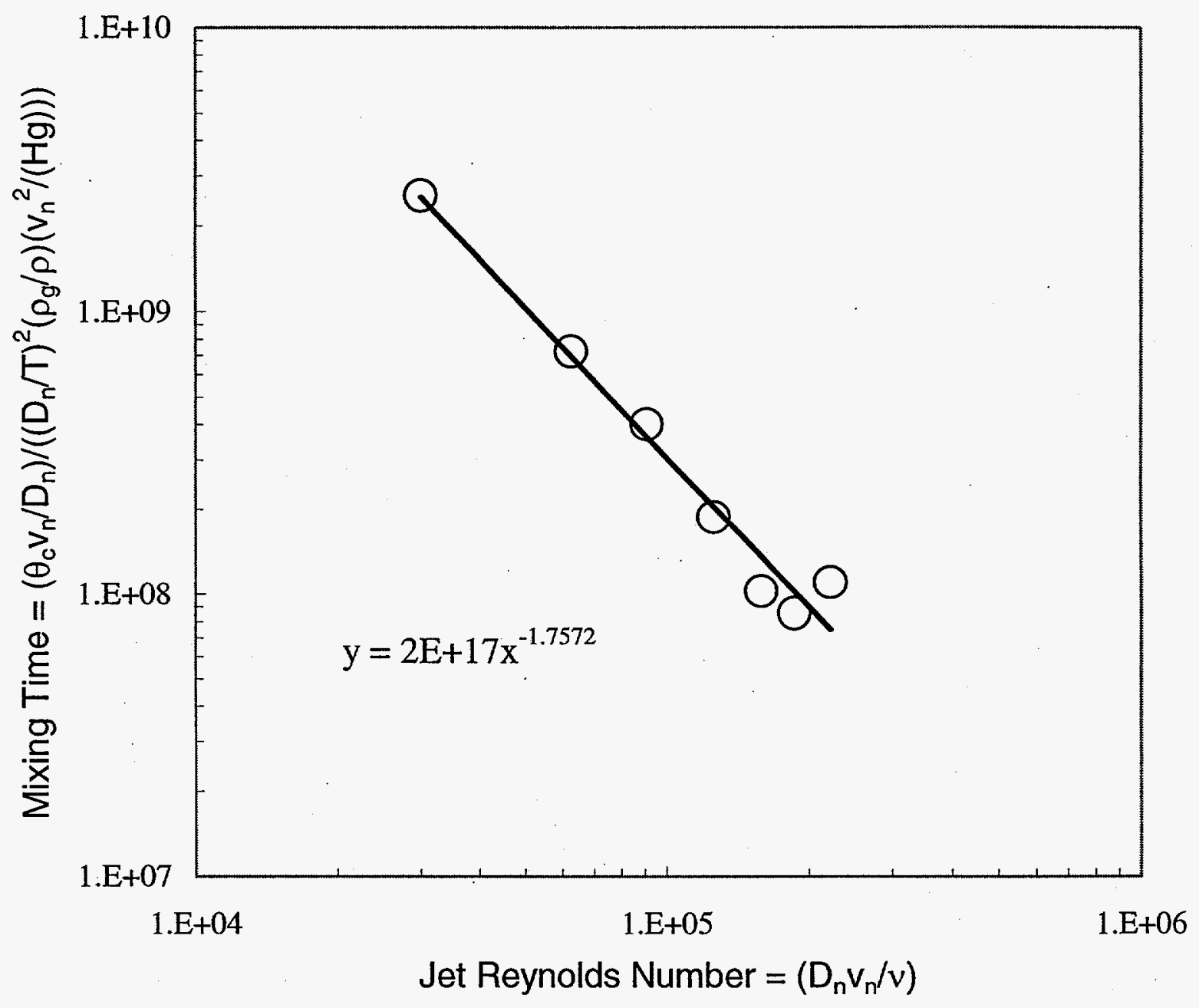

Figure C-2. Correlation of Circulation Times as a Function of Jet Reynolds Number 


\section{Appendix D: Correlation of Heat Loss Coefficients for Individual Tests}

This appendix presents correlations of heat loss coefficients for individual tests, based on rates of temperature decrease in the organic layer after the flow of hot gas to the test vessel was discontinued. As explained in Appendix B, the heat loss coefficient can be calculated from the expression:

$h_{t}=-\frac{\rho c_{p} V_{\text {org }}+\rho_{\text {ves }} c_{p, v e s} V_{\text {ves }}}{A_{\text {ves }}} \frac{d \ln \left(T_{\text {org }}-T_{\text {amb }}\right)}{d t}$

Curve fit values for this coefficient were obtained from least-squares regression fits to test data, shown in Appendix E. It was assumed that the rate of heat transfer from a canyon would be similar to that from the test vessel and therefore can be approximated by measuring experimental heat losses.

Equivalent loss coefficients $\bar{h}_{t}$ in units of $1 /$ min were computed from measured rates of temperature decrease, using the expression

$\overline{\mathrm{h}}_{\mathrm{t}}=-\frac{\mathrm{d} \ln \left(\mathrm{T}_{\mathrm{org}}-\mathrm{T}_{\mathrm{amb}}\right)}{\mathrm{dt}}$

The figures in this appendix list the least squares regression coefficients used to correlate the heat loss coefficients. Table D-1 summarizes the regression results for each test, as well as the average coefficient and upper and lower confidence bounds. These statistics are calculated for Test 3 through 6 . Tests 1 and 2 are not included. The first test did not provide a valid measure of the heat loss coefficient because the heater was turned off before the gas flow to the vessel was discontinued. Results for the second test differ from those for subsequent tests because insulation was added around the top and sides of the test vessel after this test.

\section{Table D-1. Summary and Statistical Analysis of Heat Loss Coefficients}

Test

2

3

4

5

6

Average
Heat Loss Coefficient ( $1 / \mathrm{min})$

0.0111

0.0045

0.0050

0.0047

0.0060

0.0050 


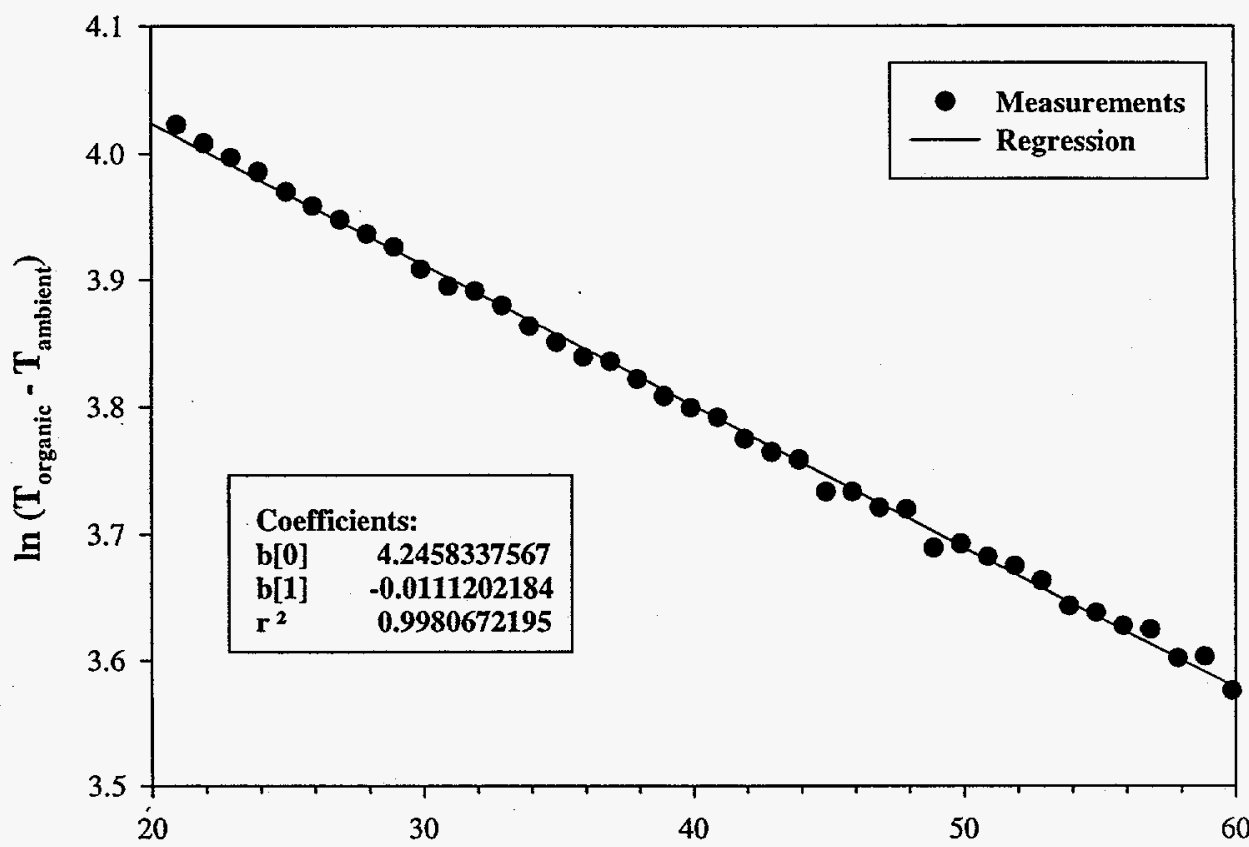

Time after Gas Flow to Vessel Discontinued (min)

Figure D-1. Correlation of Heat Loss Coefficient for Test 2.

\footnotetext{
${ }^{1}$ The lower confidence bound is a $95 \%$ one-sided confidence bound, computed from the Student's t distribution for 4 degrees of freedom.
} 


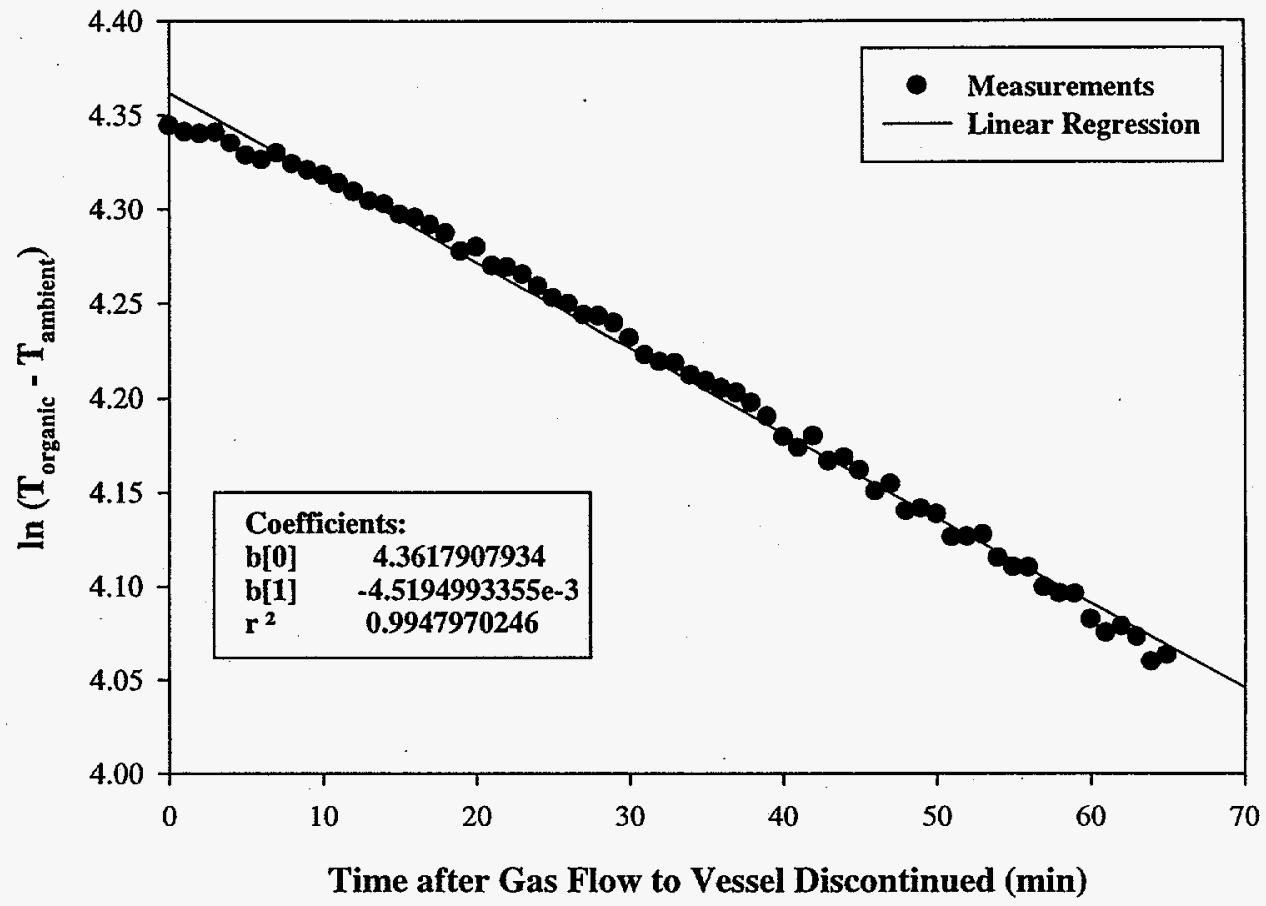

Figure D-2. Correlation of Heat Loss Coefficient for Test 3. 


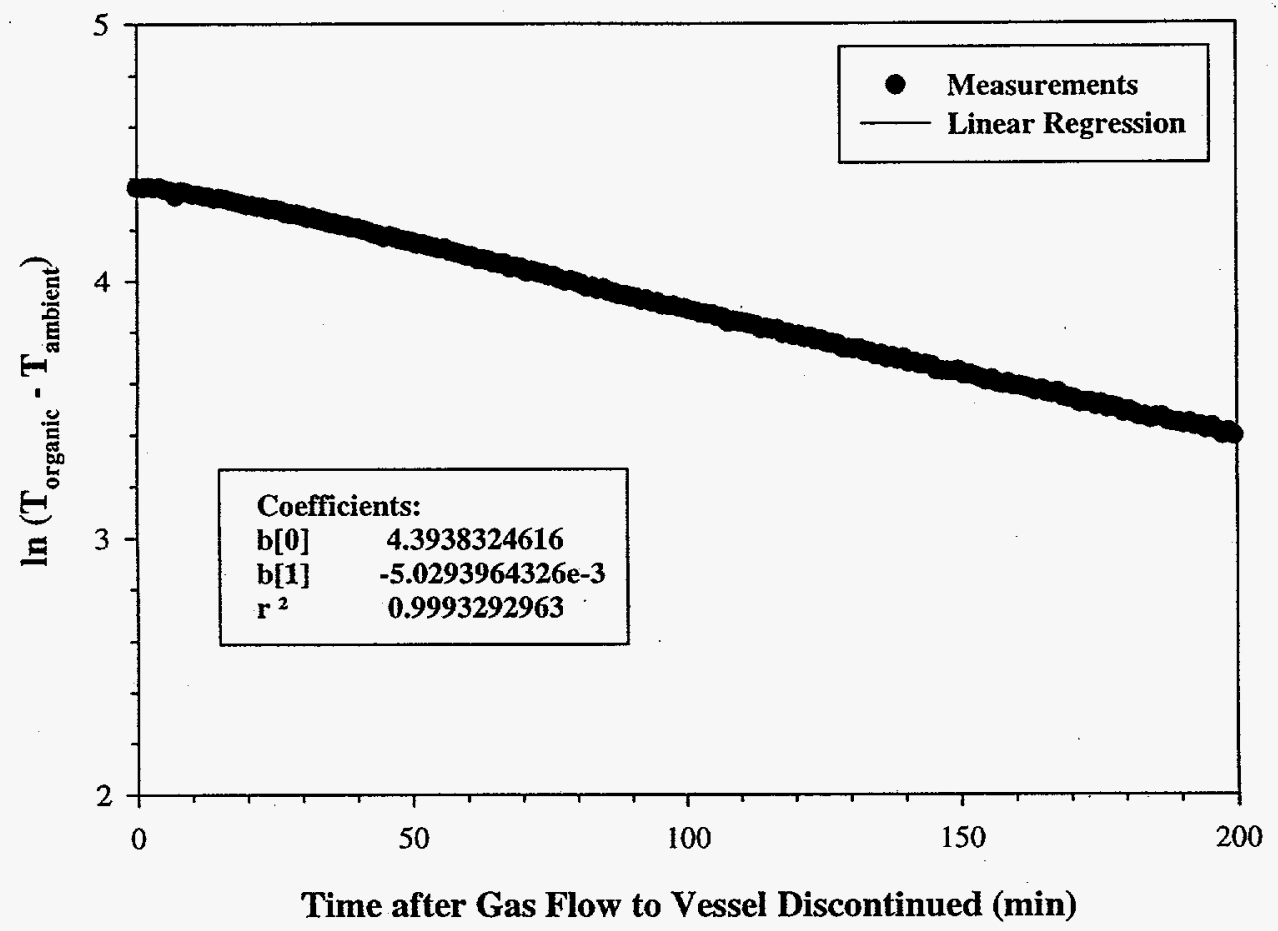

Figure D-3. Correlation of Heat Loss Coefficient for Test 4. 


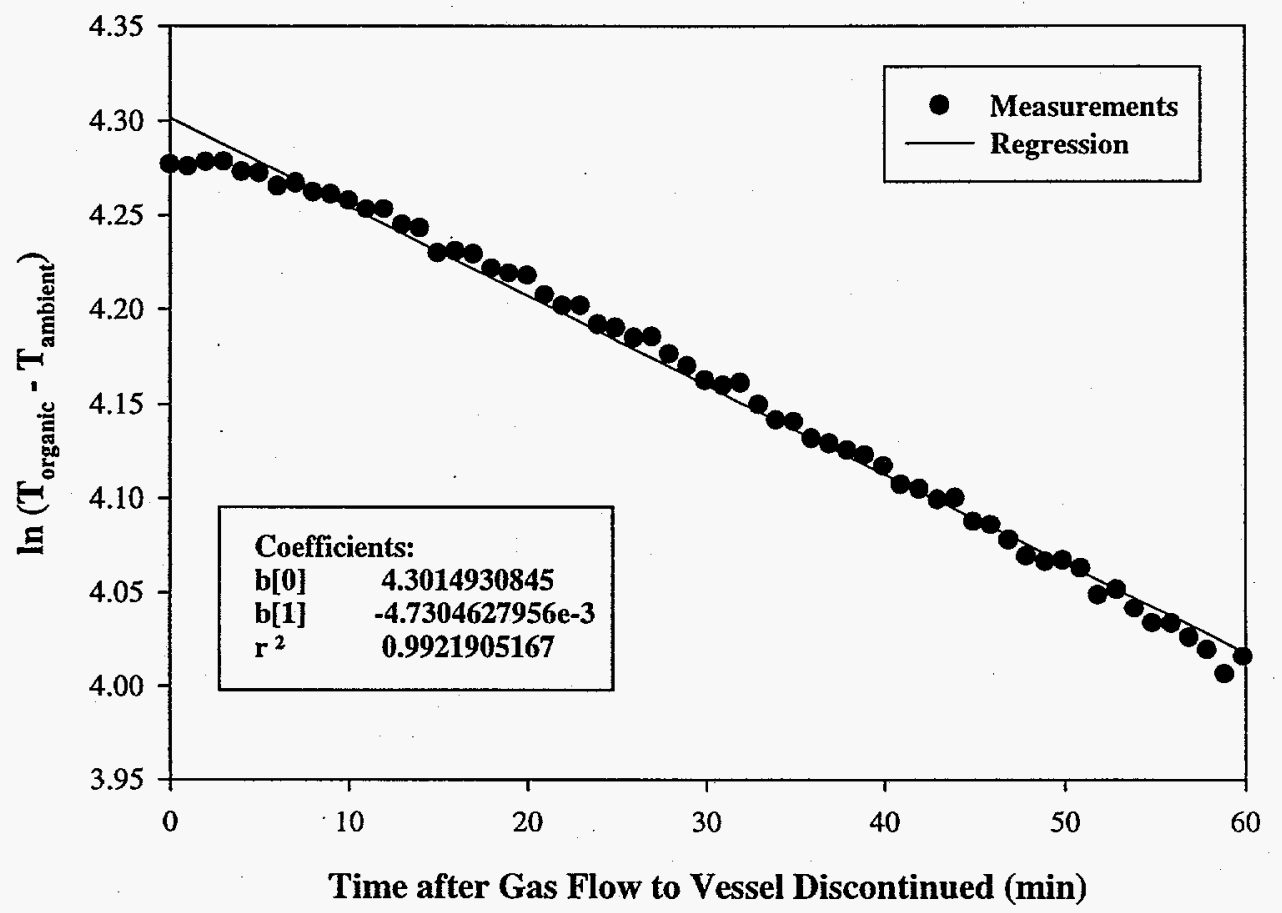

Figure D-4. Correlation of Heat Loss Coefficient for Test 5. 


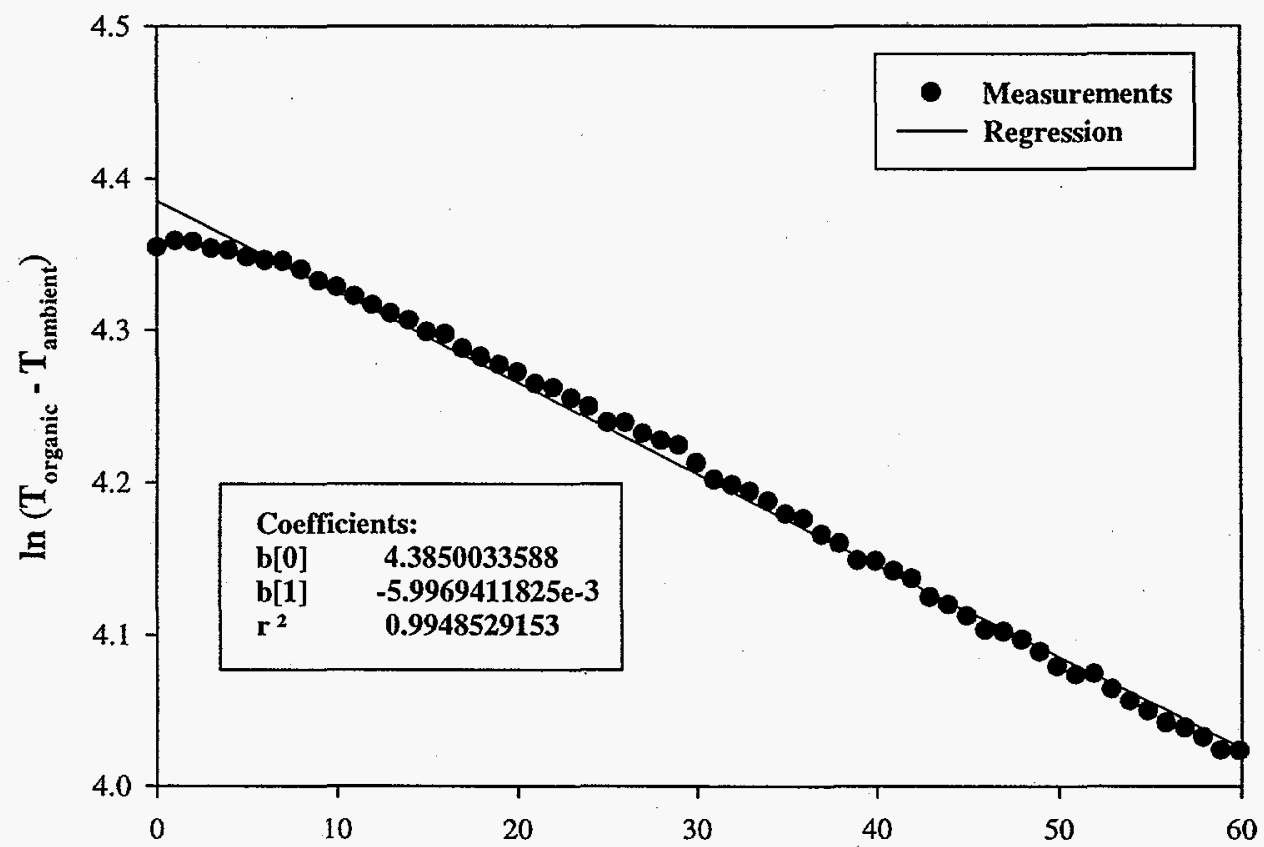

Time after Gas Flow to Vessel Discontinued (min)

Figure D-5. Correlation of Heat Loss Coefficient for Test 6. 


\section{Appendix E: Physical Property and Phase Equilibrium Correlations}

This appendix lists the physical property and phase equilibrium correlations used in the two-layer mixing model. Included are density, heat capacity, and thermal conductivity correlations for mixtures of TBP, $\mathrm{H}_{2} \mathrm{O}$, and $\mathrm{HNO}_{3}$; correlations of $\mathrm{H}_{2} \mathrm{O}$ and $\mathrm{HNO}_{3}$ vapor pressures over the TBP phase; and organic-aqueous mutual solubility correlations.

The mixture density for both the TBP and aqueous layers is calculated assuming that there is no volume change with mixing. With this assumption, the mixture density is given by

$$
\begin{aligned}
& \rho=\mathrm{x}_{\mathrm{TBP}} \rho_{\mathrm{TBP}}+\mathrm{x}_{\mathrm{HNO}_{3}} \rho_{\mathrm{HNO}_{3}}+\mathrm{x}_{\mathrm{H}_{2} \mathrm{O}} \rho_{\mathrm{H}_{2} \mathrm{O}}+ \\
& \mathrm{x}_{\mathrm{C}_{12} \mathrm{H}_{26}} \rho_{\mathrm{C}_{12} \mathrm{H}_{26}}+\mathrm{x}_{\mathrm{C}_{13} \mathrm{H}_{28}} \rho_{\mathrm{C}_{13} \mathrm{H}_{28}}+\mathrm{x}_{\mathrm{C}_{14} \mathrm{H}_{30}} \rho_{\mathrm{C}_{14} \mathrm{H}_{30}}
\end{aligned}
$$

The densities of $\mathrm{H}_{2} \mathrm{O}$ and $\mathrm{HNO}_{3}$ are correlated from nitric acid density data. ${ }^{22}$ As Figure E-1 shows, nitric acid densities were first correlated as linear functions of composition for different temperatures. The slopes and intercepts of these correlations were then correlated as functions of temperature, as depicted in Figure E-2. From this figure, the following correlations were obtained.

$$
\rho_{\mathrm{H}_{2} \mathrm{O}}=0.99683-0.00013010 \mathrm{~T}-0.0000024358 \mathrm{~T}^{2}
$$

and

$$
\rho_{\mathrm{HNO}_{3}}=1.6603-0.0019894 \mathrm{~T}
$$

where the temperature is given in ${ }^{\circ} \mathrm{C}$.

Figure E-3 shows the correlation of TBP densities, which were obtained from Reference 23. This correlation takes the form

$\rho_{\mathrm{TBP}}=0.99503-0.00098344 \mathrm{~T}$

Values for the densities for dodecane, tridecane, and tetradecane at $293^{\circ} \mathrm{C}$ are used. ${ }^{24}$ These values are

$$
\begin{aligned}
& \rho_{\mathrm{C}_{12} \mathrm{H}_{26}}=0.748 \\
& \rho_{\mathrm{C}_{13} \mathrm{H}_{28}}=0.756
\end{aligned}
$$

and $\quad \rho_{\mathrm{C}_{14} \mathrm{H}_{30}}=0.763$

Mixture heat capacities are calculated based on the relative mass fractions of each component. This gives 


$$
\begin{aligned}
& \left.\mathrm{x}_{\mathrm{TBP}} \rho_{\mathrm{TBP}} \mathrm{c}_{\mathrm{p}, \mathrm{TBP}}+\left(\mathrm{x}_{\mathrm{HNO}_{3}} \rho_{\mathrm{HNO}_{3}}+\mathrm{x}_{\mathrm{H}_{2} \mathrm{O}} \rho_{\mathrm{H}_{2} \mathrm{O}}\right)\right)_{\mathrm{p}, \mathrm{a}}+
\end{aligned}
$$

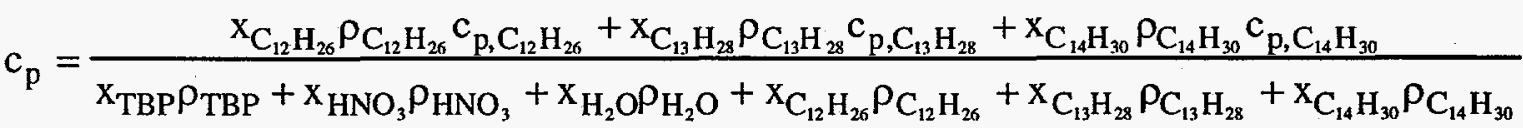

This expression includes a heat capacity for the mixture of $\mathrm{H}_{2} \mathrm{O}$ and $\mathrm{HNO}_{3}$ in solution, $c_{p, a}$, which is correlated as a function of the relative mass fraction of $\mathrm{HNO}_{3}, \mathrm{w}_{\mathrm{a}}$, using data taken at $20^{\circ} \mathrm{C}^{25}$ :

$c_{p, a}=0.99897-0.80256 w_{a}-2.3208 w_{a}^{2}+9.5504 w_{a}^{3}-10.903 w_{a}^{4}+3.9103 w_{a}^{5}$

where $w_{a}$ is defined by

$\mathrm{w}_{\mathrm{a}}=\frac{\mathrm{x}_{\mathrm{HNO}_{3} \rho_{\mathrm{HNO}_{3}}}}{\mathrm{x}_{\mathrm{HNO}_{3}} \rho_{\mathrm{HNO}_{3}}+\mathrm{x}_{\mathrm{H}_{2}} \mathrm{O}_{\mathrm{H}_{2} \mathrm{O}}}$

Single values are used for the heat capacities of $\mathrm{TBP}^{26}$, dodecane ${ }^{24}$, tridecane ${ }^{24}$, and tetradecane ${ }^{24}$ :

$\mathrm{c}_{\mathrm{p}, \mathrm{TBP}}=0.41$

$\mathrm{c}_{\mathrm{p}, \mathrm{c}_{12} \mathrm{H}_{26}}=0.53$

$c_{p, C_{13} H_{28}}=0.53$

$c_{p, C_{14} H_{30}}=0.53$

Mutual solubility data for a TBP layer in contact with an aqueous nitric acid layer were obtained from Reference 12 . These data were taken at $25^{\circ} \mathrm{C}$, they are used without any correction at more elevated temperatures. As shown in Figure E-6, these data are correlated by the following two expressions.

$\mathrm{x}_{\mathrm{HNO}_{3}, \mathrm{org}}^{*}=1.0594 \mathrm{x}_{\mathrm{HNO}_{3}, \mathrm{aq}}^{*}-2.9022 \mathrm{x}_{\mathrm{HNO}_{3}, \mathrm{aq}}^{* 2}+3.3389 \mathrm{x}_{\mathrm{HNO}_{3}, \mathrm{aq}}^{* 3}$

and

$\mathrm{x}_{\mathrm{H}_{2} \mathrm{O}, \mathrm{org}}^{*}=0.068627-0.30678 \mathrm{x}_{\mathrm{HNO}_{3}, \mathrm{aq}}^{*}+0.55192 \mathrm{x}_{\mathrm{HNO}_{3}, \mathrm{aq}}^{* 2}-0.18170 \mathrm{x}_{\mathrm{HNO}_{3}, \mathrm{aq}}^{* 3}$

Organic layer vapor pressures are correlated in terms of the mole fraction $\mathrm{HNO}_{3}$ in the aqueous phase that is in equilibrium with the organic phase. The correlations are in the 
form of van der Waals' expressions, where the van der Waals' constants A and B are functions of the mole fraction $\mathrm{HNO}_{3}$ in the aqueous phase. A multiplier is added to account for the possibility that the organic layer may not be saturated with nitric acid.

Correlations for vapor pressures of saturated organic solutions were derived by first calculating van der Waals' constants for measured vapor pressures at different nitric acid compositions ${ }^{27}$ and then correlating these constants as functions of composition. Figures E-6 through E-9 illustrate these correlations. The van der Waals' expressions for the vapor pressures of $\mathrm{HNO}_{3}$ and $\mathrm{H}_{2} \mathrm{O}$ in saturated solutions are

$$
\mathrm{p}_{\mathrm{HNO}_{3}}^{*}=\exp \left(17.120-11.374 \mathrm{y}_{\mathrm{HNO}_{3}, \mathrm{aq}}^{*}-\frac{8774.0-9350.9 \mathrm{y}_{\mathrm{HNO}_{3}, \mathrm{aq}}^{*}}{\mathrm{~T}}\right)
$$

and

$$
\mathrm{p}_{\mathrm{H}_{2} \mathrm{O}}^{*}=\exp \left(\begin{array}{l}
13.552+0.45359 \mathrm{y}_{\mathrm{HNO}_{3}, \mathrm{aq}}^{*} \\
-4.1122 \mathrm{y}_{\mathrm{HNO}_{3}, \mathrm{aq}}^{* 2}-\frac{5049.3+1009.6 \mathrm{y}_{\mathrm{HNO}_{3}, \mathrm{aq}}^{*}}{\mathrm{~T}}
\end{array}\right)
$$

where $\mathrm{y}_{\mathrm{HNO}_{3} \text {,aq }}^{*}$ is the mole fraction $\mathrm{HNO}_{3}$ in the aqueous phase in equilibrium with the organic phase.

This mole fraction is related to the equilibrium volume fraction in the aqueous phase, $\mathrm{x}_{\mathrm{HNO}_{3} \text {,aq }}^{*}$, by

$$
\mathrm{y}_{\mathrm{HNO}_{3}, \mathrm{aq}}^{*}=\frac{\frac{\mathrm{x}_{\mathrm{HNO}_{3}, \mathrm{aq}}^{*} \rho_{\mathrm{HNO}_{3}}}{\mathrm{M}_{\mathrm{HNO}_{3}}}}{\frac{\mathrm{x}_{\mathrm{HNO}_{3}, \mathrm{aq}}^{*} \rho_{\mathrm{HNO}_{3}}}{\mathrm{M}_{\mathrm{HNO}_{3}}}+\frac{\left(1-\mathrm{x}_{\mathrm{HNO}_{3}, \mathrm{aq}}\right) \mathrm{p}_{\mathrm{H}_{2} \mathrm{O}}}{\mathrm{M}_{\mathrm{H}_{2} \mathrm{O}}}}
$$

The equilibrium volume fraction in the aqueous phase, in turn, is calculated based on the ratio of $\mathrm{HNO}_{3}$ to $\mathrm{H}_{2} \mathrm{O}$ in solution in the organic phase. This calculation implicitly assumes that the vapor pressures for $\mathrm{HNO}_{3}$ and $\mathrm{H}_{2} \mathrm{O}$ in unsaturated TBP/n-paraffin solutions are proportional to the relative saturation of the mixture of these two components. This is a variation of the Lewis-Randall rule in terms of volume fractions rather than mole fractions. The following explicit formula for the saturation concentration of $\mathrm{HNO}_{3}$ in the organic phase, $\mathrm{x}_{\mathrm{HNO}_{3} \text {, aq }}$, was derived by fitting a curve to an iterative solution to Equations E-13 and E-14. As shown in Figure E-11, this results in 


$$
\mathrm{x}_{\mathrm{HNO}_{3}, \mathrm{aq}}^{*}=0.065183\left(\frac{\mathrm{x}_{\mathrm{HNO}_{3}}}{\mathrm{x}_{\mathrm{H}_{2} \mathrm{O}}}\right)-0.0068494\left(\frac{\mathrm{x}_{\mathrm{HNO}_{3}}}{\mathrm{x}_{\mathrm{H}_{2} \mathrm{O}}}\right)^{2}+0.00053995\left(\frac{\mathrm{x}_{\mathrm{HNO}_{3}}}{\mathrm{x}_{\mathrm{H}_{2} \mathrm{O}}}\right)^{3} .
$$

The vapor pressures of $\mathrm{HNO}_{3}$ and $\mathrm{H}_{2} \mathrm{O}$ in bubbles formed by reaction product gases in the organic layer are calculated based on the equivalent vapor pressures of these components in the aqueous phase based on the modified Lewis-Randall rule. This gives

$\mathrm{p}_{\mathrm{HNO}_{3}}=\frac{\mathrm{x}_{\mathrm{HNO}_{3}}}{\mathrm{x}_{\mathrm{HNO}_{3}, \mathrm{org}}^{*}} \mathrm{p}_{\mathrm{HNO}_{3}}^{*}$

and $\quad \mathrm{p}_{\mathrm{H}_{2} \mathrm{O}}=\frac{\mathrm{x}_{\mathrm{HNO}_{3}}}{\mathrm{x}_{\mathrm{HNO}_{3}, \mathrm{org}}^{*}} \mathrm{p}_{\mathrm{H}_{2} \mathrm{O}}^{*}$

As stated in Appendix B, the $\mathrm{HNO}_{3}$ and $\mathrm{H}_{2} \mathrm{O}$ vapor pressures in the bulk of the organic layer are assumed to be equal to that of TBP.

The pure component vapor pressure for TBP is calculated from a correlation given in Reference 16, and pure component vapor pressures for dodecane, tridecane, and tetradecane are calculated from correlations in Reference 24 . These correlations are:

$$
\begin{aligned}
& \mathrm{p}_{\mathrm{TBP}}^{*}=\frac{1}{760} \exp \left(20.53-\frac{7735}{\mathrm{~T}}\right) \\
& \mathrm{p}_{\mathrm{C}_{12} \mathrm{H}_{26}}^{*}=\frac{1}{760} \exp \left(16.1134-\frac{3774.56}{\mathrm{~T}-91.31}\right) \\
& \mathrm{p}_{\mathrm{C}_{13} \mathrm{H}_{28}}^{*}=\frac{1}{760} \exp \left(16.1355-\frac{3892.91}{\mathrm{~T}-98.93}\right) \\
& \text { and } \quad \mathrm{p}_{\mathrm{C}_{14} \mathrm{H}_{30}}^{*}=\frac{1}{760} \exp \left(16.1480-\frac{4008.52}{\mathrm{~T}-105.4}\right)
\end{aligned}
$$

Mixture vapor pressures for these compounds are computed from pure component vapor pressures in a manner similar to that used for $\mathrm{HNO}_{3}$ and $\mathrm{H}_{2} \mathrm{O}$, but based on mole fractions rather than volume fractions. Any reduction in vapor pressure due to the presence of water or nitric acid is assumed to be negligible. The vapor pressure expressions for TBP, dodecane, tridecane, and tetradecane in the organic layer are computed from the following equations.

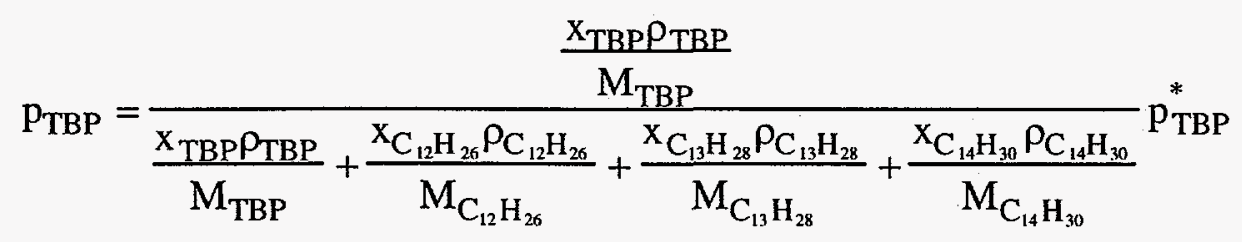




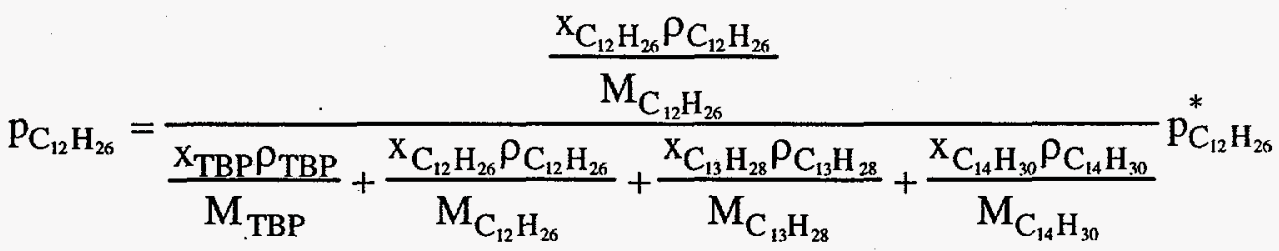

$$
\begin{aligned}
& \frac{\mathrm{x}_{\mathrm{C}_{13} \mathrm{H}_{28}} \rho_{\mathrm{C}_{13} \mathrm{H}_{28}}}{\mathrm{M}_{\mathrm{C}}}
\end{aligned}
$$

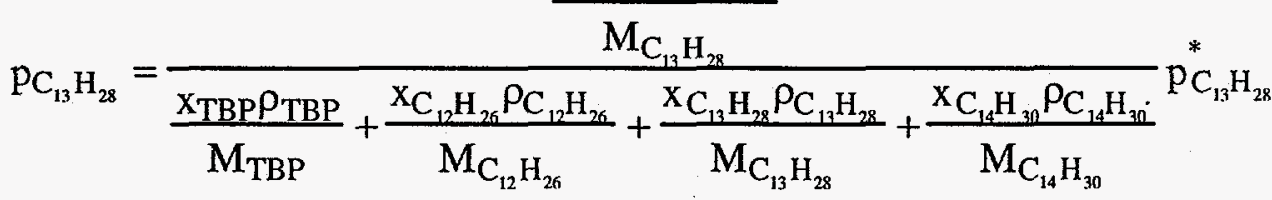

and

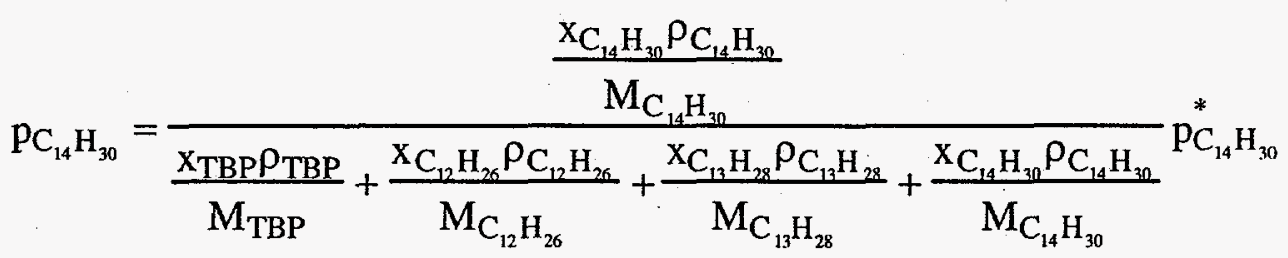

Values of the heats of vaporization of pure compounds are used in the analysis; heats of mixing are ignored. To further simplify the calculations, single temperature values evaluated near the normal boiling points of $\mathrm{H}_{2} \mathrm{O}$ and $\mathrm{HNO}_{3}$ and at room temperature for the remaining compounds are used. The decrease in the heat of vaporization as the temperature increases is neglected. The following table summarizes the heats of vaporization.

\section{Table E-1. Heats of Vaporization}

\section{Compound Heat of Vaporization (kcal/gmole) Reference}

$\mathrm{HNO}_{3}$

$\mathrm{H}_{2} \mathrm{O}$

TBP

Dodecane

Tridecane

Tetradecane
$7: 239$

9.705

15.368

14.647

15.830

17.010

$28,29^{1}$
30
16
31
31
31

\footnotetext{
${ }^{1}$ The heat of vaporization of molecular $\mathrm{HNO}_{3}$ at its normal boiling point is used. ${ }^{28}$ This is conservative in that it is less than the heat of vaporization of $\mathrm{NO}_{3}{ }^{-}$by about a factor of $\mathrm{two}^{29}$ and therefore gives about half the cooling that would be calculated if it were assumed that ionic $\mathrm{HNO}_{3}$ evaporates from the organic layer. The justification for using the molecular value is the assumption that the $\mathrm{HNO}_{3}$ that dissolves in the organic layer is chemically bound to the TBP (see discussion in Appendix $\mathrm{B}^{16}$ ).
} 


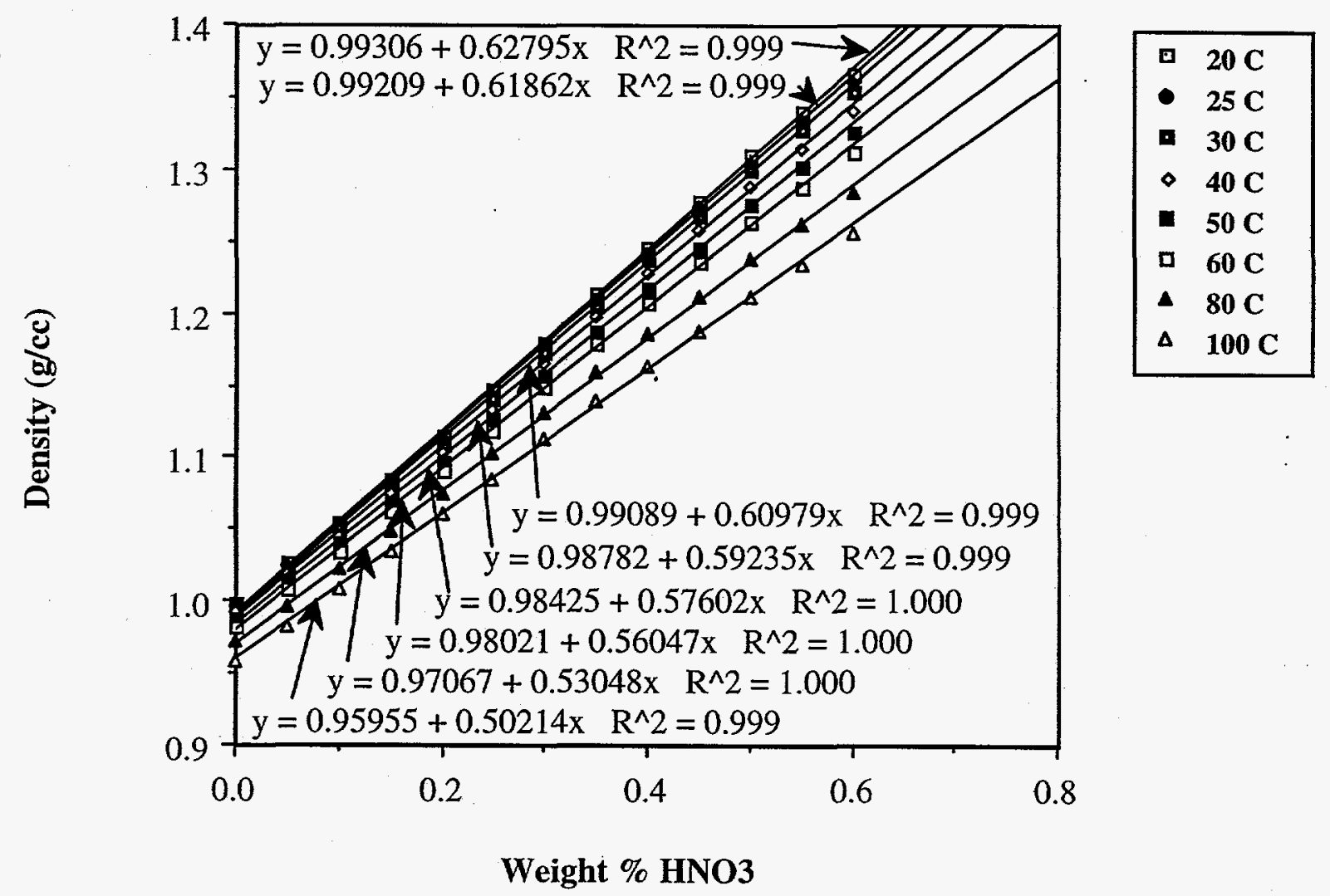

Figure E-1. Correlation of Nitric Acid Densities as a Function of Composition at Different Temperatures 


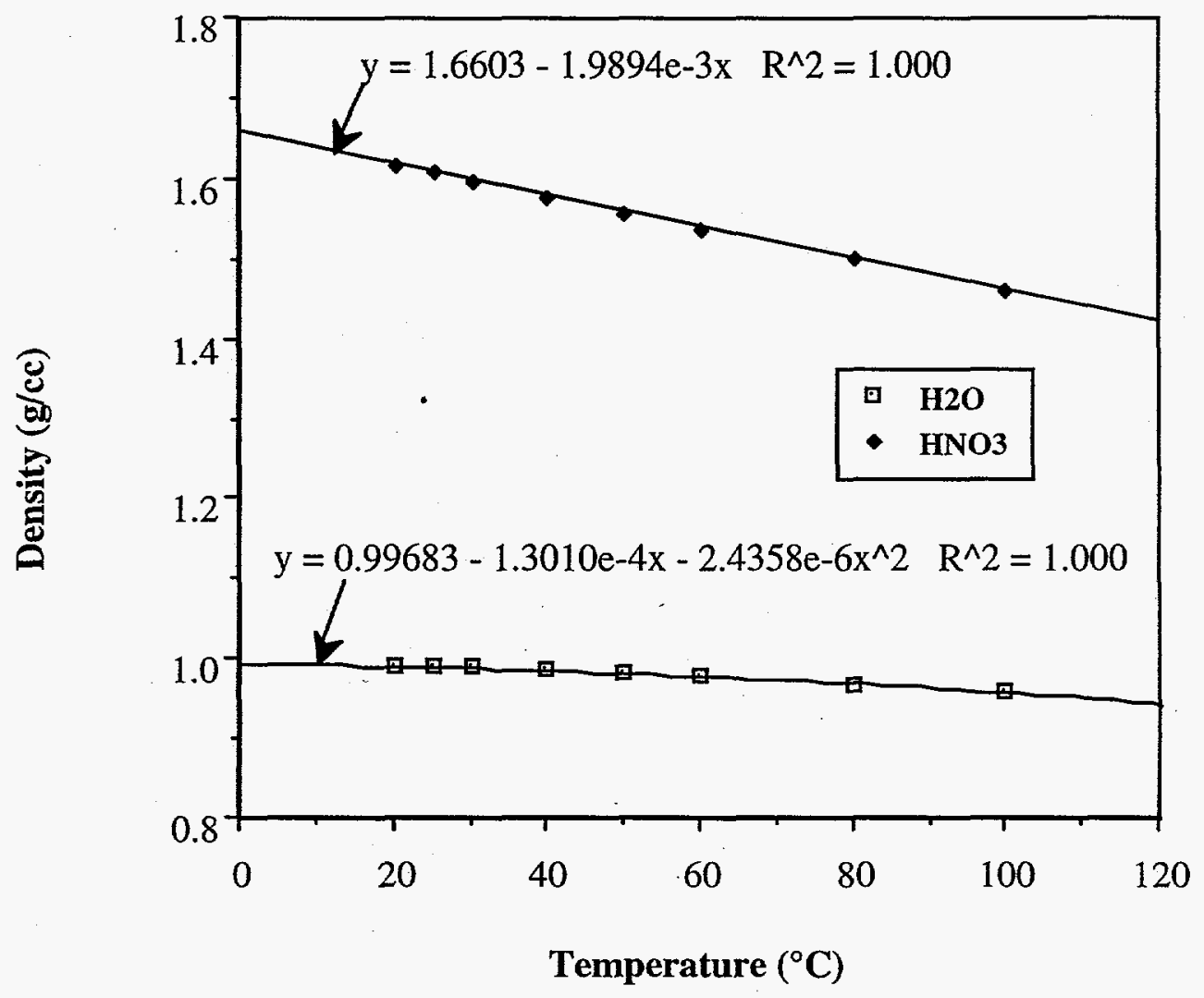

Figure E-2. Correlation of $\mathrm{H}_{2} \mathrm{O}$ and $\mathrm{HNO}_{3}$ Partial Densities 


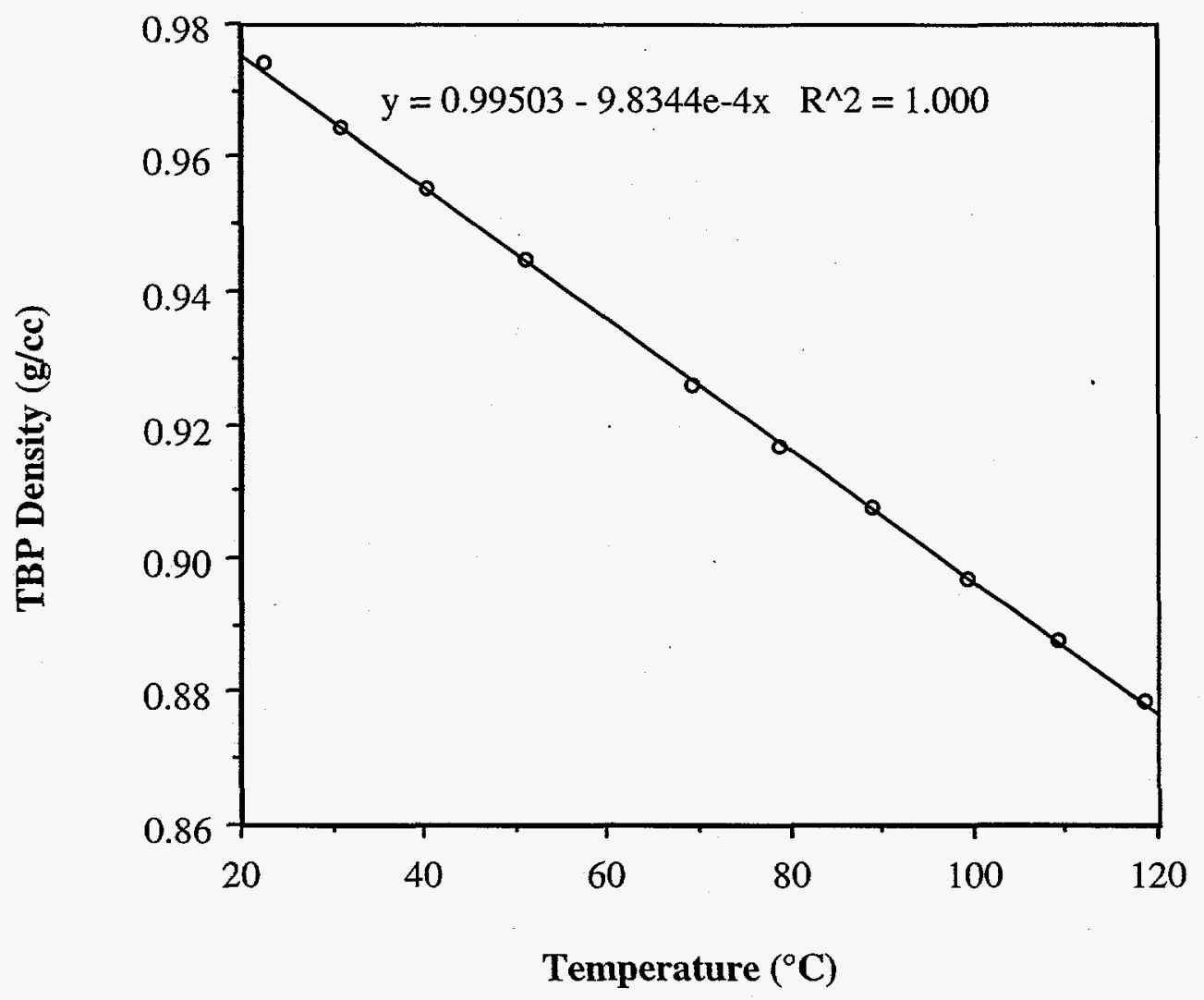

Figure E-3. Correlation of TBP Densities 


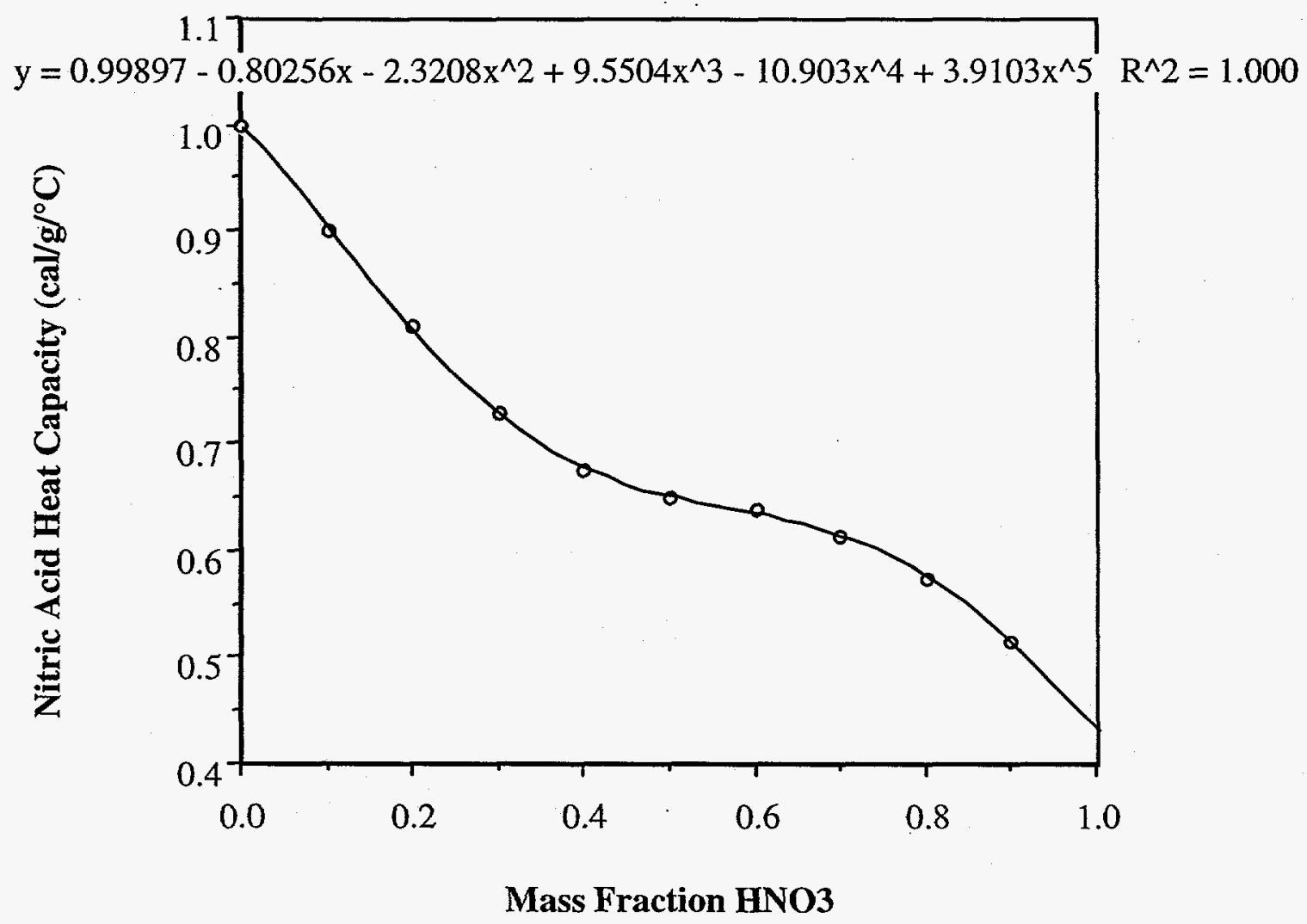

Figure E-4. Correlation of Nitric Acid Heat Capacities 


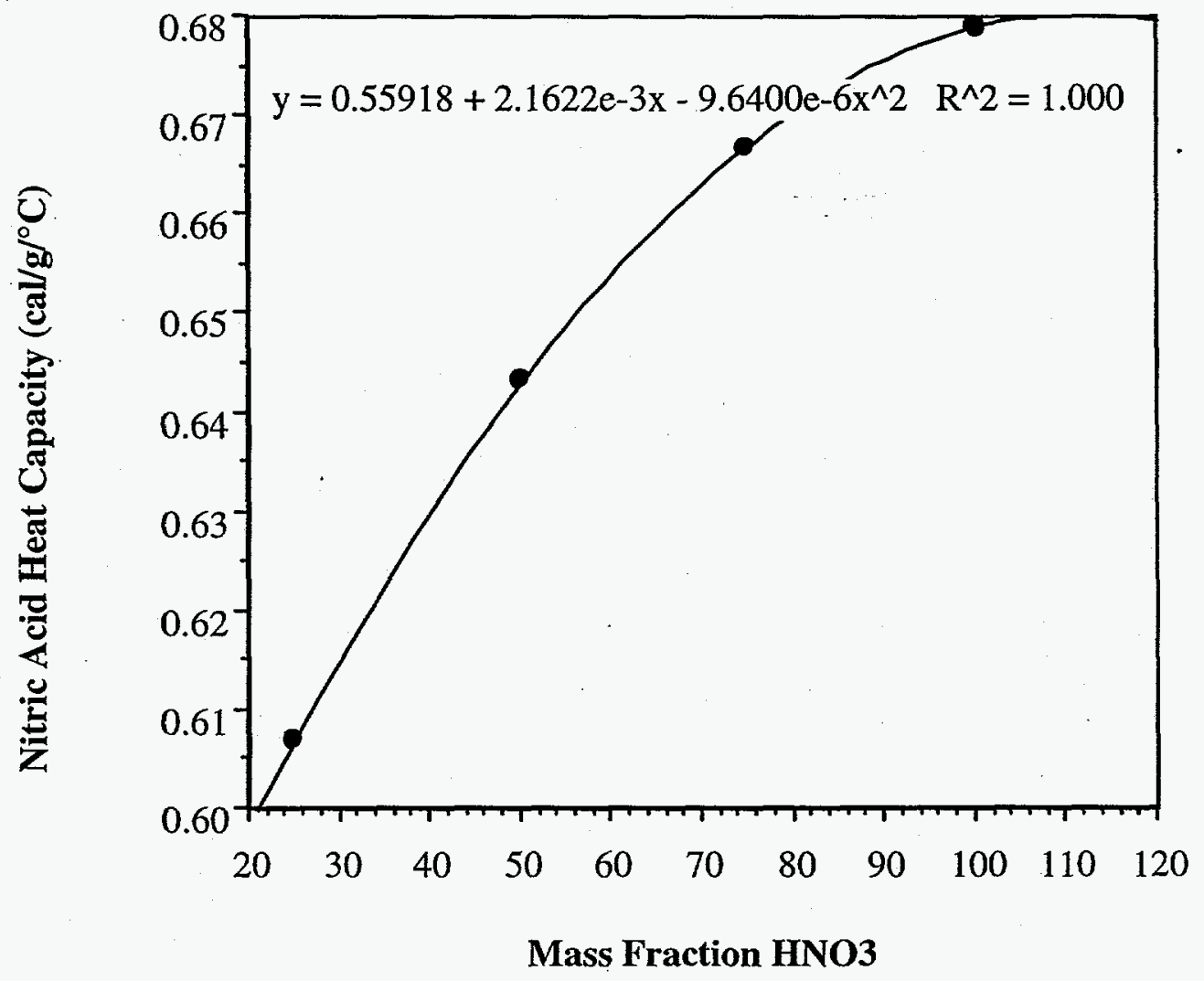

Figure E-5. Correlation of Thermal Conductivities for $\mathrm{H}_{2} \mathrm{O}$ 


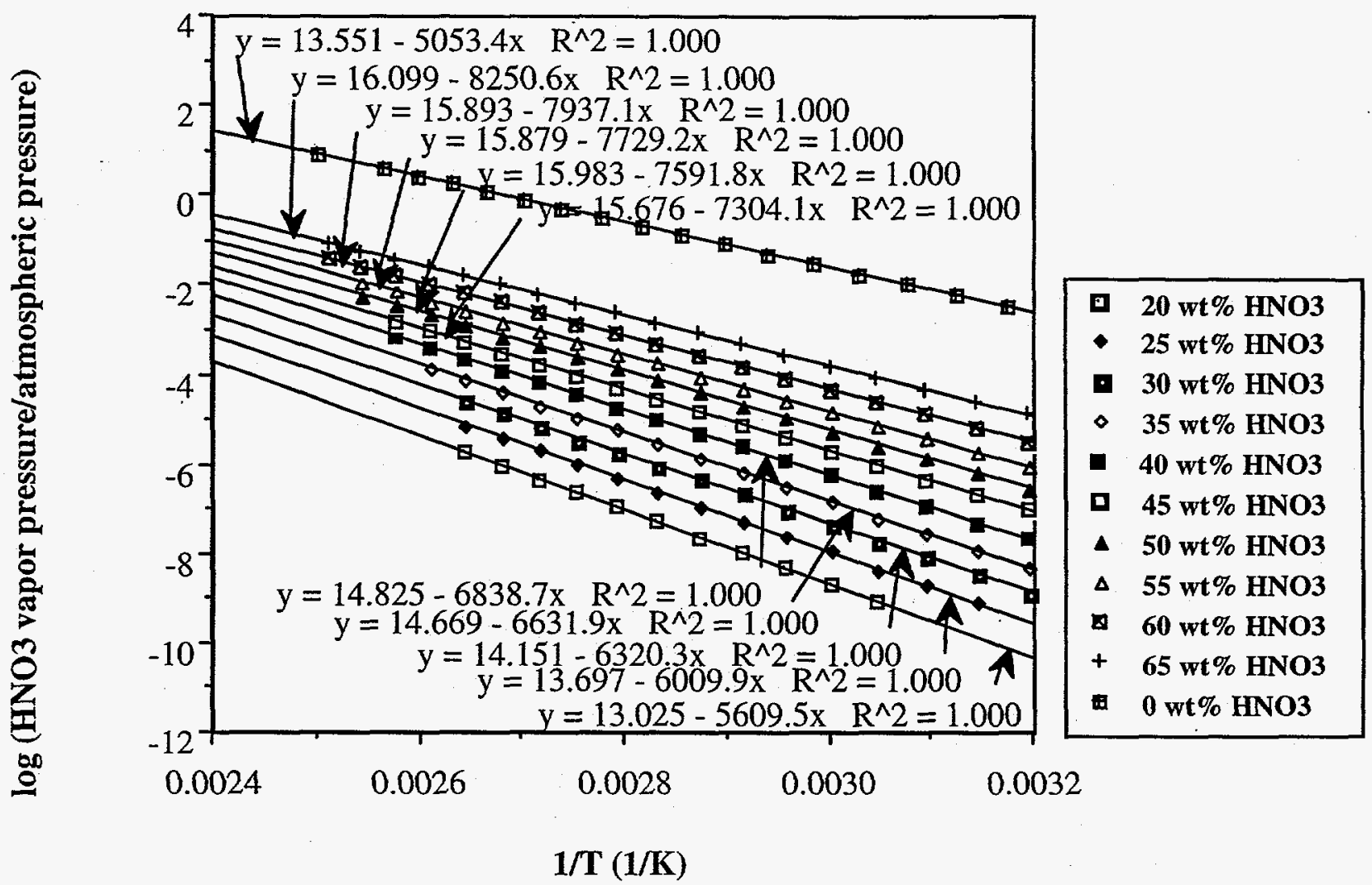

Figure E-6. Correlation of $\mathrm{HNO}_{3}$ Vapor Pressures for Different Temperatures and Nitric Acid Concentrations 


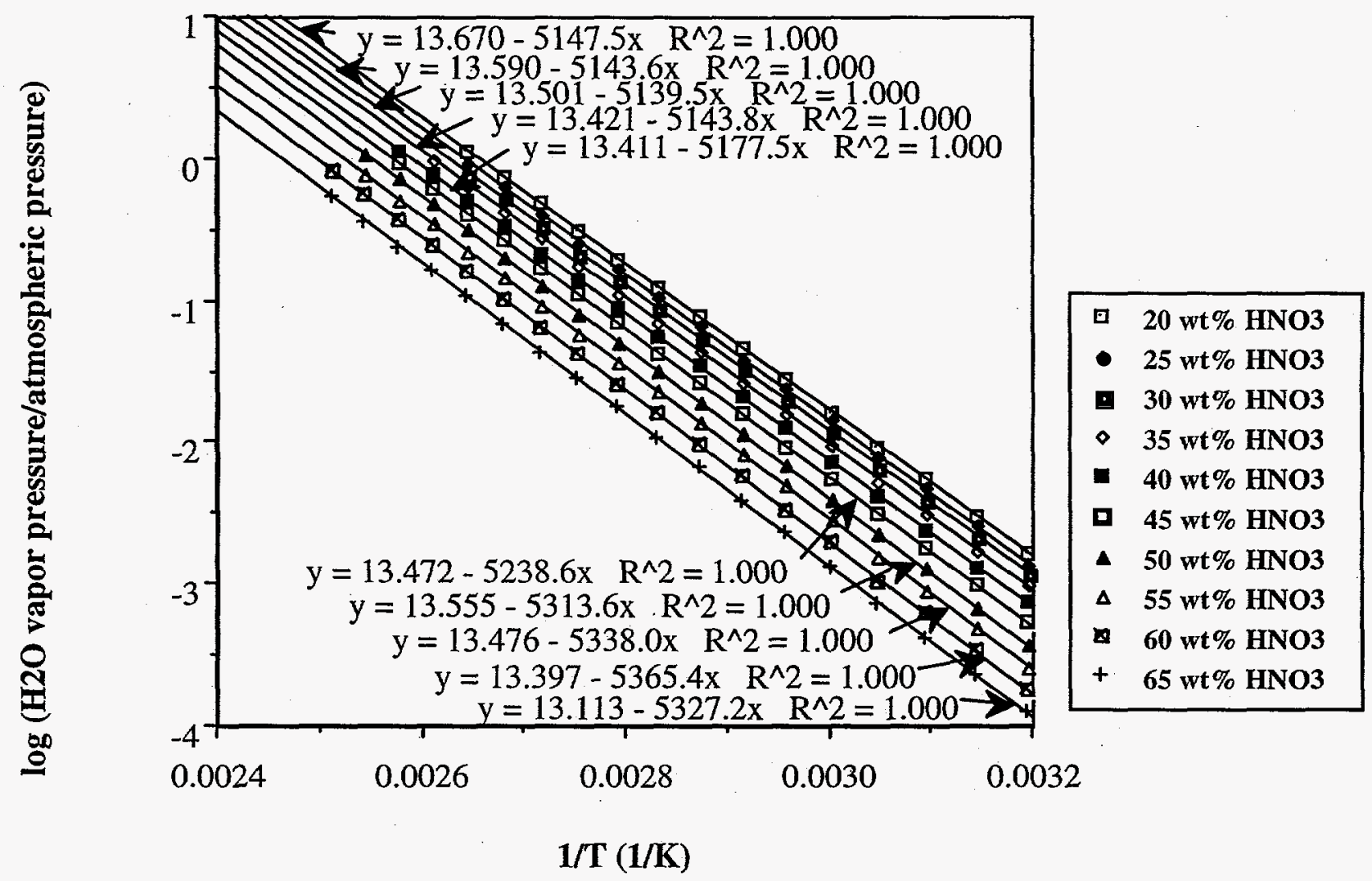

Figure E-7. Correlation of $\mathrm{H}_{2} \mathrm{O}$ Vapor Pressures for Different Temperatures and Nitric Acid Concentrations 


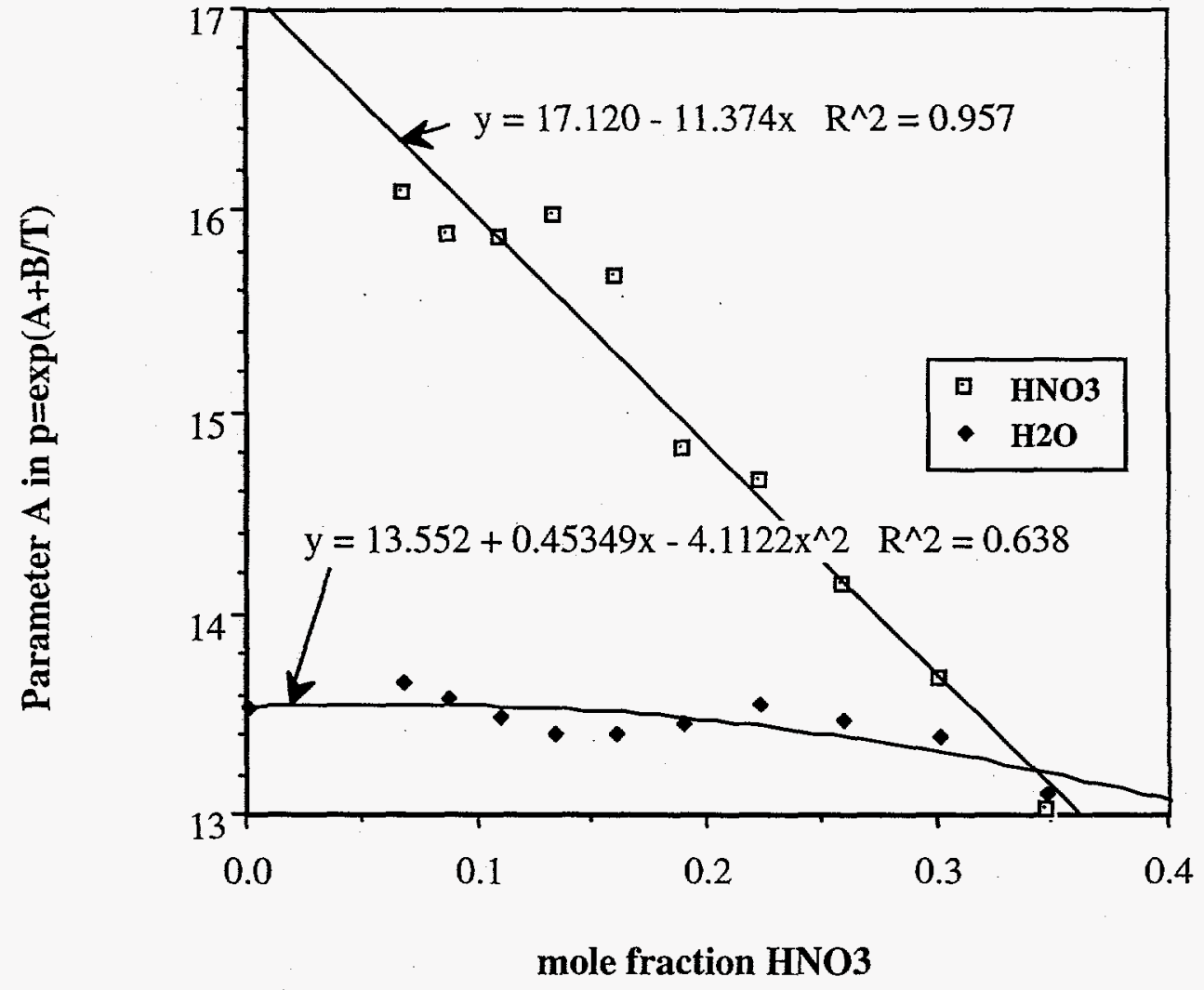

Figure E-8. Correlation of the A Parameter for Van der Waals' Vapor Pressure Equations for $\mathrm{H}_{2} \mathrm{O}$ and $\mathrm{HNO}_{3}$ 


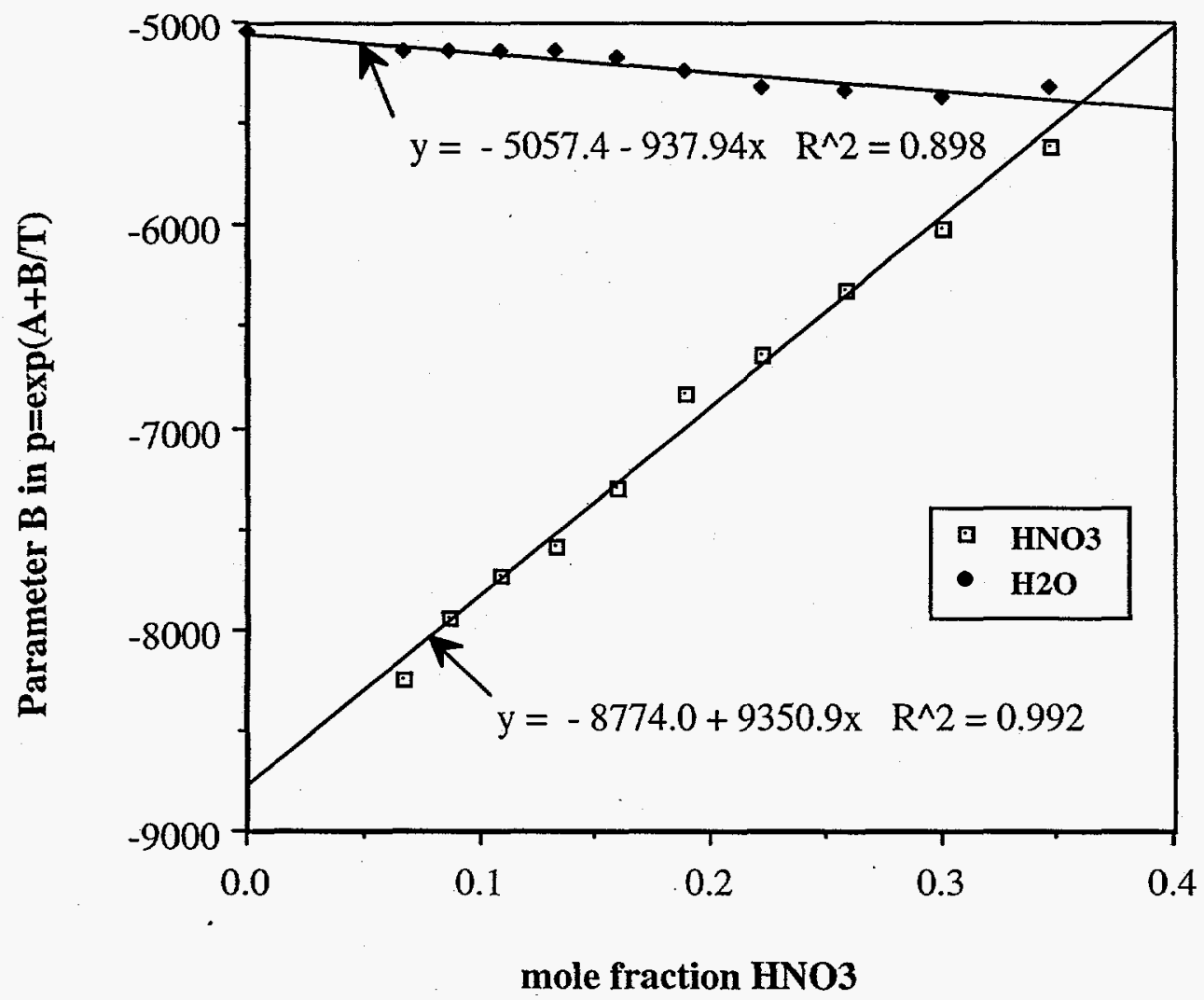

Figure E-9. Correlation of the B Parameter for Van der Waals' Vapor Pressure Equations for $\mathrm{H}_{2} \mathrm{O}$ and $\mathrm{HNO}_{3}$ 


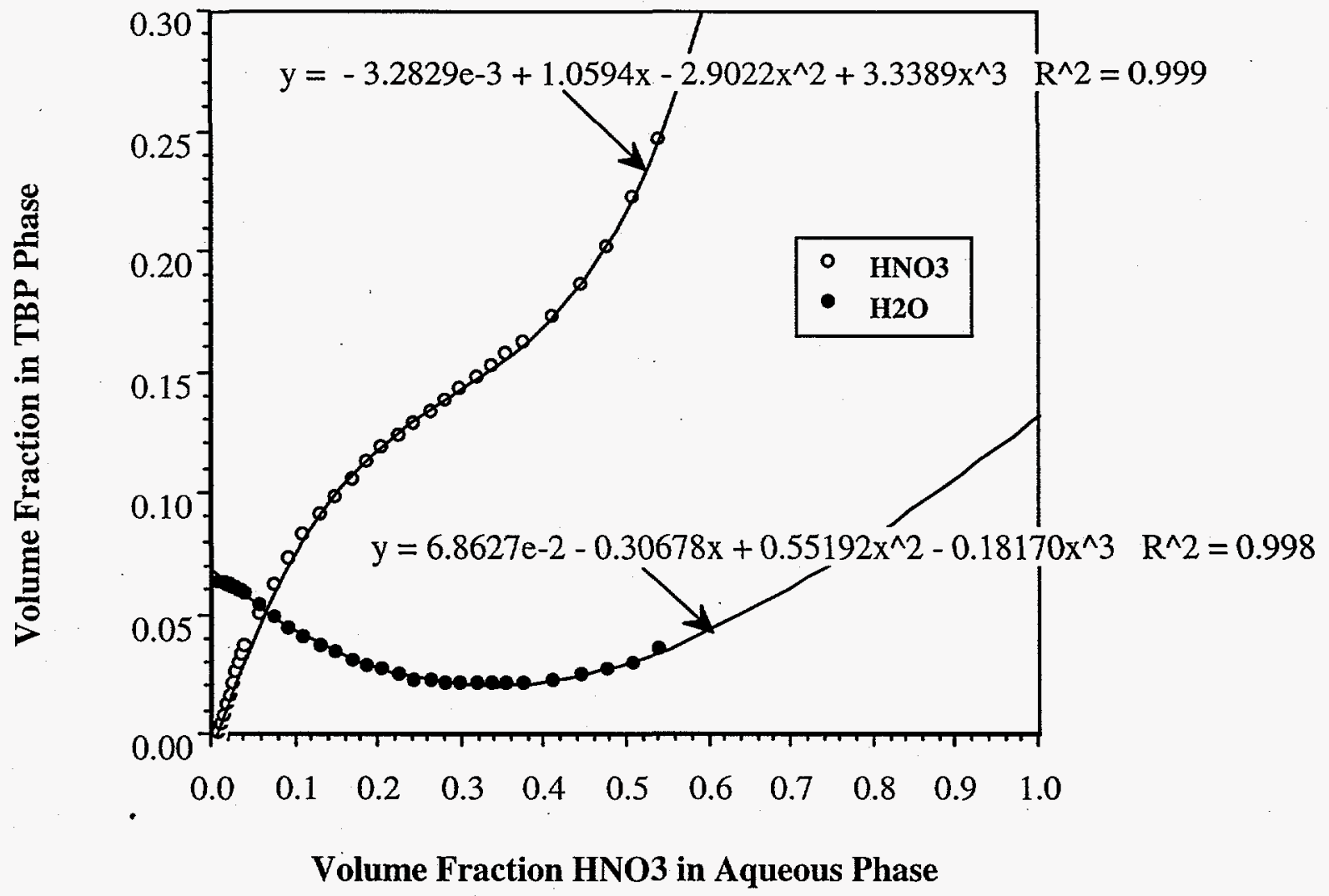

Figure E-10. Correlation of Nitric Acid Solubilities in TBP in Terms of Volume Fractions 


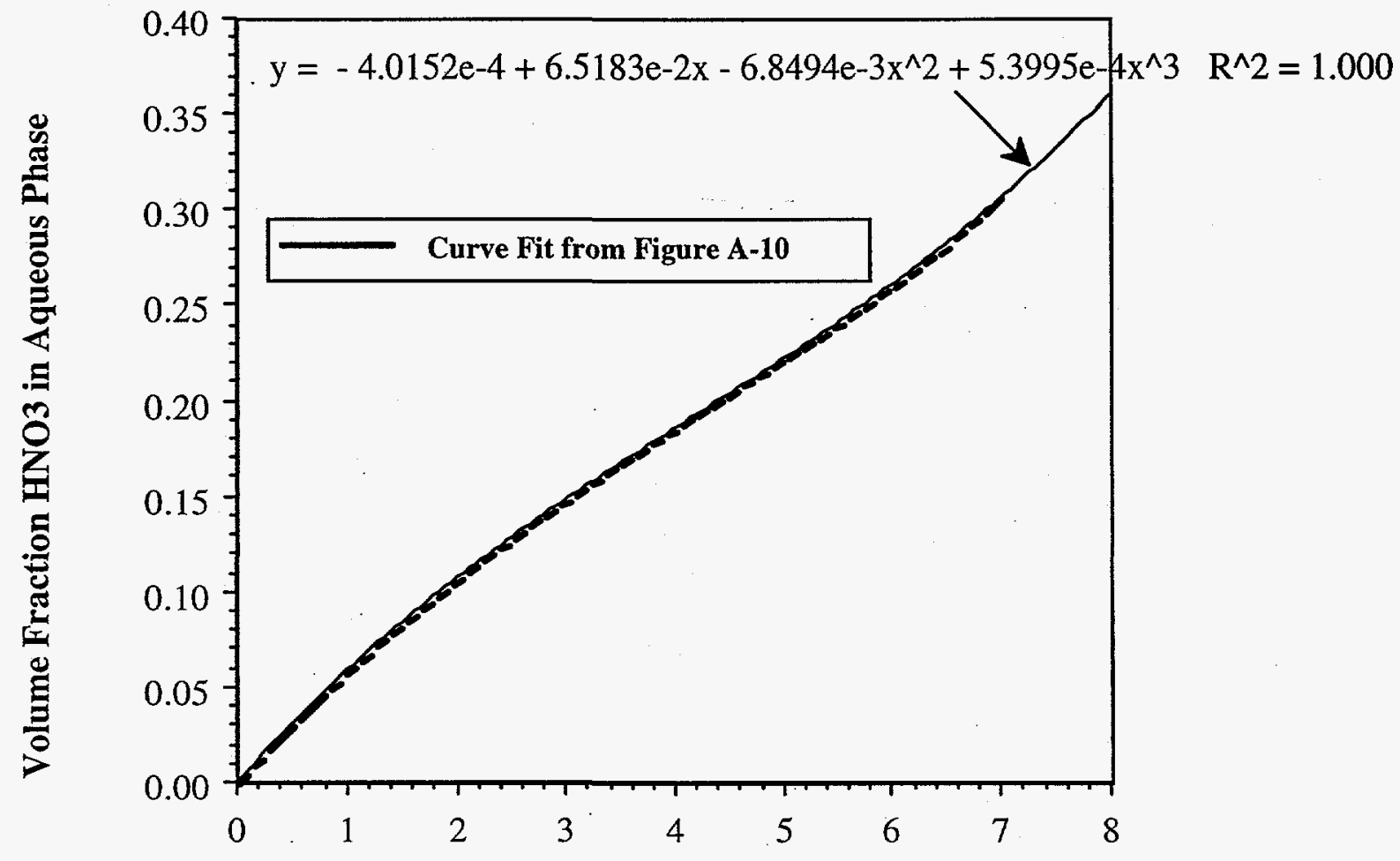

Volume Fraction HNO3/Volume Fraction H2O in TBP Phase

Figure E-11. Correlation of Equilibrium Volume Fraction $\mathrm{HNO}_{3}$ in Nitric Acid 


\section{Appendix F: Computer Code Listing for Bubble Mixing Model Calculations}

This appendix contains a listing for the computer code that was used to model heating of an organic layer in a canyon tank by a steam jet. When this calculations were performed, best estimate values for reaction parameters and vapor pressures were used.

The code is written in VAX Fortran and was run on the SRS VAX computer. It is stored in VAX directory [t6930] as stmbe2.for.

\section{Source Code Listing}

C This program computes temperature and concentration transients for heating of $C$ an organic layer containing TBP by steam condensate. The program solves heat $c$ and mass balances using a finite difference method. The heat and mass

c balances include source terms for the TBP-nitric acid decomposition reaction, $c$ and the heat balance includes a term for heat transfer with the surroundings.

c The program reads input parameters from an input file and writes output to c several output files. A definition of terms follows.

Definition of terms

dn - mixture density, gm/ $\mathrm{cm}^{\star \star} 3$

dn1 - TBP density, $\mathrm{gm} / \mathrm{cm}^{* * 3}$

dn2 - HNO3 density, gm/ $\mathrm{cm} * * 3$

dn 3 - H2O density, $\mathrm{gm} / \mathrm{cm}^{\star *} 3$

dt - time step increment, min

eff - for test simulations, fraction of organic vapor that leaves the vessel (does not recondense in the vent line)

frat - hot gas flow rate, scfm

fvp - vapor pressure multiplier, 0.9 for worst case calculations, 1.0 for best estimate calculations

hc - mixture heat capacity, cal/gm/C

hcpl - TBP heat capacity, cal/gm/C

hcp23 - combined heat capacity of HNO3 and $\mathrm{H} 2 \mathrm{O}, \mathrm{cal} / \mathrm{gm} / \mathrm{C}$

hnc - heat transfer coefficient at. the top surface of the TBP layer, $\mathrm{cal} / \mathrm{cm}^{* *} 2 / \mathrm{min} / \mathrm{C}$

ibw - one indicates worst case calculations with respect vapor pressures and rates and heats of reaction, zero indicates best estimate calculations with respect to these parameters

iind - one indicates calculation includes heat of reaction and component generation by reaction, zero indicated calculation omits these terms

imx - one indicates that the calculation is for a maximum thickness organic. layer in a tank, zero indicates that it is not

ind2 - one indicates that the time will automatically be incremented at each time step for simulation of heating of organic layer in solvent storage tank, two indicates that times will be read from input file to simulate experiment

itme - one indicates that the temperature for the thermocouple originally in the organic layer is read from the data file, two indicates that the temperature for the thermocouple originally at the organic/aqueous interface is read from the data file

jmax - number of time steps in calculation

qg - gas flow rate, cc/min

rhocpg - hot gas volumetric heat capacity, cal/cc/C

c rhoml - hot gas molar density, gmole/cc

Cr1 - right-hand side for finite difference formulation of TBP mass balance, containing rates of consumption of TBP by reaction and of loss of TBP by evaporation

rr2 - right-hand side for finite difference formulation of HNO3 mass balance, containing rates of consumption of HNO3 by reaction and of loss of HNO3 by evaporation 
c rr3 - right-hand side for finite difference formulation of H2O mass balance, c containing rates of consumption of $\mathrm{H} 2 \mathrm{O}$ by reaction and of loss of $\mathrm{H} 2 \mathrm{O}$ c by evaporation

c rr4 - right-hand side for finite difference formulation of dodecane mass

c balance, containing rates of consumption of dodecane by reaction and of loss of dodecane by evaporation

cr5 - right-hand side for finite difference formulation of tridecane mass balance, containing rates of consumption of tridecane by reaction and of loss of tridecane by evaporation

rr6 - right-hand side for finite difference formulation of tetradecane mass balance, containing rates of consumption of tetradecane by reaction and of loss of tetradecane by evaporation

rr7 - right-hand side for finite difference formulation of heat balance, containing rate of temperature increases due to heat of reaction, of temperature decreases due to evaporation, and temperature changes due to heat transfer from the gas to the organic layer and from the organic layer to the ambient air, $C$

sumx - sum of component volume fractions in organic layer, used in normalization of these volume fractions at each time step

$t$ - elapsed time, min

c tamb - ambient air temperature, C

$c$ tend - ending time for flow of hot gas to test vessel, min

$c$ tmass - thermal mass of walls of vessel or tank in contact with organic layer or vapor space above organic layer, cal/C

$c$ tme - measured organic layer temperature, taken as the temperature

$c$ measurement $2 / 3$ of the distance from the surface to the interface, $c$

$c$ tstart - starting time for simulation of test transient, min

c $t 1$ - temperature, $C$

c t1o - temperature at previous time step, $c$

c vs - organic layer volume, cc

c vso - final organic layer volume, $\mathrm{cc}$

c vt - total vapor pressure of HNO3 and H2O in TBP layer, atm

C Vw - steam pressure, atm

C V1 - vapor pressure of TBP for the organic layer, atm

c v2 - vapor pressure of HNO3 for the organic layer as it mixes with the hot gas, calculated as proportional to the TBP vapor pressure based on relative volume fractions in solution, atm

V21 - vapor pressure of HNO3 used in the computation of the heat of reaction, calculated based on vapor-liquid equilibrium relationships between organic and aqueous phases, atm

v3 - vapor pressure of H2O for the organic layer as it mixes with the hot gas, calculated as proportional to the TBP vapor pressure based on relative volume fractions in solution, atm

v31 - vapor pressure of H2O used in the computation of the heat of reaction, calculated based. on vapor-liquid equilibrium relationships between organic and aqueous phases, atm

v4 - vapor pressure of dodecane for the organic layer, atm

C v5 - vapor pressure of tridecane for the organic layer, atm

c v6 - vapor pressure of tetradecane for the organic layer, atm

c $\mathrm{xf2}$ - volume fraction HNO3 in the aqueous phase when that phase is in

c equilibrium with the TBP phase layer, used for the calculation of vapor pressures in the TBP layer

xfs2 - volume fraction HNO3 in the TBP phase when that phase is saturated with nitric acid at the equilibrium concentration, used for the calculation of vapor pressures in the TBP layer

xmult - ratio of volume fractions of HNO3 and H2O to volume fractions of these components at saturation

xl - volume fraction TBP

c $x 1 \max$ - initial, maximum, TBP volume fraction, used to calculate the rate of consumption of TBP by reaction

C x10 - volume fraction TBP at previous time step

c $\mathrm{x} 2$ - volume fraction HNO3

c $\mathrm{x} 20$ - volume fraction HNO3 at previous time step

C $\times 3$ - volume fraction $\mathrm{H} 2 \mathrm{O}$

c $\times 30$ - volume fraction $\mathrm{H} 2 \mathrm{O}$ at previous time step

c $\times 4$ - volume fraction dodecane

c $\times 40$ - volume fraction dodecane at previous time step 
c $x 5$ - volume fraction tridecane

c $\times 50$ - volume fraction tridecane at previous time step

c $\mathrm{x} 6$ - volume fraction tetradecane

c $x 60$ - volume fraction tetradecane at previous time step

c Assign an external subroutine prop to calculate solution properties. implicit double precision $(a-h, 0-z)$

external prop external prop dimension $x 1(200), x 2(200), x 3(200), x 4(200), x 5(200), x 6(200)$, $1 \mathrm{dx}(200), \mathrm{x} 10(200), \mathrm{x} 20(200), \mathrm{x} 30(200), \mathrm{x} 40(200), \mathrm{x} 50(200), \mathrm{x} 60(200)$, $2 t 10(200), t 1(200), \operatorname{tc}(200), v 1(200), v 2(200), v 3(200), v 4(200)$, $3 v 5(200), v 6(200), v 21(200), v 31(200)$, $3 \mathrm{dn}(200), \mathrm{hc}(200), \mathrm{vg}(200), \operatorname{tc} 2(200), \mathrm{vgi}(200), \mathrm{xx}(200), \operatorname{tc} 3(200)$, $4 \mathrm{fx}(200), \operatorname{dn} 1(200), \operatorname{dn} 2(200), \operatorname{dn} 3(200), \operatorname{vt}(200), \operatorname{tc} 4(200), \operatorname{tc} 5(200)$, $5 \mathrm{vgii}(200), \operatorname{rr} 1(200), \operatorname{rr} 2(200), \operatorname{rr} 3(200), \operatorname{rr} 4(200), \operatorname{rr} 5(200), \operatorname{rr} 6(200)$, $6 \operatorname{rr} 7(200), \operatorname{dn} 4(200), \operatorname{dn} 5(200), \operatorname{dn} 6(200)$

dimension tc2o(200), tc $30(200), \operatorname{tc} 40(200), \operatorname{tc} 50(200)$

dimension hep1 (200), hcp 23(200), dxa (200), xxa (200) character tab /9/

$c$ set the initial time to zero. $t=0$.

$c$ Read input variables. read $(5, *) d t$ read $(5, *) \mathrm{n}$ read $(5, *)$ dxi read $(5, *)$ jmax

read $(5, *)$ xloi, $x 20 i, x 30 i, x 40 i, x 50 i, x 60 i$ read $(5, *)$ tloi

read $(5, *)$ qg

read $(5, *)$ tin

read $(5, *)$ vs

read $(5, *)$ vso

read $(5, *)$ eff

read $(5, *)$ hnc

read $(5, *)$ tamb

read $(5, *)$ tmass

read $(5, *)$ hsurf

read $(5, *)$ xksurf

read $(5, *)$ iind

read $(5, *)$ ind2

read $(5, *)$ itme

read $(5, *)$ ibw

read $(5, *)$ imx

read $(5, *)$ tstart

read $(5, *)$ tend

tsts $=1.0$

c Assign vapor pressure multiplier for worst case $(=0.9)$. and best. estimate

c $(=1.0)$ calculations

fvp $=1$. 0

if (ibw:eq.1) then

fvp $=0.9$ endif

c If this program is to calculate transients for the maximum amount of organic

$c$ in a tank (imx=1), calculate initial volumes. Call Subroutine prop to update

$c$ solution densities, heat capacities, vapor pressures, and thermal

c conductivities.

if (imx.eq. 1) then

call prop ( $x 10, x 20, x 30, x 40, x 50, x 60, t 10, \mathrm{dn}, \mathrm{hc}$,

$1 v 1, v 2, v 3, v 4, v 5, v 6, v 21, v 31, \operatorname{dn} 1, \operatorname{dn} 2, \operatorname{dn} 3, \operatorname{dn} 4, \operatorname{dn} 5, \operatorname{dn} 6$,

$3 v t, v w, h v 1, h v 2, h v 3$, hv4, hv5, hv6, xmult, fvp, tcond)

$v s=3000 * 453.59 / \mathrm{dn}$

vso $=\mathrm{vs}$

hnc $=$ hnc $* 711680 . / \mathrm{vs}$

endif

C If this program is to benchmark existing tabulated data (ind2=2) read data

c from an input log file (file \#4) until the time in minutes equals tstart. 
c Backspace this file one line to begin with $t=t s t a r t$.

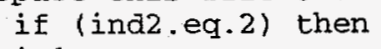




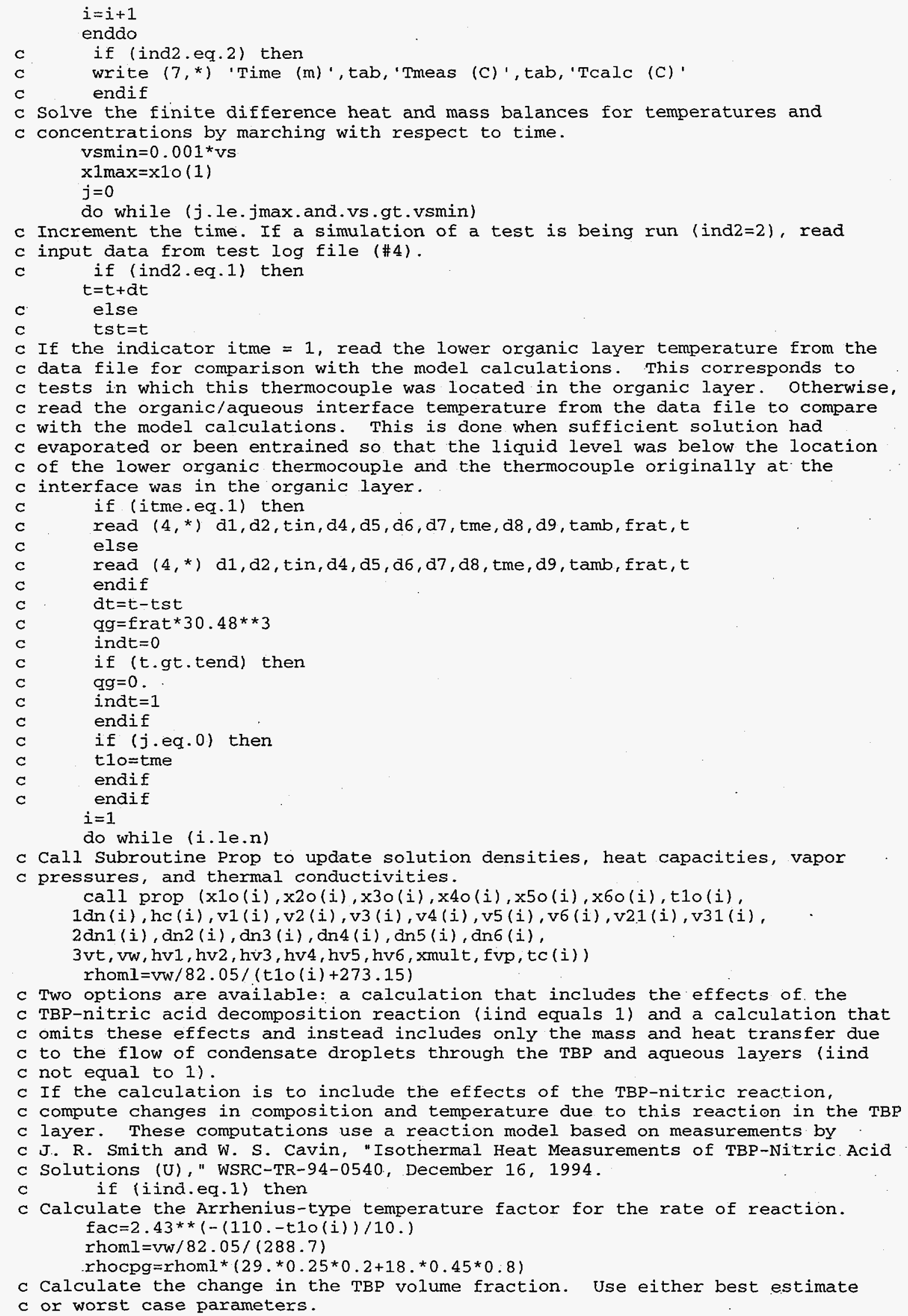


if (ibw.eq.1) then

$\operatorname{rr} 1(i)=-d t * x 20(i) * 11.97 e-4 * f^{*} * 266 . / 63 . * \operatorname{dn} 2(i) / \operatorname{dn} 1(i) * x 10(i)$

$1 /(x 1 \max +x 40(i)+x 50(i)+x 60(i)) / 3$.

else

$\operatorname{rr} 1(i)=-d t * x 20(i) * 13.3 e-4 * \operatorname{fac}^{*} 266 . / 63 . * \operatorname{dn} 2(i) / \operatorname{dn} 1(i) * \times 10(i)$

$1 /(x 1 \max +x 40(i)+x 50(i)+x 60(i)) / 3$.

endif

if $(1 .-v 1(i)-v 21(i)-v 31(i)-v 4(i)-v 5(i)-v 6(i) .1 t .0$.$) then$

write $(6, *)$ 'Simulation ended by boiling reaction.'

stop

endif

if (ibw.eq.1) then

$\operatorname{rr} 2(i)=-d t * x 20(i) *(4.86 e-4+7.7 e-4 * v 21$ (i)/abs $(1 .-v 1(i)-v 21$ (i)

$1-v 31(i)-v 4(i)-v 5(i)-v 6(i))+11.97 e-4 * x 10(i) / x I \max ) *$ fac

else

$\operatorname{xr} 2(i)=-d t^{*} \times 2 \circ(i) *(5,4 e-4+7.0 e-4 * v 21(i) / a b s(1 .-v 1(i)-v 21$ (i)

$1-v 31(i)-v 4(i)-v 5(i)-v 6(i))+13 \cdot 3 e-4 * \times 10(i) / \times 1 \max ) * f a c$

endif

if $(\operatorname{rr} 2(i) .1 t .0.) \operatorname{rr} 2(i)=0$.

if (ibw.eg.I) then

$\operatorname{rr3}(i)=d t * x 20(i) *(5.49 e-4-7.7 e-4 * v 31$ (i) $/ \mathrm{abs}(1 .-v 1$ (i) $-v 21$ (i)

$1-\mathrm{v} 31(\mathrm{i})-\mathrm{v} 4(\mathrm{i})-\mathrm{v} 5(\mathrm{i})-\mathrm{v} 6(\mathrm{i}))) * \mathrm{fac} * 18 . / 63 . * \operatorname{dn} 2(\mathrm{i}) / \operatorname{dn} 3(i)$

else

$\operatorname{rr} 3(i)=d t * x 20(i) *(6.1 e-4-7.0 e-4 * v 31(i) / a b s(1 .-v 1(i)-v 21(i)$

$1-v 31(i)-v 4(i)-v 5(i)-v 6(i))) * f a c * 18 . / 63 . * \operatorname{dn} 2(i) / \operatorname{dn} 3(i)$

endif

c Calculate the change in the HNO3 volume fraction. This is assumed to be zero

c because of replenishment of HNO3 due to mixing with the aqueous phase.

c $\quad \operatorname{rr} 2(i)=0$.

c Calculate the change in the H2O volume fraction. This is assumed to be zero

$\mathrm{C}$ because of replenishment of $\mathrm{H} 2 \mathrm{O}$ due to mixing with the aqueous phase.

c $\quad \operatorname{rr} 3(i)=0$.

c Calculate the change in the temperature. Use either best estimate or worst

c case parameters.

if (ibw.eq.1) then

$\operatorname{rr} 7(i)=d t * 7.7 e-4 * \times 20(i) *\left(71.694-\left(h v 3 / 1000 *{ }^{*} 31(i)\right.\right.$

$\left.1+\mathrm{hv} 2 / 1000{ }^{*} \mathrm{v} 21(\mathrm{i})\right)$

$2 / \operatorname{abs}(v w-v 1(i)-v 21(i)-v 31(i)-v 4(i)-v 5(i)-v 6(i))) * \times 10(i) /$

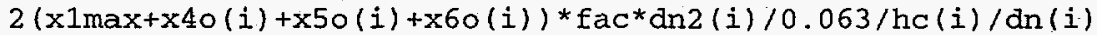

else

$\operatorname{rr} 7(i)=d t * 7.0 e-4 * x 20(i) *(61.965-(h v 3 / 100.0 * v 31(i)$

$\left.1+\mathrm{hv} 2 / 1000{ }^{*} \mathrm{v} 21(i)\right)$

$1 / a b s(v w-v 1(i)-v 21(i)-v 31(i)-v 4(i)-v 5(i)-v 6(i))) * \times 10(i) /$

$2(x 1 \max +x 40(i)+x 50(i)+x 60(i)) * f a c^{*} \operatorname{dn} 2(i) / 0.063 / \mathrm{hc}(i) / \mathrm{dn}(i)$

endif

c else

c Calculate the incremental change in the bubble flow rate.

if ( $x 10(i) . g t .0$.$) then$

if (ibw.eq.1) then

$\operatorname{vg}(i)=x 20(i) * 7.7 e-4 / 60 *(1 .+v w / a b s(v w-v 1(i)-v 21(i)-v 31(i)-v 4(i)$

$1-v 5(i)-v 6(i))) * f a c * d n 2(i) / 0.063 * 0.08205 *(t 1(i)+273.15)$

else

$v g(i)=x 20(i) * 7.0 e-4 / 60 * *(1 .+v w / a b s(v w-v 1(i)-v 21(i)-v 31(i)-v 4(i)$

$1-v 5(i)-v 6(i))) * f a c * \operatorname{dn} 2(i) / 0.063 * 0.08205 *(t 1(i)+273.15)$

endif

else

$\operatorname{vg}(i)=0$.

endif

c. Calculation the changes in volume fractions and temperature if no reaction is

c involved. rhocpg $=r$ hom $1 * 0.25 * 28$.

$\operatorname{rr} 1(i)=0$.

$\operatorname{rr} 2(i)=0$.

$\operatorname{rr} 3(i)=0$.

$\operatorname{rr} 7(i)=0$.

endif

Calculate the change in the TBP volume fraction due to mixing with the hot 
c gas.

c $\quad \operatorname{rr} 1 i=-d t^{*} r h o m 1 * q g * v 1 / a b s(v w-v 1-v 2-v 3-v 4-v 5-v 6)$

c $\quad 1 * 266 . / \mathrm{dn} 1 / \mathrm{vs}$

c $\operatorname{rrl}(i)=\operatorname{rrl}(i)+\operatorname{rrli}$

c Calculate the change in the HNO3 volume fraction due to mixing with the hot

c gas. Assume that this change is proportional to that of the TBP. This

$c$ assumption is valid either if the organic and aqueous layers are well-mixed,

$c$ so that the HNO3 volume fraction is limited by its solubility in TBP, or if

$c$ the TBP and HNO3 are chemically bound so that HNO3 cannot be preferentially

c stripped from solution.

$\operatorname{rr} 2(i)=\operatorname{rr} 2(i)+\times 20 / \times 10^{*} \operatorname{rr} 1 i$

Calculate the change in the $\mathrm{H} 2 \mathrm{O}$ volume fraction due to mixing with the hot

gas. Assume that this change is proportional to that of the TBP. This

assumption is valid either if the organic and aqueous layers are well-mixed,

so that the H2O volume fraction is limited by its solubility in TBP, or if

the TBP and H2O are chemically bound so that HNO3 cannot be preferentially

stripped from solution.

$\operatorname{rr} 3(i)=\operatorname{rr} 3(i)+\times 30 / \times 10 * \operatorname{rr} 1 i$

Calculate the change in the dodecane volume fraction due to mixing with the

hot gas.

$r r 4(i)=-d t^{*} r h o m l * q g * v 4 / a b s(v w-v 1-v 2-v 3-v 4-v 5-v 6)$

$1 * 170 . /$ dn 4 /vs

Calculate the change in the tridecane volume fraction due to mixing with the

hot gas.

$\operatorname{rr} 5(i)=-d t * r h o m l * q g * v 5 / a b s(v w-v 1-v 2-v 3-v 4-v 5-v 6)$

$1 * 184 . / \mathrm{dn} 5 / \mathrm{vs}$

Calculate the change in the tetradecane volume fraction due to mixing with the hot gas.

$\operatorname{rr} 6(i)=-d t * x h o m l * q g * v 6 / a b s(v w-v 1-v 2-v 3-v 4-v 5-v 6)$

$1 * 198 . / \mathrm{dn} 6 / \mathrm{vs}$

Calculate the change in the temperature due to mixing with hot gas. This

calculation includes terms for cooling by evaporation, sensible heat transfer

from the gas to the organic layer, and heat losses to the ambient air. Heat

transfer to the underlying aqueous layer is assumed to be negligible. $\operatorname{rr} 7(i)=\operatorname{rr} 7(i)+d t *(-r h o m l * g g *(h v 1 * v 1+h v 2 * v 2+h v 3 * v 3$

$1+h v 4 * v 4+h v 5 * v 5+h v 6 * v 6) /(v w-v 1-v 2-v 3-v 4-v 5-v 6)$

$2+r h o c p g * q g *(t i n-t 1 o(i))+h n c *(t a m b-t l o(i)) *(d n * h c * v s o+t m a s s))$

$3 /\left(d n^{\star} h c^{\star} v s+\right.$ tmass $)$

$i=i+1$

enddo

$\operatorname{rr} 1(1)=\operatorname{rr} 1(1)+d t * 0.5 *(\operatorname{tc} 2(1)+\operatorname{tc} 2(2)+\operatorname{tc} 4(1)+\operatorname{tc} 4(2))$

$1 *(\mathrm{x} 10(2)-\mathrm{x} 10(1)) / \mathrm{dx}(1) / \mathrm{dx}(1)$

$\operatorname{xr} 2(1)=\operatorname{rr} 2(1)+d t * 0.5 *(\operatorname{tc} 2(1)+\operatorname{tc} 2(2)+\operatorname{tc} 4(1)+\operatorname{tc} 4(2))$

$1 *(x 20(2)-x 20(1)) / d x(1) / d x(1)$

$\operatorname{rr} 3(1)=\operatorname{rr} 3(1)+d t * 0.5 *(\operatorname{tc} 2(1)+\operatorname{tc} 2(2)+\operatorname{tc} 4(1)+\operatorname{tc} 4(2))$

$1 *(\mathrm{x} 30(2)-\mathrm{x} 30(1)) / \mathrm{dx}(1) / \mathrm{dx}(1)$

$\operatorname{rr} 4(1)=\operatorname{rr} 4(1)+d t * 0.5 *(\operatorname{tc} 2(1)+\operatorname{tc} 2(2)+\operatorname{tc} 4(1)+\operatorname{tc} 4(2))$

$1 *(\mathrm{x} 4 \mathrm{o}(2)-\mathrm{x} 4 \mathrm{o}(1)) / \mathrm{dx}(1) / \mathrm{dx}(1)$

$\operatorname{rr} 5(1)=\operatorname{rr} 5(1)+d t * 0.5^{*}(\operatorname{tc} 2(1)+\operatorname{tc} 2(2)+\operatorname{tc} 4(1)+\operatorname{tc} 4(2))$

$1 *(x 50(2)-x 50(1)) / d x(1) / d x(1)$

$\operatorname{rr} 6(1)=\operatorname{rr} 6(1)+d t * 0.5 *(\operatorname{tc} 2(1)+\operatorname{tc} 2(2)+\operatorname{tc} 4(1)+\operatorname{tc} 4(2))$

$1 *(\mathrm{x} 60(2)-\mathrm{x} 60(1)) / \mathrm{dx}(1) / \mathrm{dx}(1)$

$\operatorname{rr} 7(1)=\operatorname{rr} 7(1)+d t * 0.5^{*}(\operatorname{tc}(1)+\operatorname{tc}(2)+\operatorname{tc} 3(1)+\operatorname{tc} 3(2)$

$1+\operatorname{tc} 5(1)+\operatorname{tc} 5(2)) *(\operatorname{to}(2)-\operatorname{to}(1)) / d x(1) / d x(1)$

$i=2$

do while (i.le.nn1)

$\operatorname{rr} 1(i)=\operatorname{rr} 1(i)+d t^{*}(0.5 *(\operatorname{tc} 2(i)+\operatorname{tc} 2(i+1)+\operatorname{tc} 4(i)+\operatorname{tc} 4(i+1))$

$1 *(x 10(i+1)-x 10(i)) / d x(i)-0.5 *(\operatorname{tc} 2(i-1)+\operatorname{tc} 2(i)+\operatorname{tc} 4(i-1)+\operatorname{tc} 4(i))$

$2 *(x 10(i)-x 10(i-1)) / d x(i-1)) / d x(i)$

$\operatorname{rr} 2(i)=\operatorname{rr} 2(i)+d t *(0.5 *(\operatorname{tc} 2(i)+\operatorname{tc} 2(i+1)+\operatorname{tc} 4(i)+\operatorname{tc} 4(i+1))$

$1^{*}(\times 20(i+1)-\times 20(i)) / d x(i)-0.5 *(\operatorname{tc} 2(i-1)+\operatorname{tc} 2(i)+\operatorname{tc} 4(i-1)+\operatorname{tc} 4(i))$

$2 *(x 2 \circ(i)-x 20(i-1)) / d x(i-1)) / d x(i)$

$\operatorname{rr} 3(i)=\operatorname{rr} 3(i)+d t^{*}(0.5 *(\operatorname{tc} 2(i)+\operatorname{tc} 2(i+1)+\operatorname{tc} 4(i)+\operatorname{tc} 4(i+1))$

$1^{*}(\times 30(i+1)-x 30(i)) / d x(i)-0.5 *(\operatorname{tc} 2(i-1)+\operatorname{tc} 2(i)+\operatorname{tc} 4(i-1)+\operatorname{tc} 4(i))$

$2 *(x 30(i)-x 30(i-1)) / d x(i-1)) / d x(i)$

$\operatorname{rr} 4(i)=\operatorname{rr} 4(i)+d t *(0.5 *(\operatorname{tc} 2(i)+\operatorname{tc} 2(i+1)+\operatorname{tc} 4(i)+\operatorname{tc} 4(i+1))$

$1^{*}(x 40(i+1)-x 40(i)) / \mathrm{dx}(i)-0.5^{*}(\operatorname{tc} 2(i-1)+\operatorname{tc} 2(i)+\operatorname{tc} 4(i-1)+\operatorname{tc} 4(i))$ 
$2 *(x 4 \circ(i)-x 4 \circ(i-1)) / d x(i-1)) / d x(i)$

$\operatorname{rr5}(i)=\operatorname{rr} 5(i)+d t *\left(0.5^{*}(\operatorname{tc} 2(i)+\operatorname{tc} 2(i+1)+\operatorname{tcc} 4(i)+\operatorname{tc} 4(i+1))\right.$

$1 *(x 5 \circ(i+1)-x 50(i)) / d x(i)-0.5 *(\operatorname{tc} 2(i-1)+\operatorname{tc} 2(i)+\operatorname{tc} 4(i-1)+\operatorname{tc} 4(i))$

$2 *(x 50(i)-x 50(i-1)) / d x(i-1)) / d x(i)$

$\operatorname{rr6}(i)=\operatorname{rr} 6(i)+d t *(0.5 *(t c 2(i)+\operatorname{tc} 2(i+1)+\operatorname{tc} 4(i)+t c 4(i+1))$

$1 *(x 60(i+1)-x 60(i)) / d x(i)-0.5 *(\operatorname{tc} 2(i-1)+\operatorname{tc} 2(i)+\operatorname{tc} 4(i-1)+\operatorname{tc} 4(i))$

$2 *(x 60(i)-x 60(i-1)) / d x(i-1)) / d x(i)$

$\operatorname{rr} 7(i)=\operatorname{rr} 7(i)+d t^{*}\left(0.5^{*}(\operatorname{tc}(i)+\operatorname{tc}(i+1)+\operatorname{tc} 3(i)+\operatorname{tc} 3(i+1)+\operatorname{tc} 5(i)\right.$

$1+\operatorname{tc} 5(i+1)) *(t 10(i+1)-t 10(i)) / d x(i)-0.5 *(t c(i-1)+t c(i)$

$2+\operatorname{tc} 3(i-1)+\operatorname{tc} 3(i)+\operatorname{tc} 5(i-1)+\operatorname{tc} 5(i)) *(t 10(i)-t 10(i-1))$

$3 / d x(i-1)) / d x(i)$

$i=i+1$

enddo

$\operatorname{rr} 7(n)=\operatorname{rr} 7(n)-d t * 0.5 *(t c(n n 1)+t c(n)+\operatorname{tc} 3(n n 1)+\operatorname{tc} 3(n)$

$1+\operatorname{tc} 5(\operatorname{nn} 1)+\operatorname{tc} 5(n)) *(\operatorname{to}(n)-\operatorname{to}(\operatorname{nn} 1)) / d x(n n 1) * * 2$

c Calculate the heat transfer and bubble flow rate due to evaporation of

$c$ aqueous solution at the interface. Use this calculation if the total

$C$ aqueous vapor pressure exceeds 0.95 atmospheres.

if $(v 2(n)+v 3(n) \cdot g t .0 .95)$ then

$\mathrm{x} l \mathrm{~d}=\mathrm{dx}(\mathrm{nn} 1)$

$\mathrm{x} 2 \mathrm{~d}=\mathrm{dx}(\mathrm{nn} 1-1)+\mathrm{dx}(\mathrm{nn} 1)$

$\operatorname{vgix}=(\operatorname{tc}(n)+\operatorname{tc} 3(n)+\operatorname{tc} 5(n)) / 60$.

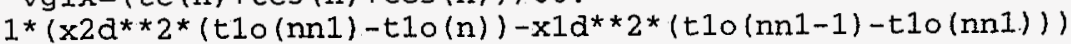

$2 / x 1 d / x 2 d / d x(n n 1-1) * 0.08205 *(t 10(n)+273.15)$

$2 /(\mathrm{v} 2(\mathrm{n}) * \mathrm{hv} 2+\mathrm{v} 3(\mathrm{n}) * \mathrm{hv} 3)$

else

$\operatorname{vgix}=0$.

endif

c Update the volume fractions of the organic layer components and the organic

c layer temperature.

$$
i=1
$$

do while (i.le.nnl)

$x 1(i)=x I 0(i)+\operatorname{rr} 1(i)$

$x 2(i)=x 20(i)+\operatorname{rr} 2(i)$

$x 3(i)=x 30(i)+\operatorname{rr} 3(i)$

$x 4(i)=x 40(i)+\operatorname{rr} 4(i)$

$x 5(i)=x 50(i)+\operatorname{rr} 5(i)$

$x 6(i)=x 60(i)+\operatorname{rr} 6(i)$

$t 1(i)=t 10(i)+\operatorname{rr} 7(i)$

$i=i+1$

enddo

$t 1(n)=t 10(n)+r r 7(n)$

if (tI $(n) . g t .123$.$) then$

$t 1(n)=123$.

endif

$x 1(n)=x 10(n)$

$x 2(n)=x 20(n)$

$x 3(n)=x 30(n)$

$x 4(n)=x 40(n)$

$x 5(n)=x 50(n)$

$x 6(n)=x 60(n)$

$i=1$

do while (i.le.nn1)

if $(x 1(i) .1 t .0$.$) then$

$x 1(i)=0$.

endif

if $\left(x_{2}(i) .1 t .0.\right)$ then

$x 2$ (i) $=0$.

endif

if $(x 3(i) .1 t .0$.$) then$

$x 3(i)=0$.

endif

$i=i+1$

enddo

c $\quad \times 2(n)=0.1762 / 0.8008 * x 1(n)$

C $\quad x 3(n)=0.0230 / 0.8008 * x 1(n)$

c If the HNO3 and H2O volume fractions exceed saturation (xmult.gt.1) apply 


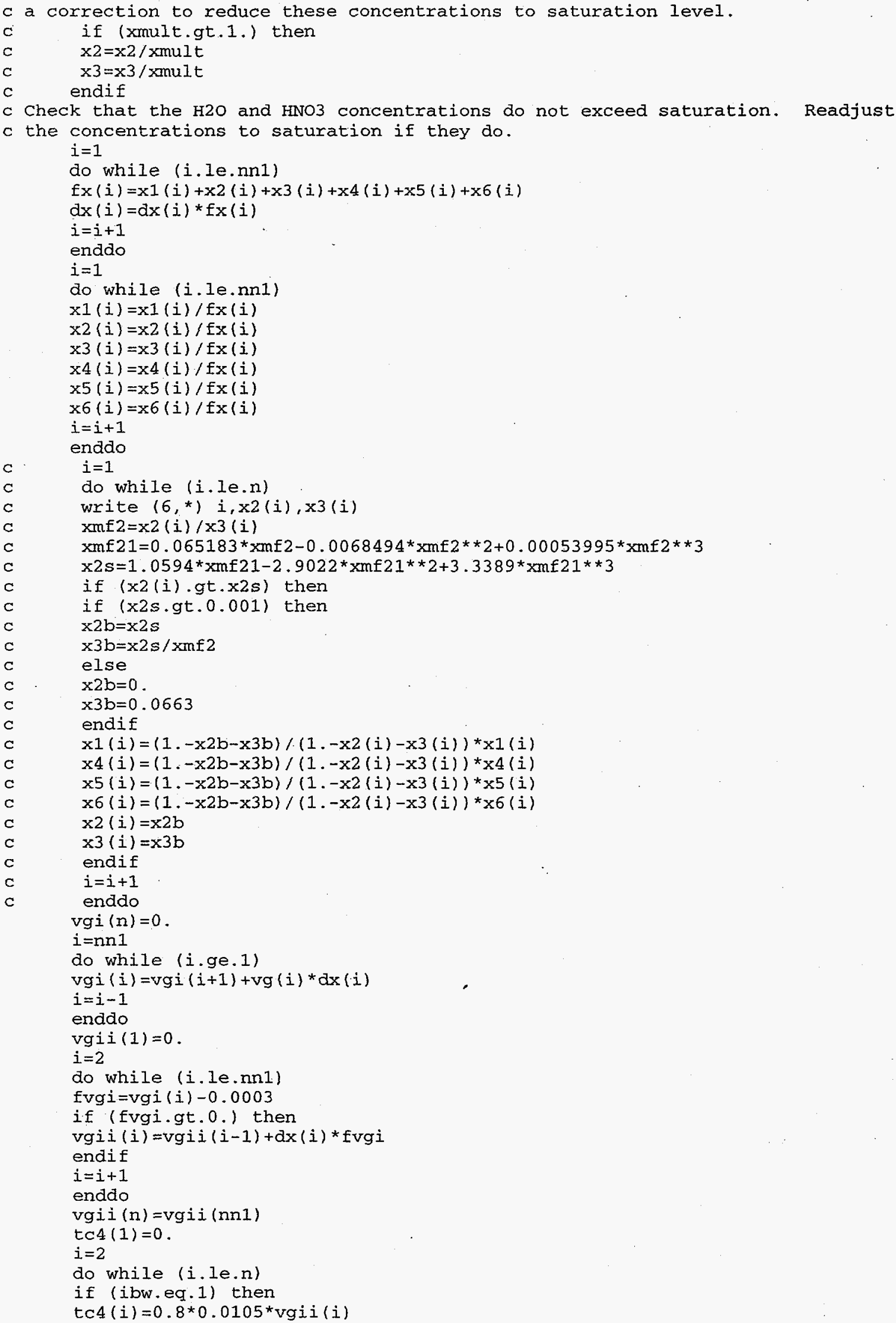




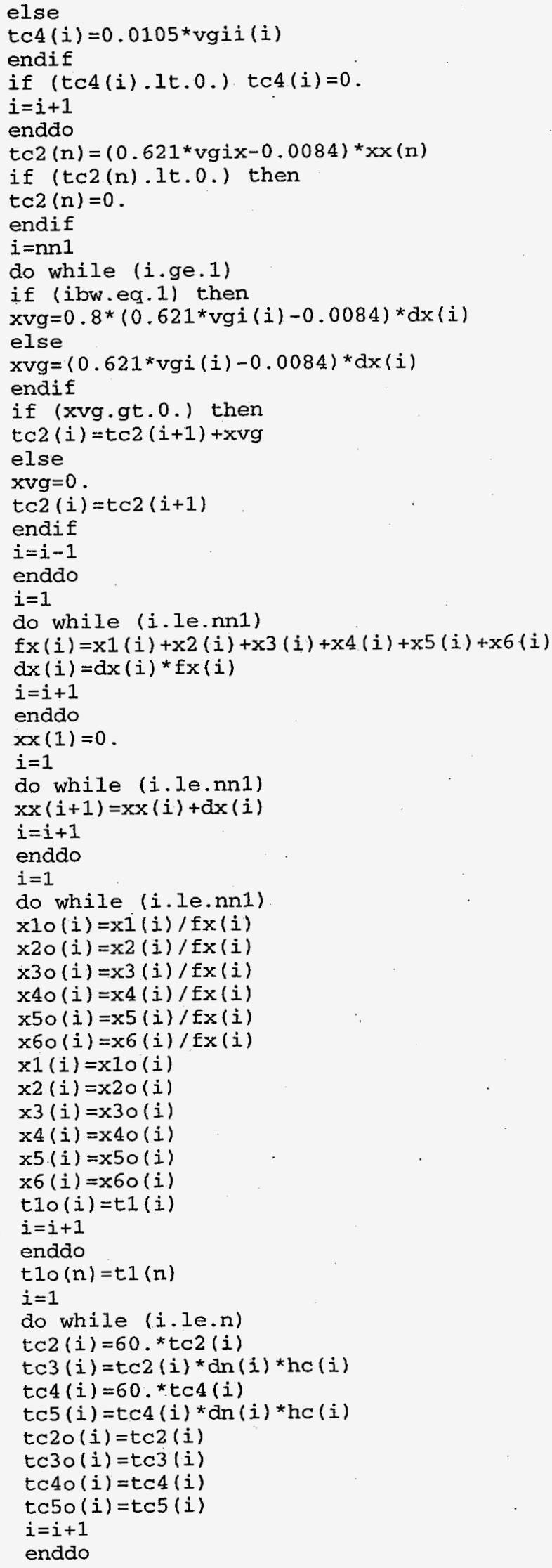


ita $=t$

c Write results to output files.

if $(a b s(t-i t a) .1 t . d t$. and.abs $(t s t s-1.0) .1 t .0 .001)$ then

tsts $=0.0$

write $(7,107) t, t a b, x 10(1), t a b, x 2 \circ(1), t a b, x 3 \circ(1), t a b$,

$1 \mathrm{v} 21(\mathrm{n})+\mathrm{v} 31(\mathrm{n}), \mathrm{tab}, \mathrm{vgix}, \mathrm{tab}, \mathrm{vg} i(25), \mathrm{tab}, \mathrm{t} 10(1), \mathrm{tab}, \mathrm{xx}(1)$

$i=1$

do while (i.le.n)

write $(6,102) t, t a b, x 1 \circ(i), t a b, x 2 \circ(i), t a b, x 3 \circ(i), t a b, x 4 \circ(i)$,

$1 \mathrm{tab}, \mathrm{tc} 2(i), \mathrm{tab}, \mathrm{tc} 4(i), t a b, t 10(i), t a b, \mathrm{xx}(i)$

102 format ( $f 9.3,4(a 1, f 8.4), a 1, f 8.2, a 1, f 8.4, a 1, f 10.2, a 1, f 9.5$ )

107 format ( $f 9.3,6(\mathrm{a} 1, \mathrm{f} 8.4), \mathrm{a} 1, \mathrm{f} 10.2, \mathrm{a} 1, \mathrm{f9} .5)$

$c$ if (ind2.eq.2) then

write $(7,103) t, t a b, t m e, t a b, t 10$

103 format ( $\mathrm{f} 9.4,2(\mathrm{a} 1, \mathrm{f} 10.2)$ )

endif

$i=i+1$

enddo

else

tsts $=1.0$

endif

$j=j+1$

enddo

stop

end

c Subroutine Prop calculates densities, heat capacities, and vapor pressures,

$c$ based on the composition of those layers and the temperature. This

c subroutine uses regression correlations of data referenced in the program.

c listing comments. Cricket Graph computer software was used to perform the

c data regressions. A definition of terms used in this subroutine follows.

c Definition of terms

den - mixture density, $\mathrm{gm} / \mathrm{cm} * * 3$

den1 - TBP density, gm/ $\mathrm{cm}^{\star *} 3$

den2 - HNO3 density, $\mathrm{gm} / \mathrm{cm}^{*} * 3$

den 3 - H2O density, $\mathrm{gm} / \mathrm{cm}^{* * 3}$

den 4 - dodecane density, $\mathrm{gm} / \mathrm{cm}^{*} * 3$

den 5 - tridecane density, $\mathrm{gm} / \mathrm{cm}^{* *} 3$

den 6 - tetradecane density, $\mathrm{gm} / \mathrm{cm}^{* * 3}$

c fvp-vapor pressure multiplier, 0.9 for worst case calculations, 1.0 for best estimate calculations

hcap - mixture heat capacity, cal/gm/C

c hcapl - TBP heat capacity, cal/gm/C

c heap23 - heat capacity for HNO3-H2O mixture, cal/gm/C

c hcap3 - H2O heat capacity, cal/gm/C

c hcap4 - dodecane heat capacity, cal/gm/C

c hcap5 - tridecane heat capacity, cal $/ \mathrm{gm} / \mathrm{C}$

c hcap6 - tetradecane heat capacity, cal/gm/C

$c$ tempa - absolute temperature, $k$

C Vpl - vapor pressure of TBP for the organic layer, atm

C Vp2 - vapor pressure of $\mathrm{HNO}$ 3 for the organic layer as it mixes with the hot gas, calculated as proportional to the TBP vapor pressure based on relative volume fractions in solution, atm

vp21 - vapor pressure of HNO3 used in the computation of the heat of reaction, calculated based on vapor-liquid equilibrium relationships between organic and aqueous phases, atm

vp3 - vapor pressure of H2O for the organic layer as it mixes with the hot gas, .calculated as proportional to the TBP vapor pressure based on relative volume fractions in solution, atm

vp31 - vapor pressure of H2O used in the computation of the heat of reaction, calculated based on vapor-liquid equilibrium relationships between organic and aqueous phases, atm

vp4 - vapor pressure of dodecane for the organic layer, atm

c vp5 - vapor pressure of tridecane for the organic layer. atm

c vp6 - vapor pressure of tetradecane for. the organic layer, atm

c vtot - total vapor pressure for the TBP layer, atm

c xmf2 - ratio of volume fraction HNO3 to volume fraction $\mathrm{H} 2 \mathrm{O}$ 
c xmf21 - volume fraction HNO3 in aqueous phase in equilibrium with TBP phase

c xmf22 - mole fraction HNO3 in aqueous phase in equilibrium with TBP phase

c $x \mathrm{mml}$ - partial mixture density of $\mathrm{TBP}, \mathrm{gm} / \mathrm{cm}^{* * 3}$

c xmm2 - partial mixture density of $\mathrm{HNO}, \mathrm{gm} / \mathrm{cm} * * 3$

c $x m m 3$ - partial mixture density of $\mathrm{H} 2 \mathrm{O}, \mathrm{gm} / \mathrm{cm}^{*} * 3$

c xmm4 - partial mixture density of dodecane, $\mathrm{gm} / \mathrm{cm} * * 3$

c xmm5 - partial mixture density of tridecane, $\mathrm{gm} / \mathrm{cm} * \star 3$

c xmm6 - partial mixture density of tetradecane, $\mathrm{gm} / \mathrm{cm} * \star 3$

c xmult - ratio of volume fractions of HNO3 and H2O to volume fractions of these

c components at saturation

c xmw23 - mass fraction of the mixture of HNO3 and H2O that is HNO3

subroutine prop (xm1, xm2, xm3, xm4, xm5, xm6, temp,

1den, hcap, vp1, vp $2, \mathrm{vp} 3, \mathrm{vp} 4, \mathrm{vp} 5, \mathrm{vp} 6, \mathrm{vp} 21, \mathrm{vp} 31$, den1, den2, den3,

2 den $4, \operatorname{den} 5$, den $6, v t o t, v w, h v 1, h v 2, h v 3, h v 4, h v 5, h v 6, x m u 1 t$, fvp, tcond)

implicit double precision $(a-h, o-z)$ tempa $=$ temp +273.15

c Calculate the densities of the TBP and aqueous layers from the densities of

$c$ pure TBP and nitric acid, assuming that there is no change of volume due to

$c$ mixing between the TBP and the nitric acid $i \div$ the TBP layer. The densities of

C TBP are from V. M. Pilyugin, V. P. Krasavin, E. E. Grinberg, and A. A.

C Efremov, "Physicochemical Properties of Specially Purified Tributyl

c Phosphate," Russ. J. Phys. Chem., 60(6), 926-927 (1986). The densities of

c nitric acid mixtures are from Perry's Chemical Engineers' Handbook, 6 th ed.,

c p. 3-81 and 82 .

den $1=0.99503-9.8344 \mathrm{e}-4 *$ temp

$\operatorname{den} 2=1.6603-1.9894 \mathrm{e}-3 *$ temp

den $3=0.99683-1.3010 e-4 *$ temp $-2.4358 e-6 *$ temp $* * 2$

$\operatorname{den} 4=0.748$

den $5=0.756$

den $6=0.763$

$\mathrm{xmm} 1=\mathrm{xm} 1 * \operatorname{den} 1$

$\mathrm{xmm} 2=\mathrm{xm} 2$ * den 2

$\mathrm{xmm} 3=\mathrm{xm} 3 * \operatorname{den} 3$

$\mathrm{xmm} 4=\mathrm{xm} 4$ *den 4

$\mathrm{xmm} 5=\mathrm{xm} 5 * \operatorname{den} 5$

$\mathrm{xmm} 6=\mathrm{xm} 6$ * den 6

den $=x m m 1+x m m 2+x m m 3+x m m 4+x m m 5+x m m 6$

c Calculate the heat capacities of the liquids in the TBP and aqueous layers.

c The heat capacity of TBP is from H. A. C. McKay and T: V. Healy, "Tri-n-Butyl

C Orthophosphate (TBP) as an Extracting Solvent," Appendix III in F. R. Bruce,

C J. M. Fletcher, and H. H. Hyman, Progress in Nuclear Energy, Series III:

C Process Chemistry, Vol. 2, Pergamon Press, New York (1958). The heat capacity

c of nitric acid mixtures is from Perry's Chemical Engineers' Handbook, 6th ed.,

c p. 3-145.

hcap $1=0.41$

xmw2 $3=x m 2 /(x m m 2+x m m 3)$

hcap $23=0.99897-0.80256 * x m w 23-2.3208 * x m w 23 * * 2+9.5504 * x m w 23 * * 3$

$1-10.903 * x m w 23 * * 4+3.9103 * x \operatorname{mw} 23 * * 5$

hcap $3=0.99897$

hcap $4=375.8 / 170 . / 4.184$

hcap $5=406.7 / 184 . / 4.184$

hсap $6=438.3 / 198 . / 4.184$

hcap $=(x \operatorname{mm} 1 *$ hcap $1+h \operatorname{cap} 23 *(x m m 2+x \operatorname{mm} 3)+x m m 4 * h c a p 4+x m m 5 * h c a p 5$

$1+\mathrm{xmm} 6$ *hcap 6$) /(\mathrm{xmm} 1+\mathrm{xmm} 2+\mathrm{xmm} 3+\mathrm{xmm} 4+\mathrm{xmm} 5+\mathrm{xmm} 6)$

c Calculate the vapor pressures of HNO3 and H2O for the TBP layer. First,

c relate the mole fraction of $\mathrm{HNO} 3$ and $\mathrm{H} 2 \mathrm{O}$ in the TBP. layer that is HNO3 to

$c$ its equilibrium mole fraction in the aqueous phase, using liquid phase

c solubility data at $25 \mathrm{C}$. (W. Davis, Jr., J. Mrochek, and C. J. Hardy, "The

c System: Tri-n-Butyl Phosphate (TBP)-Nitric Acid-Water-I: Activities of TBP

c in Equilibrium with Aqueous Nitric Acid and Partial Molar Volumes of the Three

c Components in the TBP Phase," J. Inorg. Nucl. Chem., 28, pp. 2001-2014, 1966.) $\mathrm{xmf} 2=\mathrm{xm} 2 / \mathrm{xm} 3$

$x \operatorname{mf} 21=0.065183 * x \mathrm{mf} 2-0.0068494 * x \operatorname{mf} 2 * * 2+0.00053995 * x \mathrm{mf} 2 * * 3$

$x \operatorname{mf} 22=\operatorname{xmf} 21 * \operatorname{den} 2 / 63 . /(\operatorname{xmf} 21 * \operatorname{den} 2 / 63 .+(1 .-x m f 21) * \operatorname{den} 3 / 18$.

c Calculate the vapor pressures of TBP, HNO3, H2O, and n-paraffin constituents for the

C TBP layer, using the equilibrium mole fractions in the aqueous phase. Vapor 
$c$ pressure equations for HNO3 and H2O are regression correlations of nitric acid vapor

c pressure data from Perry's. Chemical Engineers' Handbook, 6th ed., p. 3-70. Vapor

C pressure equations for n-paraffin constituents are from R. C. Reid, J. M. Prausnitz,

C and T. K. Sherwood, The Properties of gases and Liquids, 3rd ed., McGraw-Hill, New

c York (1977), pp. 629-665. Vapor pressure for TBP is from W. W. Schulz and J.

D.

C Navrati1, Science and Technology of Tributyl Phosphate, Volume 1: Synthesis, c Properties, Reactions, and Analysis, CRC Press, Inc., Boca Raton, Florida $(1984)$,

c p. 27.

c Calculate the vapor pressures at saturation.

$\operatorname{vp} 1=\exp (20.53-7735 . /$ tempa $) / 760$.

vp2 $=\exp (17.120-11.374 * x m f 22-(8774.0-9350.9 * x m f 22) /$ tempa $)$

$\operatorname{vp} 3=\exp (13.552+0.45359 * x \mathrm{xf} 22-4.1122 * x \mathrm{mf} 22 * \star 2$

$1-(5049.3+1009.6 * x m f 22) /$ tempa $)$

vp $4=\exp (16.1134-3774.56 /($ tempa -91.31$)) / 760$.

vp5 $=\exp (16.1355-3892.91 /($ tempa-98.93)) $/ 760$.

vp6 $=\exp (16.1480-4008.52 /($ tempa-105.4))/760.

c Apply a correction to account for the fact that the TBP may not be saturated

$c$ with nitric acid, assuming that the TBP phase behaves as an ideal solution.

if $(x \mathrm{mf} 22.1 \mathrm{t} .0 .001)$ then

$x m u l t=x m 3 /(x m 1+x m 2+x m 3) / 0.0663$

else

xf $2=63 .{ }^{*} x m f 22 / \operatorname{den} 2 /\left(63 .{ }^{*} \operatorname{xmf} 22 / \operatorname{den} 2+18 .{ }^{*}(1 .-\operatorname{xmf} 22) / \operatorname{den} 3\right)$

$x f s 2=1.0594^{*} x f 2-2.9022^{*} x f 2 * * 2+3.3389 * x f 2 * * 3$

$\mathrm{xmult}=\mathrm{xm} 2 /(\mathrm{xm} 1+\mathrm{xm} 2+\mathrm{xm} 3) / \mathrm{xfs} 2$

endif

xmult $2=1.0$

if (xmult.lt.xmult2) then

xmult $2=x m u l t$

endif

$\operatorname{vp} 21=f v p * v p 2 * x m u 1 t 2$

$v p 31=f v p * v p 3 * x \operatorname{mult} 2$

$\mathrm{vp} 1=\mathrm{Evp}{ }^{*} \mathrm{vp} 1 * \mathrm{xmm} 1 / 266 . /(\mathrm{xmm} 1 / 266 .+\mathrm{xmm} 4 / 170 .+\mathrm{xmm} 5 / 184 .+\mathrm{xmm} 6 / 198$.

vp4 $=\mathrm{fvp}^{*} \mathrm{vp} 4{ }^{*} \mathrm{xmm} 4 / 170 . /(\mathrm{xmm} 1 / 266 .+\mathrm{xmm} 4 / 170 .+\mathrm{xmm} 5 / 184 .+\mathrm{xmm} 6 / 198$. $)$

vp5 $=$ fvp *vp $5 * x m m 5 / 184 . /(x \operatorname{mm1} / 266 .+x m m 4 / 170 .+x m m 5 / 184 .+x m m 6 / 198$.

vp $6=f v p * v p 6 * x m m 6 / 198 . /(x m m 1 / 266 .+x m m 4 / 170 .+x m m 5 / 184+x m m 6 / 198$. $)$

C $\quad$ vp2 $2=\operatorname{vp} 1$

C $\quad \mathrm{vp} 3=\mathrm{vp} 1$

vtot $=v p 1+v p 2+v p 3+v p 4+v p 5+v p 6$

c Calculate heats of vaporization.

hv $1=15368$.

hv $2=7239$.

hv3 $=9705$.

hv $4=14647$.

hv $5=15830$.

hv $6=17010$.

denom $=x m m 1 / \operatorname{den} 1+x m m 2 / \operatorname{den} 2+x m m 3 / \operatorname{den} 3$

ph $1=x m n 1 / \operatorname{den} 1 /$ denom

ph $2=x m m 2 /$ den $2 /$ denom

ph3 $=x$ mm $3 /$ den $3 /$ denom

$\mathrm{ph} 4=\mathrm{xmm} 4 /$ den $4 /$ denom

ph $5=x m m 5 /$ den $5 /$ denom

ph $6=x m m 6 /$ den $6 /$ denom

tc $1=60 . * 4.3 e-4 *(1124 .-$ tempa $) / 1010$.

tc2 $=60 . * 2.58 \mathrm{e}-4 *(900$. -tempa $) / 374$.

tc $3=60 . * 0.002389 *(0.55918+2.1622 e-3 *$ temp $-9.64 e-6 *$ temp $* * 2)$

$\operatorname{tc} 4=\operatorname{tc} 1$

tc $5=\operatorname{tc} 1$

tc $6=\operatorname{tc} 1$

tcond $=\mathrm{ph} 1 * * 2 * \operatorname{tc} 1+\mathrm{ph} 2 * * 2 * \operatorname{tc} 2+\mathrm{ph} 3 * * 2 * \operatorname{tc} 3+\mathrm{ph} 4 * * 2 * \operatorname{tc} 4+\mathrm{ph} 5 * * 2 * \operatorname{tc} 5$

$1+\mathrm{ph} 6 * * 2 * \operatorname{tc} 6$

$1+4 \cdot{ }^{*} \mathrm{ph} 1 * \mathrm{ph} 2{ }^{*} \operatorname{tc} 1 * \operatorname{tc} 2 /(\operatorname{tc} 1+\operatorname{tc} 2)+4 .{ }^{*} \mathrm{ph} 1{ }^{*} \mathrm{ph} 3 * \operatorname{tc} 1 * \operatorname{tc} 3 /(\operatorname{tc} 1+\operatorname{tc} 3)$ 
Revision 1

$2+4 .{ }^{*} \mathrm{ph} 2 * \mathrm{ph} 3 * \operatorname{tc} 2 * t c 3 /(\operatorname{tc} 2+\operatorname{tc} 3)+4 .{ }^{*} \mathrm{ph} 1 * \mathrm{ph} 4 * \operatorname{tc} 1 * t c 4 /(\operatorname{tc} 1+\operatorname{tc} 4)$

$3+4 .{ }^{*} \mathrm{ph} 1 * \mathrm{ph} 5 * \operatorname{tc} 1 * \operatorname{tc} 5 /(\operatorname{tc} 1+\mathrm{tc} 5)+4 .{ }^{*} \mathrm{ph} 1 * \mathrm{ph} 6 * \operatorname{tc} 1 * \operatorname{tc} 6 /(\mathrm{tc} 1+\mathrm{tc} 6)$

$4+4 .{ }^{*} \mathrm{ph} 2 * \mathrm{ph} 4 * \operatorname{tc} 2 * \operatorname{tc} 4 /(\operatorname{tc} 2+\operatorname{tc} 4)+4 .{ }^{*} \mathrm{ph} 2 * \mathrm{ph} 5 * \operatorname{tc} 2 * \operatorname{tc} 5 /(\operatorname{tc} 2+\operatorname{tc} 5)$

$5+4 .{ }^{*} \mathrm{ph} 2 * \mathrm{ph} 6 * \operatorname{tc} 2 * \operatorname{tc} 6 /(\operatorname{tc} 2+\operatorname{tc} 6)+4 .{ }^{*} \mathrm{ph} 3 * \mathrm{ph} 4 * \operatorname{tc} 3 * \operatorname{tc} 4 /(\operatorname{tc} 3+\mathrm{tc} 4)$

$6+4 .{ }^{*} \mathrm{ph} 3 * \mathrm{ph} 5 * \operatorname{tc} 3 * \operatorname{tc} 5 /(\operatorname{tc} 3+\operatorname{tc} 5)+4 .{ }^{*} \mathrm{ph} 3 * \mathrm{ph} 6 * \operatorname{tc} 3 * \operatorname{tc} 6 /(\operatorname{tc} 3+\operatorname{tc} 6)$

$7+4 .{ }^{*} \mathrm{ph} 4{ }^{*} \mathrm{ph} 5 * \operatorname{tc} 4 * \operatorname{tc} 5 /(\operatorname{tc} 4+\operatorname{tc} 5)+4 .{ }^{*} \mathrm{ph} 4 * \mathrm{ph} 6 * \operatorname{tc} 4 * \operatorname{tc} 6 /(\operatorname{tc} 4+\operatorname{tc} 6)$

$8+4{ }^{*} \mathrm{ph} 5 * \mathrm{ph} 6 * \operatorname{tc} 5 * \operatorname{tc} 6 /(\operatorname{tc} 5+\operatorname{tc} 6)$

return

end 


\section{Appendix G: Computer Code Listing for Test Benchmarking Calculations}

This appendix contains a listing for the computer code that was used to benchmark the bench scale heat transfer tests described in Appendix B.

The code is written in VAX Fortran and was run on the SRS VAX computer. It is stored in VAX directory [t6930] as stmbe.for.

\section{Source Code Listing}

c This program computes temperature and concentration transients for heating of $c$ an organic layer containing TBP by steam condensate. The program solves heat $C$ and mass balances using a finite difference method. The heat and mass

c balances include source terms for the TBP-nitric acid decomposition reaction, $c$ and the heat balance includes a term for heat transfer with the surroundings.

c The program reads input parameters from an input file and writes output to

c several output files. A definition of terms follows.

Definition of terms

c dn - mixture density, gm/ cm**3

dn1 - TBP density, $\mathrm{gm} / \mathrm{cm}^{*} * 3$

c an2 - HNO3 density, $\mathrm{gm} / \mathrm{cm}^{* * 3}$

c dn3 - H2O density, $\mathrm{gm} / \mathrm{cm}^{*} * 3$

c $d t$ - time step increment, min

eff - for test simulations, fraction of organic vapor that leaves the vessel (does not recondense in the vent line)

Erat - hot gas flow rate, scfm

hc - mixture heat capacity, cal/gm/C

hop1 - TBP heat capacity, cal/gm/C

hcp23 - combined heat capacity of $\mathrm{HNO} 3$ and $\mathrm{H} 2 \mathrm{O}$, cal/gm/C

hnc - heat transfer coefficient at the top surface of the TBP layer, $\mathrm{cal} / \mathrm{cm} * 2 / \mathrm{min} / \mathrm{C}$

iind - one indicates calculation includes heat of reaction and component generation by reaction, zero indicated calculation omits these terms

ind2 - one indicates that the time will automatically be incremented at each time step for simulation of heating of organic layer in solvent storage tank, two indicates that times will be read from input file to simulate experiment

itme - one indicates that the temperature for the thermocouple originally in the organic layer is read from the data file, two indicates that the temperature for the thermocouple originally at the organic/aqueous interface is read from the data file

jmax - number of time steps in calculation

qg - gas flow rate, cc/min

rhocpg - hot gas volumetric heat capacity, cal/cc/C

rhoml - hot gas molar density, gmole/cc

rr1 - right-hand side for finite difference formulation of TBP mass balance, containing rates of consumption of TBP by reaction and of loss of TBP by evaporation

rr2 - right-hand side for finite difference formulation of HNO3 mass balance, containing rates of consumption of HNO3 by reaction and of loss of HNO3 by evaporation

rr3 - right-hand side for finite difference formulation of H2O mass balance, containing rates of consumption of $\mathrm{H} 2 \mathrm{O}$ by reaction and of loss of $\mathrm{H} 2 \mathrm{O}$ by evaporation

rr4 - right-hand side for finite difference formulation of dodecane mass balance, containing rates of consumption of dodecane by reaction and of loss of dodecane by evaporation

rr5 - right-hand side for finite difference formulation of tridecane mass balance, containing rates of consumption of tridecane by reaction and of loss of tridecane by evaporation 
c rr6 - right-hand side for finite difference formulation of tetradecane mass c balance, containing rates of consumption of tetradecane by reaction and c of loss of tetradecane by evaporation

c rr7 - right-hand side for finite difference formulation of heat balance, containing rate of temperature increases due to heat of reaction, of temperature decreases due to evaporation, and temperature changes due to heat transfer from the gas to the organic layer and from the organic layer to the ambient air, C

sumx - sum of component volume fractions in organic layer, used in normalization of these volume fractions at each time step

$t$ - elapsed time, min

tamb - ambient air temperature, $C$

$c$ tend - ending time for flow of hot gas to test vessel, min

$c$ tmass - thermal mass of walls of vessel or tank in contact with organic layer or vapor space above organic layer, cal/C

tme - measured organic layer temperature, taken as the temperature measurement $2 / 3$ of the distance from the surface to the interface, $C$

tstart - starting time for simulation of test transient, min

t1 - temperature, $C$

t10 - temperature at previous time step, $C$

vs - organic layer volume, cc

c vso - final organic layex volume, cc

$c$ vt - total vapor pressure of HNO3 and H2O in TBP layer, atm

c vw - steam pressure, atm

c V1 - vapor pressure of TBP for the organic layer, atm

c v2 - vapor pressure of HNO3 for the organic layer as it mixes with the hot gas, calculated as proportional to the TBP vapor pressure based on relative volume fractions in solution, atm

v21 - vapor pressure of HNO3 used in the computation of the heat of reaction, calculated based on vapor-liquid equilibrium relationships between organic and aqueous phases, atm

v3 - vapor pressure of H2O for the organic layer as it mixes with the hot gas, calculated as proportional to the TBP vapor pressure based on relative volume fractions in solution, atm

v31 - vapor pressure of H2O used in the computation of the heat of reaction, calculated based on vapor-liquid equilibrium relationships between organic and aqueous phases, atr

v4 - vapor pressure of dodecane for the organic layer, atm

c v5 - vapor pressure of tridecane for the organic layer, atm

c v6 - vapor pressure of tetradecane for the organic layer, atm

c xf2 - volume fraction HNO3 in the aqueous phase when that phase is in

c equilibrium with the TBP phase layer, used for the calculation of vapor pressures in the TBP layer

c xfs2 - volume fraction HNO3 in the TBP phase when that phase is saturated with nitric acid at the equilibrium concentration, used for the calculation of vapor pressures in the TBP layer

c xmult - ratio of volume fractions of HNO3 and H2O to volume fractions of these components at saturation

c $\mathrm{x} 1$ - volume fraction TBP

c $x 1 \max$ - initial, maximum, TBP volume fraction, used to calculate the rate

c of consumption of TBP by reaction

c $\times 10$ - volume fraction TBP at previous time step

c $x 2$ - volume fraction HNO3

c $\times 20$ - volume fraction HNO3 at previous time step

c $x 3$ - volume fraction H2O

c $\times 30$ - volume fraction H2O at previous time step

c $\times 4$ - volume fraction dodecane

c $x 40$ - volume fraction dodecane at previous time step

C $\times 5$ - volume fraction tridecane

c $x 50$ - volume fraction tridecane at previous time step

c $\times 6$ - volume fraction tetradecane

c $x 60$ - volume fraction tetradecane at previous time step

$\mathrm{c}$

C Assign an external subroutine prop to calculate solution properties. external prop character tab /9/

c set the initial time to zero. 
$t=0$.

$c$ Read input variables.

read $\left(5,{ }^{*}\right)$ dt

read $(5, *) j \max$

read $(5, *) \times 10, x 20, x 30, x 40, x 50, x 60$

read $(5, *)$ t 10

read $(5, *)$ gg

read $(5, *)$ tin

read $(5, *)$ vs

read $(5, *)$ vso

read $(5, *)$ eff

read $(5, *)$ hnc

read $(5, *)$ tamb

read $(5, *)$ tmass

read $(5, *)$ iind

read $(5, *)$ ind2

read $(5, *)$ itme

read $(5, *)$ tstart

read $(5, *)$ tend

c If this program is to benchmark existing tabulated data (ind2=2) read data

c from an input log file (file \#4) until the time in minutes equals tstart.

c Backspace this file one line to begin with $t=t s t a r t$. if (ind2:eq. 2) then

$i=1$

do while (i.le.7)

read $(4, *)$

$i=i+1$

enddo

$t=-2$.

do while (t.1t.tstart)

read $(4, *) \mathrm{d} 1, \mathrm{~d} 2, \mathrm{~d} 3, \mathrm{~d} 4, \mathrm{~d} 5, \mathrm{~d} 6, \mathrm{~d} 7, \mathrm{~d} 8, \mathrm{~d} 9, \mathrm{~d} 10, \mathrm{~d} 11$, frat,

enddo

backspace 4

endif

$v w=1$.

$c$ Write initial temperatures to an output file.

write $\left(6,{ }^{*}\right)$ 'Time $(\mathrm{m})$ ', tab, 'xTBP', tab, 'xHNO3', tab,

1 'xH2O', tab, 'xC12', tab, 'xC13', tab, 'xC14', tab, 'T (C)', tab,

2 'Vol (cc)'

write $(6,102) t, t a b, x 10, t a b, x 20, t a b, x 30, t a b, x 40, t a b, x 50$,

1 tab, x6o, tab, t1o, tab, vs

if (ind2,eq.2) then

write $(7, *)$ 'Time (m)', tab, 'Tmeas (C)', tab, 'Tcalc (C)'

endif

c Solve the finite difference heat and mass balances for temperatures and

c concentrations by marching with respect to time.

vsmin $=0.001^{\star}$ vs

$x 1 \max =x 10$

$j=0$

do while (j.le.jmax.and.vs.gt.vsmin)

$c$ Increment the time. If a simulation of a test is being run (ind2 $=2$ ), read

c input data from test log file (\#4).

if (ind2.eq. 1) then

$t=t+d t$

else

tst $=t$

c If the indicator itme $=1$, read the lower organic layer temperature from the

c data file for comparison with the model calculations. This corresponds to

$c$ tests in which this thermocouple was located in the organic layer. Otherwise,

$c$ read the organic/aqueous interface temperature from the data file to compare

$c$ with the model calculations. This is done when sufficient solution had

$c$ evaporated or been entrained so that the liquid level was below the location

$c$ of the lower organic thermocouple and the thermocouple originally at the

$c$ interface was in the organic layer.

if (itme.eq.1) then

read $\left(4,{ }^{*}\right) \mathrm{d} 1, \mathrm{~d} 2, \mathrm{tin}, \mathrm{d} 4, \mathrm{~d} 5, \mathrm{~d} 6, \mathrm{~d} 7, \mathrm{tme}, \mathrm{d} 8, \mathrm{~d} 9$, tamb, frat, $t$

else 
read $(4, *) d 1, d 2, t i n, d 4, d 5, d 6, d 7, d 8$, tme, d9, tamb, frat, $t$

endif

$d t=t-t s t$

$q g=$ frat $* 30,48 * * 3$

indt $=0$

if (t.gt.tend) then

$q g=0$.

ind $=1$

endif

if $(j$. eq. 0$)$ then

tIo $=$ tme

endif

endif

c Call Subroutine Prop to update solution densities, heat capacities, vapor

c pressures, and thermal conductivities. call prop $(x 10, x 20, x 30, x 40, x 50, x 60, t 10$, an, hc,

$1 v 1, v 2, v 3, v 4, v 5, v 6, v 21, v 31, d n 1, \operatorname{dn} 2, \operatorname{dn} 3, \operatorname{dn} 4, \operatorname{dn} 5, a_{n} 6$,

$3 v t, v w, h v 1, h v 2, h v 3, h v 4, h v 5, h v 6, x m u l t)$

rhoml $=\mathrm{vw} / 82.05 /(t 10+273.15)$

c Two options are available: a calculation that includes the effects of the

C TBP-nitric acid decomposition reaction (iind equals 1) and a calculation that

$c$ omits these effects and instead includes only the mass and heat transfer due

$c$ to the flow of condensate droplets through the TBP and aqueous layers (iind

c not equal to 1 ).

c If the calculation is to include the effects of the TBP-nitric reaction,

c compute changes in composition and temperature due to this reaction in the TBP

c layer. These computations use a reaction model based on measurements by

C J. R. Smith and W. S. Cavin, "Isothermal Heat Measurements of TBP-Nitric Acid

c Solutions (U), "WSRC-TR-94-0540, December. 16, 1994. if (iind.eq.1) then

c Calculate the Arrhenius-type temperature factor for the rate of reaction. fac $=2.43 * *(-(110 .-t 10) / 10$. rhoml $=\mathrm{vw} / 82.05 /(288.7)$

rhocpg $=$ rhoml $*(29 . * 0.25 * 0.2+18 . * 0.45 * 0.8)$

C Calculate the change in the TBP volume fraction. $\operatorname{rr} 1=-d t * x 20 * 13: 3 e-4 * \mathrm{fac}^{\star} 266 . / 63 . * \operatorname{dn} 2 / \mathrm{dn} 1 * \times 10$ $1 /(x 1 \max +x 40+x 50+x 6 o) / 3$.

c Calculate the change in the HNO3 volume fraction. This is assumed to be zero

$c$ because of replenishment of HNO3 due to mixing with the aqueous phase. $r \mathrm{r} 2=0$.

c Calculate the change in the $\mathrm{H} 2 \mathrm{O}$ volume fraction. This is assumed to be zero

$c$ because of replenishment of $\mathrm{H} 2 \mathrm{O}$ due to mixing with the aqueous phase. $r \times 3=0$.

c Calculate the change in the temperature. rr $7=d t * 7.0 e-4 * x 20 *\left(46.774-\left(h v 3 / 1000 . * v 31+h v 2 / 1000 .{ }^{*} v 21\right)\right.$

$2 / \mathrm{abs}(\mathrm{vw}-\mathrm{v} 1-\mathrm{v} 21-\mathrm{v} 31-\mathrm{v} 4-\mathrm{v} 5-\mathrm{v} 6)) * \times 10 /(\mathrm{x} 1 \max +\mathrm{x} 40+\mathrm{x} 50+\mathrm{x} 60)$

$3 *$ fac*dn $2 / 0.063 / \mathrm{hc} / \mathrm{dn}$ else

c Calculation the changes in volume fractions and temperature if no reaction is $c$ involved.

rhocpg=rhom $1 * 0.25 * 28$.

$\operatorname{rr} 1=0$.

$\operatorname{rr} 2=0$.

$\operatorname{rr} 3=0$.

$\operatorname{rr} 7=0$.

endif

c Calculate the change in the TBP volume fraction due to mixing with the hot

c gas.

$\operatorname{rr} 1 i=-d t * r h o m 1 * g g * v 1 / a b s(v w-v 1-v 2-v 3-v 4-v 5-v 6)$

$1 * 266 . / \mathrm{dn} 1 / \mathrm{vs}$

$\operatorname{rr} 1=\operatorname{rr} 1+\operatorname{rr} 1 i$

c Calculate the change in the HNO3 volume fraction due to mixing with the hot

c gas. Assume that this change is proportional to that of the TBP. This

$c$ assumption is valid either if the organic and aqueous layers are well-mixed,

$c$ so that the HNO3 volume fraction is limited by its solubility in TBP, or if

c the TBP and HNO3 are chemically bound so that HNO3 cannot be preferentially

c stripped from solution. 
$\operatorname{rr} 2=\operatorname{rr} 2+x 20 / x 10 * \operatorname{rr} 1 i$

$c$ Calculate the change in the H2O volume fraction due to mixing with the hot

c gas. Assume that this change is proportional to that of the TBP. This

$c$ assumption is valid either if the organic and aqueous layers are well-mixed,

$C$ so that the H2O volume fraction is limited by its solubility in TBP, or if

$c$ the TBP and H2O are chemically bound so that HNO3 cannot be preferentially

$C$ stripped from solution. $r \times 3=r r 3+\times 30 / \times 10^{*} \operatorname{rr} 1 i$

$c$ Calculate the change in the dodecane volume fraction due to mixing with the

c hot gas.

$\operatorname{rr} 4=-d t * r h o m l * q g * v 4 / a b s(v w-v 1-v 2-v 3-v 4-v 5-v 6)$

$1 * 170 . / \mathrm{dn} 4 / \mathrm{vs}$

C Calculate the change in the tridecane volume fraction due to mixing with the

$c$ hot gas.

$\mathrm{rr} 5=-d t * \mathrm{rhom} 1 * \mathrm{qg} * \mathrm{v} 5 / \mathrm{abs}(\mathrm{vw}-\mathrm{v} 1-\mathrm{v} 2-\mathrm{v} 3-\mathrm{v} 4-\mathrm{v} 5-\mathrm{v} 6)$

$1 * 184 . / \operatorname{dn} 5 / \mathrm{vs}$

$c$ Calculate the change in the tetradecane volume fraction due to mixing with the

$c$ hot gas.

$r r 6=-d t^{*} r h o m 1 * q g * v 6 / a b s(v w-v 1-v 2-v 3-v 4-v 5-v 6)$

$1 * 198 . /$ dn $6 /$ vs

$c$ Calculate the change in the temperature due to mixing with hot gas. This

c calculation includes terms for cooling by evaporation, sensible heat transfer

$c$ from the gas to the organic layer, and heat losses to the ambient air. Heat

$c$ transfer to the underlying aqueous layer is assumed to be negligible.

$r r 7=r r 7+d t *\left(-r h o m l * \mathrm{qg}^{*}(\mathrm{hv} 1 * \mathrm{v} 1+\mathrm{hv} 2 * \mathrm{v} 2+\mathrm{hv} 3 * \mathrm{v} 3\right.$

$1+\mathrm{hv} 4 * \mathrm{v} 4+\mathrm{hv} 5 * \mathrm{v} 5+\mathrm{hv} 6 * \mathrm{v} 6) /(\mathrm{vw}-\mathrm{v} 1-\mathrm{v} 2-\mathrm{v} 3-\mathrm{v} 4-\mathrm{v} 5-\mathrm{v} 6)$

$2+$ rhocpg* $q g *(t i n-t 10)+h n c *(t a m b-t 10) *(d n * h c * v s o+t m a s s))$

$3 /\left(d n * h c^{*} v s+t m a s s\right)$

c Update the volume Eractions of the organic layer components and the organic

c layer temperature.

$\mathrm{x} 1=\mathrm{x} 10+\mathrm{rr} 1$ *eff

$\mathrm{x} 2=\mathrm{x} 2 \mathrm{o}+\mathrm{rr} 2 * \mathrm{eff}$

$\mathrm{x} 3=\mathrm{x} 30+\mathrm{rr} 33^{*}$ eff

$\mathrm{x} 4=\mathrm{x} 40+\mathrm{rr} 4$ * eff

$\mathrm{x} 5=\mathrm{x} 50+\mathrm{rr} 5 * \mathrm{eff}$

$\mathrm{x} 6=\mathrm{x} 60+\mathrm{rr} 6 *$ eff

$t 1=t 10+\operatorname{rr} 7$

c If the HNO3 and H2O volume Eractions exceed saturation (xmult.gt.1) apply

$c$ a correction to reduce these concentrations to saturation level.

if (xmult.gt.1.) then

$\mathrm{x} 2=\mathrm{x} 2 / \mathrm{xmult}$

$\mathrm{x} 3=\mathrm{x} 3 / \mathrm{xmult}$

endif

$c$ Calculate the change in the organic layer volume. $\mathrm{vs}=\mathrm{vs} *(1 .-\mathrm{x} 10-\mathrm{x} 20-\mathrm{x} 30-\mathrm{x} 40-\mathrm{x} 50-\mathrm{x} 60+\mathrm{x} 1+\mathrm{x} 2+\mathrm{x} 3+\mathrm{x} 4+\mathrm{x} 5+\mathrm{x} 6)$

$c$ Normalize the updated component volume fractions. sum $x=x 1+x 2+x 3+x 4+x 5+x 6$

$\mathrm{x} 10=\mathrm{x} I /$ sumx

$\mathrm{x} 20=\mathrm{x} 2 / \operatorname{sum} \mathrm{x}$

$\mathrm{x} 30=\mathrm{x} 3 / \operatorname{sum} \mathrm{x}$

$x 40=x 4 /$ sumx

$x 50=x 5 /$ sum $x$

$\mathrm{x} 60=\mathrm{x} 6 / \mathrm{sumx}$

$t 10=t 1$

$c$ Write results to output files.

write $(5,102) t, t a b, x 10, t a b, x 20, t a b, x 30, t a b, x 40, t a b, x 50$,

1 tab, $\times 60$, tab, t10, tab, vs

102 format ( $f 9.3,6(a 1, f 8.4), a 1, f 10.2, a 1, f 9.0)$

if (ind2.eq.2) then

write $(7,103) t, t a b, t m e, t a b, t 10$

103 format (f9.4.2(a1,f10.2))

endif

$j=j+1$

enddo

stop

end

c Subroutine Prop calculates densities, heat capacities, and vapor pressures, 
c based on the composition of those layers and the temperature. This

c subroutine uses regression correlations of data referenced in the program

c listing comments. Cricket Graph computer software was used to perform the

c data regressions. A definition of terms used in this subroutine follows.

c Definition of terms

c den - mixture density, $\mathrm{gm} / \mathrm{cm}^{*} * 3$

c den1 - TBP density, $\mathrm{gm} / \mathrm{cm}^{* * 3}$

c den2 - HNO3 density, $\mathrm{gm} / \mathrm{cm} * * 3$

c den 3 - H2O density, gm/ $\mathrm{cm}^{* *} 3$

c den4 - dodecane density, $\mathrm{gm} / \mathrm{cm}^{* * 3}$

$c$ den5 - tridecane density, $\mathrm{gm} / \mathrm{cm}^{\star *} 3$

c den 6 - tetradecane density, gm/ $\mathrm{cm}^{* * 3}$

c hcap - mixture heat capacity, cal/gm/C

C hcap1 - TBP heat capacity, cal/gm/C

c hcap23 - heat capacity for HNO3-H2O mixture, cal/gm/C

c hcap3 - H2O heat capacity, cal/gm/C

c hcap4 - dodecane heat capacity, cal/gm/C

c hcap5 - tridecane heat capacity, cal/gm/C

c hcap6 - tetradecane heat capacity, cal/gm/C

c tempa - absolute temperature, $\mathrm{K}$

C VpI - vapor pressure of TBP for the organic layer, atm

c $\mathrm{vp} 2$ - vapor pressure of HNO3 for the organic layer as it mixes with the hot

c gas, calculated as proportional to the TBP vapor pressure based on

C relative volume fractions in solution, atm

c vp21 - vapor pressure of HNO3 used in the computation of the heat of reaction,

c. calculated based on vapor-liquid equilibrium relationships between

c organic and aqueous phases, atm

C vp3 - vapor pressure of H2O for the organic layer as it mixes with the hot

c gas, calculated as proportional to the TBP vapor pressure based on

C relative volume fractions in solution, atm

c vp31 - vapor pressure of H2O used in the computation of the heat of reaction,

c calculated based on vapor-liquid equilibrium relationships between

$\mathrm{C} \quad$ organic and aqueous phases, atm

C vp4 - vapor pressure of dodecane for the organic layer, atm

c vp5 - vapor pressure of tridecane for the organic layer, atm

c vp6 - vapor pressure of tetradecane for the organic layer, atm

c vtot - total vapor pressure for the TBP layer, atm

c xmf2 - ratio of volume fraction HNO3 to volume fraction $\mathrm{H} 2 \mathrm{O}$

c xmf21 - volume fraction HNO3 in aqueous phase in equilibrium with rBp phase

c Xmf22 - mole fraction HNO3 in aqueous phase in equilibrium with TBP phase

c xmml - partial mixture density of TBP, $\mathrm{gm} / \mathrm{cm}^{* *} 3$

c $x \mathrm{~mm} 2$ - partial mixture density of $\mathrm{HNO} 3, \mathrm{gm} / \mathrm{cm}^{* *} 3$

c $x \mathrm{~mm} 3$ - partial mixture density of $\mathrm{H} 20, \mathrm{gm} / \mathrm{cm}^{* * 3}$

c xmm4 - partial mixture density of dodecane, $\mathrm{gm} / \mathrm{cm}^{* * 3}$

c xmm5 - partial mixture density of tridecane, $\mathrm{gm} / \mathrm{cm}^{* *} 3$

c xmm6 - partial mixture density of tetradecane, $\mathrm{gm} / \mathrm{cm}^{* * 3}$

c xmult -

C xmw23 - mass fraction of the mixture of HNO3 and H2O that is HNO3 subroutine prop $(\mathrm{xm} 1, \mathrm{xm} 2, \mathrm{xm} 3, \mathrm{xm} 4, \mathrm{xm} 5, \mathrm{xm} 6$, temp,

1 den, hcap, vp1, vp $2, \operatorname{vp} 3, \operatorname{vp} 4, \operatorname{vp} 5, \operatorname{vp} 6, \operatorname{vp} 21, \operatorname{vp} 31, \operatorname{den} 1, \operatorname{den} 2, \operatorname{den} 3$,

2 den4, den5, den6, vtot, vw, hv1, hv2, hv3, hv4, hv5, hv6, xmult) tempa $=$ temp +273.15

C Calculate the densities of the TBP and aqueous layers from the densities of

$c$ pure TBP and nitric acid, assuming that there is no change of volume due to

$C$ mixing between the TBP and the nitric acid $i \div$ the TBP layer. The densities of

C TBP are from V. M. Pilyugin, V. P. Krasavin, E. E. Grinberg, and A. A.

C Efremov, "Physicochemical Properties of Specially Purified Tributyl

c Phosphate," Russ. J. Phys. Chem., 60(6), 926-927 (1986). The densities of

c nitric acid mixtures are from Perry's Chemical Engineers' Handbook, 6th ed.,

c p. 3-81 and 82 .

den $1=0.99503-9.8344 e-4 *$ temp

den $2=1.6603-1.9894 \mathrm{e}-3 *$ temp

den $3=0.99683-1.3010 e-4 *$ termp $-2.4358 e-6 *$ temp $* * 2$

$\operatorname{den} 4=0.748$

den $5=0.756$

den $6=0.763$ 
$\mathrm{xmm} 1=\mathrm{xm} 1$ * den 1

$\mathrm{xmm} 2=\mathrm{xm} 2 * \operatorname{den} 2$

$x \mathrm{~mm} 3=x \mathrm{~m} 3$ * $\operatorname{den} 3$

$\mathrm{xmm} 4=\mathrm{xm} 4$ * den 4

$\mathrm{xmm} 5=\mathrm{xm} 5$ * den 5

$\mathrm{xmm} 6=\mathrm{xm} 6$ * den 6

den $=x m m 1+x m m 2+x m m 3+x m m 4+x m m 5+x m m 6$

c Calculate the heat capacities of the liquids in the TBP and aqueous layers.

C The heat capacity of TBP is from H. A. C. McKay and T. V. Healy, "Tri-n-Butyl

C Orthophosphate (TBP) as an Extracting Solvent," Appendix III in F. R. Bruce,

C J. M. Fletcher, and H. H. Hyman, Progress in Nuclear Energy, Series III:

C Process Chemistry, Vol. 2, Pergamon Press, New York (1958). The heat capacity

$c$ of nitric acid mixtures is from Perry's Chemical Engineers' Handbook, 6th ed.,

c p. 3-145.

hcap $1=0.41$

$x \mathrm{xw} 23=\mathrm{xmm2} /(\mathrm{xmm2}+\mathrm{xmm} 3)$

hcap $23=0.99897-0.80256 * x m w 23-2.3208 * x m w 23 * * 2+9.5504 * x m w 23 * * 3$

$1-10.903 * x \operatorname{mw} 23 * * 4+3.9103 * x m w 23 * * 5$

hcap $3=0.99897$

hcap $4=375.8 / 170 . / 4.184$

hcap $5=406.7 / 184 . / 4.184$

hcap $6=438.3 / 198 . / 4.184$

hcap $=(x \operatorname{mm} 1 *$ hcap $1+$ hcap $23 *(x m m 2+x m m 3)+x m m 4 *$ hcap $4+x m m 5 *$ hcap 5

$1+\mathrm{xmm} 6$ * hcap 6$) /(\mathrm{xmm} 1+\mathrm{xmm} 2+\mathrm{xmm} 3+\mathrm{xmm} 4+\mathrm{xmm} 5+\mathrm{xmm} 6)$

c Calculate the vapor pressures of HNO3 and H2O for the TBP layer. First,

C relate the mole fraction of HNO3 and $\mathrm{H} 2 \mathrm{O}$ in the TBP layer that is HNO3 to

$c$ its equilibrium mole fraction in the aqueous phase, using liquid phase

c solubility data at $25 \mathrm{C}$. (W. Davis, Jr., J. Mrochek, and C. J. Hardy; "The

c System: Tri-n-Butyl Phosphate (TBP)-Nitric Acid-Water-I: Activities of TBP

$c$ in Equilibrium with Aqueous Nitric Acid and Partial Molar Volumes of the Three

C Components in the TBP Phase," J. Inorg. Nucl. Chem., 28, pp. 2001-2014, 1966.) $\operatorname{xmf} 2=x \mathrm{~m} 2 / \mathrm{xm} 3$

$x m f 21=0.065183 * x m f 2-0.0068494 * x m f 2 * 2+0.00053995 * x m f 2 * * 3$

$\operatorname{xmf} 22=x \operatorname{mf} 21^{*} \operatorname{den} 2 / 63 . /(\operatorname{xmf} 21 * \operatorname{den} 2 / 63 .+(1 .-\operatorname{xmf} 21) * \operatorname{den} 3 / 18$.

c Calculate the vapor pressures of TBP, HNO3, H2O, and n-paraffin constituents for the

C TBP layer, using the equilibrium mole fractions in the aqueous phase. Vapor

C pressure equations for $\mathrm{HNO} 3$ and $\mathrm{H} 2 \mathrm{O}$ are regression correlations of nitric acid

vapor

c pressure data from Perry's Chemical Engineers' Handbook, 6th ed., p. 3-70.

Vapor

$C$ pressure equations for $n$-paraffin constituents are from $R$. C. Reid, J. M.

Prausnitz,

C and T. K. Sherwood, The Properties of gases and Liquids, 3rd ed., McGraw-Hil1, New

C York (1977), pp. 629-665. Vapor pressure for TBP is from W. W. Schulz and J. D.

C Navratil, Science and Technology of Tributyl Phosphate, Volume 1: Synthesis,

C Properties, Reactions, and Analysis, CRC Press, Inc., Boca Raton, Florida

(1984).

c p. 27.

c Calculate the vapor pressures at saturation.

$\operatorname{vpl}=\exp (20.53-7735$. / tempa $) / 760$.

$\operatorname{vp} 2=\exp \left(17.120-11.374^{\star} \operatorname{xmf} 22-\left(8774.0-9350.9^{*} \operatorname{xmf} 22\right) /\right.$ tempa $)$

vp $3=\exp (13.552+0.45359 * x \operatorname{xnf} 22-4.1122 * x m f 22 * * 2$

$1-(5049.3+1009.6 * x \operatorname{mf} 22) /$ tempa $)$

vp4 $=\exp (16.1134-3774.56 /($ tempa -91.31$)) / 760$.

$\operatorname{vp} 5=\exp (16.1355-3892.91 /($ tempa-98.93) $) / 760$

vp6 $=\exp (16.1480-4008.52 /($ tempa-105.4) $) / 760$.

c Apply a correction to account for the fact that the TBP may not be saturated

$c$ with nitric acid, assuming that the TBP phase behaves as an ideal solution.

if $(x \mathrm{mf} 22.1 \mathrm{t} .0 .001)$ then

$x m u 1 t=x m 3 /(x m 1+x m 2+x m 3) / 0.0663$

else

$\mathrm{xf2}=63 .{ }^{*} \mathrm{xmf} 22 / \operatorname{den} 2 /\left(63 .{ }^{*} \mathrm{xmf} 22 / \operatorname{den} 2+18 . *(1 .-\mathrm{xmf} 22) / \operatorname{den} 3\right)$

$x$ fs $2=1.0594 * x f 2-2.9022 * x f 2 * * 2+3.3389 * x f 2 * * 3$

$x m u 1 t=x m 2 /(x m 1+x m 2+x m 3) / x f s 2$ 
WSRC-TR-98-00171

Revision 1

endif

xmult $2=1.0$

if (xmult.It.xmult2) then

$x m u l t 2=x m u l t$

endif

$\operatorname{vp} 21=v p 2 * x m u l t 2$

$\operatorname{vp} 31=\mathrm{vp} 3 * x \mathrm{xmult} 2$

vp1 $=v p 1 * x m m 1 / 266 . /(x m m 1 / 266 .+x m m 4 / 170 .+x m m 5 / 184 .+x m m 6 / 198$. $)$

$\mathrm{vp} 4=\mathrm{vp} 4 * \mathrm{xmm} 4 / 170 . /(\mathrm{xmm} 1 / 266 .+\mathrm{xmm} 4 / 170 .+\mathrm{xmm} 5 / 184 .+\mathrm{xmm} 6 / 198$.

vp5 $=v p 5 * x m m 5 / 184 . /(x \operatorname{mm} 1 / 266 .+x m m 4 / 170 .+x m m 5 / 184 .+x m m 6 / 198$.

vp6 $=$ vp $6 * x \operatorname{xmm} 6 / 198 . /(x \operatorname{mm} 1 / 266 .+x m m 4 / 170 .+x m m 5 / 184 .+x m m 6 / 198$. $)$

$\mathrm{vp} 2=\mathrm{vp} 1$

$\mathrm{vp} 3=\mathrm{vp} 1$

vtot $=v p 1+v p 2+v p 3+v p 4+v p 5+v p 6$

$c$ Calculate heats of vaporization.

hv1 $=15368$

hv $2=7239$.

hv3 $=9705$.

hV $4=14647$.

hv $5=15830$.

hv $6=17010$.

return

end 
Savannah River Technology Center

N. M. Askew, 773-A

F. R. Graham, 773-A

N. M. Hassan, 773-A

M. E. Hodges, 773-41A

J. R. Knight, 773-A

J. E. Laurinat, 773-A

T. S. Rudisill, 773-A

C. R. Wolfe, 773-A

SRTC Records, 773-52A $\underline{\text { Savannah River Site }}$

T. G. Campbell, 221-F

O. M. Ebra-Lima, 707-F

M. J. Kantz, 707-F

J. M. Low, 707-F

C. E. Pickett, 221-H

J. R. Schornhorst, 992-3W

J. C. Williams, 707-F

G. J. Winkler, 703-F

S. A. Yano, 704-2H 